LBNL-57251

\title{
Analysis of Aquifer Response, Groundwater Flow, and Plume Evolution at Site OU 1, Former Fort Ord, California
}

\author{
Final Report Part 1
}

Contract No. DACA42-02-2-0056

\author{
Preston D. Jordan \\ Curtis M. Oldenburg \\ Grace W. Su \\ Earth Sciences Division \\ Lawrence Berkeley National Laboratory
}

February 21, 2005

This work was supported by U.C. Santa Cruz through the U.S. Army Construction Engineering Research Laboratories under Contract No. DACA42-02-2-0056, and by the U.S. Department of Energy under contract No. DE-AC0376SF00098. 
This page left intentionally blank. 


\section{TABLE OF CONTENTS}

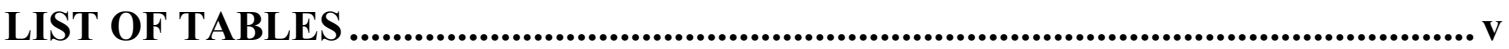

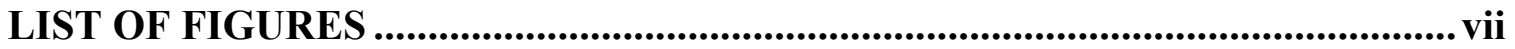

ABBREVIATIONS AND ACRONYMS ........................................................viii

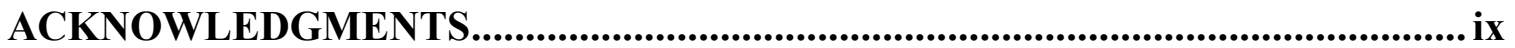

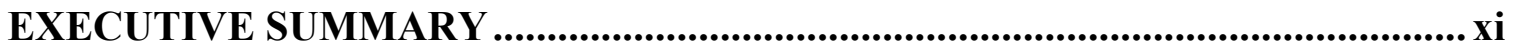

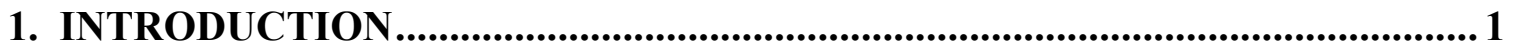

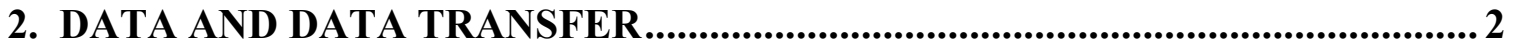

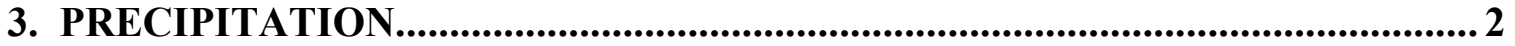

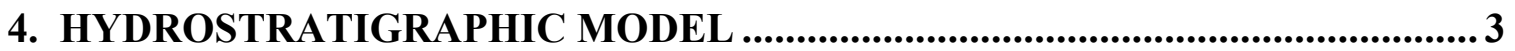

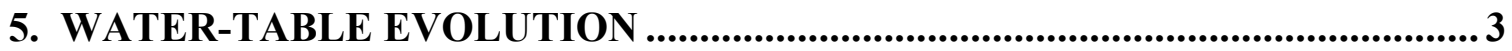

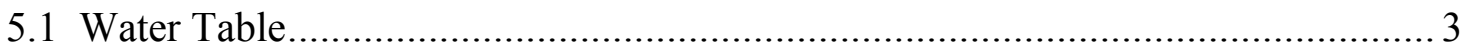

5.2 Change in Gradient Direction .................................................................. 3

5.3 Time to Peak Water Level ........................................................................... 4

6. FO-SVA AND 180-FOOT AQUIFER RESPONSES ..............................................5

6.1 Response Due to A-Aquifer Weight Increase................................................... 5

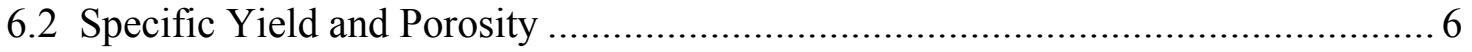

7. 1997/98 PRECIPITATION RECHARGE ................................................... 8

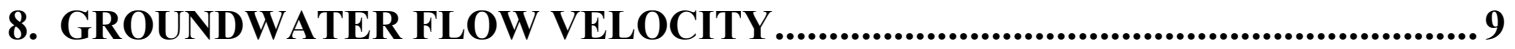

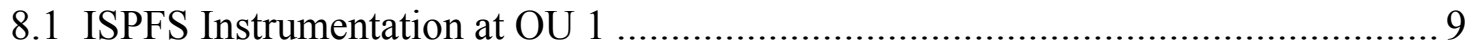

8.2 Horizontal Velocity Azimuth................................................................... 10

8.3 Horizontal Velocity Magnitude .................................................................... 11

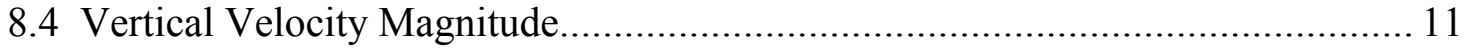

9. PERMEABLE DIFFUSION SAMPLER RESULTS...................................... 12

9.1 Water Sampling Methods .......................................................................... 12

9.2 Comparison of Purge and Sample to PDS results ........................................... 13

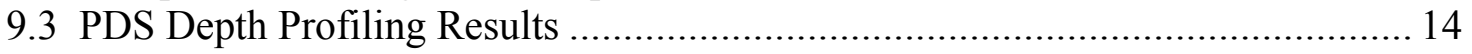

10. A-AQUIFER HYDRAULIC CONDUCTIVITY ................................................ 17

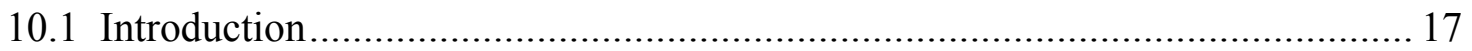

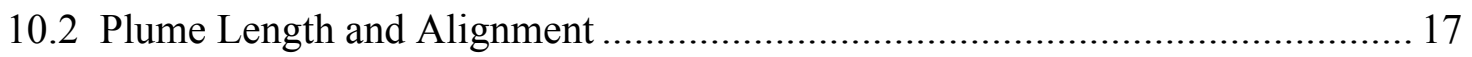

10.3 Early-1998 Precipitation Event .................................................................... 17

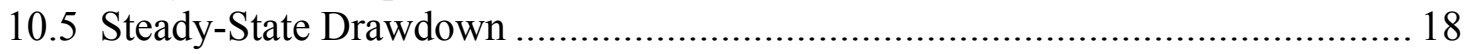

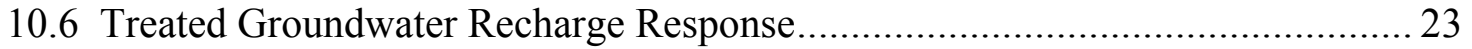

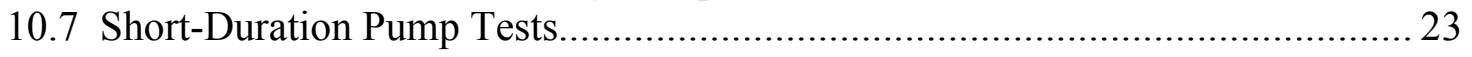

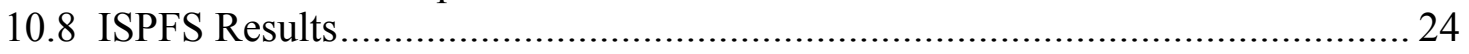

10.9 Summary Hydraulic Conductivity Comparison........................................... 24

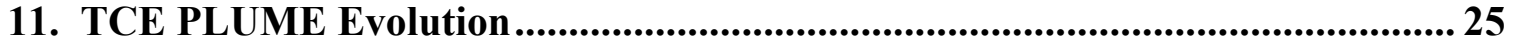

11.1 TCE Plume History .............................................................................. 25

11.2 Plume Prior to Remediation......................................................................... 26

11.3 Plume After Soil Remediation ................................................................. 26

11.4 Plume After Commencement of Pump, Treat and Recharge........................... 26

11.5 Plume Six Years After Commencing Pump, Treat, and Recharge .................... 27

11.6 Plume Prior to Early-1998 Recharge.................................................................. 27

11.7 Plume Following Early-1998 Precipitation ..................................................... 28

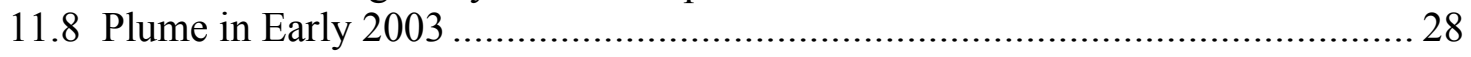

$\begin{array}{lc}\text { iii } & \text { REV. 1.3 } \\ \text { Final Report } & \end{array}$




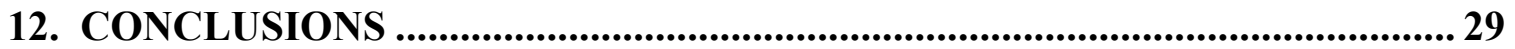

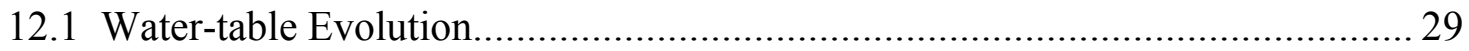

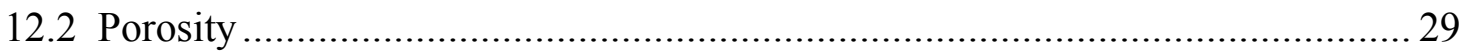

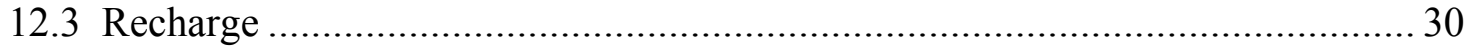

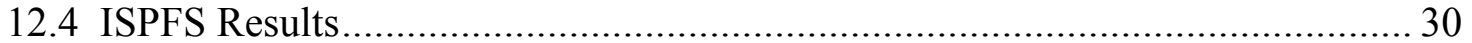

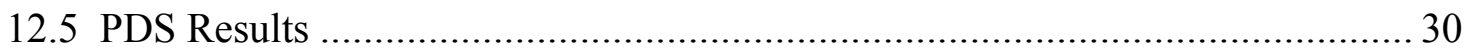

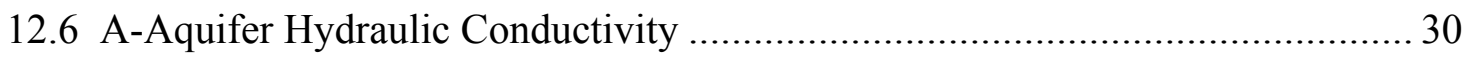

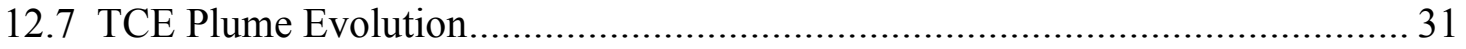

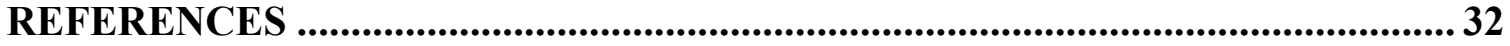




\section{LIST OF TABLES}

Table 8.2-1. Comparison of azimuths during the second quarter, 2003..................... 11

Table 9.2-1. Comparison of chemistry results from purge and sample and PDS........... 14

Table 9.3-1. Non-uniform, contaminant concentration depth profiles. ........................ 16

Table 10.5-1. Erroneous estimates of hydraulic conductivity ................................... 20

Table 10.5-2. Hydraulic conductivity estimates (ft/d) from EW-OU1-17-A pumping. .. 22

Table 10.5-3. Hydraulic conductivity estimates (ft/d) from EW-OU1-18-A pumping. .. 22

Table 10.8-1. Hydraulic conductivity estimates from ISPFS $\mathrm{V}_{\mathrm{h}}$ and gradient............... 24

Table 10.9-1. Comparison of hydraulic conductivity estimates................................ 25 
This page left intentionally blank. 


\section{LIST OF FIGURES}

Figure 3.1-1. Annual precipitation at Monterey compared to Fritzsche AAF.

Figure 3.1-2. Annual precipitation at Monterey through 2003.

Figure 4.0-1. Edge of Clay 3 and Clay 4.

Figure 5.1-1. A-aquifer isopotentials for the second quarter, 2000.

Figure 5.1-2. Detail of A-aquifer isopotentials for the second quarter, 2000.

Figure 5.1-3. A-aquifer isopotentials for the second quarter, 2002.

Figure 5.1-4. Detail of A-aquifer isopotentials for the second quarter, 2002.

Figure 5.2-1. Hydrographs from wells on transect A-A' shown on Figure 5.1-3.

Figure 5.3-1. Isochrons of time to peak water level following the 1998 precipitation.

Figure 5.3-2. Detail of isochrons of time to peak water level following 1998 precip.

Figure 5.3-3. Contours of maximum water-level increase following 1998 precipitation.

Figure 5.3-4. Increase in saturated thickness following the early-1998 precipitation.

Figure 5.3-5. A-aquifer hydrographs from the center to the edge of the FO-SVA.

Figure 5.3-6. Overview of A-aquifer isopotentials and FO-SVA boundaries .

Figure 5.3-7. Conceptual model of A-aquifer response to early-1998 precipitation.

Figure 6.1-1. Hydrographs for MW-OU1-11-SVA and PZ-OU1-16-A.

Figure 6.1-2. Hydrographs for MW-B-13-180 and MW-B-14-A.

Figure 8.2-1. Inverted ISPFS azimuth compared to extraction rates.

Figure 8.3-1. Inverted ISPFS horizontal velocities compared to extraction rates.

Figure 8.4-1. Inverted ISPFS vertical velocities compared to extraction rates.

Figure 9.1-1. Wells with PDS results.

Figure 9.3-1. TCE PDS results from MW-OU1-27-A.

Figure 9.3-2. 1,2 DCE PDS results from MW-OU1-27-A.

Figure 10.5-1. Hydrographs for EW-OU1-17-A, PZ-OU1-13-A and PZ-OU1-14-A.

Figure 10.5-2. Hydrographs for EW-OU1-18-A, PZ-OU1-15-A and PZ-OU1-16-A.

Figure 10.5-3. Elevation of the top of the FO-SVA in the vicinity of EW-OU1-17-A.

Figure 10.5-4. Consequences of variation in the elevation of the aquitard.

Figure 11.1-1. Isoconcentrations of TCE (in ug/L) in late 1986.

Figure 11.3-1. Isoconcentrations of TCE (in ug/L) in late 1987.

Figure 11.4-1. Isoconcentrations of TCE (in ug/L) in late 1990. 
Figure 11.5-1. Isoconcentrations of TCE (in ug/L) in early 1994.

Figure 11.6-1. Isoconcentrations of TCE (in ug/L) in late 1997.

Figure 11.7-1. Isoconcentrations of TCE (in ug/L) near the FDA in late 1999.

Figure 11.7-2. Isoconcentrations of TCE (in ug/L) in late 1999.

Figure 11.8-1. Isoconcentrations of TCE (in ug/L) near the FDA in early 2003.

Figure 11.8-2. Isoconcentrations of TCE (in ug/L) in early 2003.

\section{ABBREVIATIONS AND ACRONYMS}

$\begin{array}{ll}\text { 1,1,1-TCA } & \text { 1,1,1-trichloroethane } \\ \text { 1,2 DCE } & \text { 1,2 Dichloroethylene } \\ \text { bgs } & \text { below ground surface } \\ \text { cis-1,2 DCE } & \text { cis-1,2 Dichoroethylene } \\ \text { CT } & \text { Carbon Tetrachloride } \\ \text { FDA } & \text { Fire Drill Area } \\ \text { FO-SVA } & \text { Fort Ord-Salinas Valley Aquitard } \\ \text { ft/d } & \text { feet/day } \\ \text { gpm } & \text { gallons per minute } \\ \text { ISPFS } & \text { In-Situ Permeable Flow Sensor } \\ \text { MCL } & \text { Maximum Contaminant Level } \\ \text { MEK } & \text { methyl ethyl ketone } \\ \text { ug/L } & \text { micrograms/liter } \\ \text { ND } & \text { non-detect } \\ \text { OU 1 } & \text { Operational Unit 1 } \\ \text { P\&S } & \text { purge and sample } \\ \text { ppb } & \text { parts per billion } \\ \text { PDS } & \text { permeable diffusion sample } \\ \text { TCE } & \text { Trichloroethylene }\end{array}$




\section{ACKNOWLEDGMENTS}

This work was supported by U.C. Santa Cruz (UCSC) through the U.S. Army Construction Engineering Research Laboratories (USA-CERL) under Contract No. DACA42-02-2-0056, and by the U.S. Department of Energy under contract No. DE-AC0376SF00098. We thank our collaborators Paul Daley (LLNL), Barry Freifeld (LBNL), Russ Flegal (UCSC), and Patrick Mantey (UCSC) for technical and logistical help. We thank Lora Lee Martin (UCSC), Richard Lampo (USA-CERL), Jim Gill (UCSC) and Andy Fisher (UCSC) for support and encouragement. Helpful review comments were provided by Jens Birkholzer and Kenzi Karasaki (LBNL). 
This page left intentionally blank. 


\section{EXECUTIVE SUMMARY}

\section{Introduction}

This report presents a continuation from Oldenburg et al. (2002) of analysis of the hydrogeology, In-Situ Permeable Flow Sensor (ISPFS) results, aquifer response, and changes in the trichloroethylene (TCE) groundwater plume at Operational Unit 1 (OU 1) adjacent to the former Fritzsche Army Airfield at the former Fort Ord Army Base, located on Monterey Bay in northern Monterey County. Fuels and solvents were burned on a portion of OU 1 called the Fire Drill Area (FDA) during airport fire suppression training between 1962 and 1985. This activity resulted in soil and groundwater contamination in the unconfined A-aquifer. In the late 1980's, soil excavation and bioremediation were successful in remediating soil contamination at the site. Shortly thereafter, a groundwater pump, treat, and recharge system commenced operation. This system has been largely successful at remediating groundwater contamination at the head of the groundwater plume. However, a trichloroethylene (TCE) groundwater plume extends approximately $3000 \mathrm{ft}(900 \mathrm{~m})$ to the northwest away from the FDA. In the analyses presented here, we augment our prior work (Oldenburg et al., 2002) with new information including treatment-system totalizer data, recent water-level and chemistry data, and data collected from new wells to discern trends in contaminant migration and groundwater flow that may be useful for ongoing remediation efforts. Some conclusions from the prior study have been modified based on these new analyses, and these are pointed out clearly in this report.

\section{Porosity}

Water-level increases in the deeper, confined aquifers at OU 1 were interpreted by Oldenburg et al. (2002) to be due to the historically high precipitation at the beginning of 1998 and associated recharge of the deeper aquifers. These water-level increases could alternatively be due to an increase in the weight of the overlying, unconfined aquifer due to the historically large recharge event. If so, then the porosity of the unconfined aquifer can be calculated through a comparison of the water-level increase in the A-aquifer to that in the deeper aquifers. This calculation results in a porosity estimate of $30-37 \%$ for the unconfined aquifer materials.

\section{Recharge Rate}

Historically high precipitation rates occurred at OU 1 in early 1998. Analysis of water levels indicates that $38-51 \%$ of this precipitation recharged to the unconfined aquifer. This is larger than the $27 \%$ recharge rate calculated from average-year water-level data presented in Oldenburg et al. (2002). The higher recharge for 1998 is expected as there are no developed drainages at the site and therefore all precipitation is either evapotranspired back to the atmosphere or recharges to the unconfined aquifer (assuming equilibrium storage in the vadose zone). 


\section{In-Situ Permeable Flow Sensors}

In-situ permeable flow sensors (ISPFSs) were installed below five well screens in 1999. ISPFS thermistors data can be inverted to provide a measure of the Darcy velocity (magnitude and direction) around the instrument. Only three of the instruments appeared to be fully functional following installation (Oldenburg et al., 2002).

Horizontal flow magnitudes measured by the ISPFSs closely match those expected from the water-table gradient at the site and the hydraulic conductivity measured by other methods. The changes in the horizontal flow due to cessation of pumping from a nearby extraction well were also qualitatively in accord with expectations. The measured horizontal flow directions agreed with the water-table gradients to within $30^{\circ}$ with no discernable pattern to the variations between the measured direction and the gradient.

Vertical flows measured by the ISPFSs were all downward and of magnitude equal to or greater than the horizontal components of velocity. This was surprising given that the sensors were located within $0-4 \mathrm{ft}(0-1.2 \mathrm{~m})$ of the top of the aquitard beneath the unconfined aquifer. Numerical modeling suggests that thermal and hydraulic conductivity reductions at the base of the sensor near the aquitard could cause false downward velocity readings by the instruments ( $\mathrm{Su}$ et al., 2005). This is caused by reduced heat dissipation due to the lower thermal conductivity, and reduced heat advection due to the lower hydraulic conductivity.

\section{Permeable Diffusion Sampling Results}

Groundwater sampling procedures were changed from purge and sample (P\&S) to permeable diffusion sampling (PDS) at most wells at the end of 2001. Permeable diffusion sampling involves lowering a bag of clean water into the water column in the well and leaving it until the next sampling event, a period of three months at OU 1 typically. The bag is made of a special polymer that allows the concentration of organic contaminants in water outside the bag to equilibrate with the concentration inside the bag through osmosis. This method of sampling is simpler and cheaper than P\&S, and allows for profiling contaminant concentrations with depth through the water column.

Contaminant concentrations in PDSs were typically the same as the concentrations measured by $\mathrm{P} \& \mathrm{~S}$ for any given well. The only significant exception occurred in samples collected from one monitoring well (MW-OU1-10-A) out of the 51 from which PDS samples were collected. P\&S TCE concentrations were typically 3-7 micrograms/liter $(\mathrm{ug} / \mathrm{L})$ in this monitoring well. PDS TCE concentrations were typically nondetect $(<0.5$ $\mathrm{ug} / \mathrm{L})$. TCE is consistently detected in all surrounding wells during the time period of the shift from P\&S to PDS. Therefore there is no apparent explanation for the discrepancy at this monitoring well.

Concentration-depth profiling with PDS indicated that contaminant concentrations were generally constant with depth. In the one-third of wells where the concentrations were not uniform with depth, the concentrations typically increased with depth. This pattern would be consistent with off-gassing of the contaminant from the water column in the well rather than actual variations in the groundwater. The concentrations did not follow either of these patterns in two wells out of 34 in which contaminants were detected. The reason(s) for the variations in these two wells are not clear. 


\section{Hydraulic Conductivity}

The horizontal hydraulic conductivity of the unconfined aquifer was calculated from a variety of data, including In-Situ Permeable Flow Sensors (ISPFSs), short-duration pump tests, drawdowns resulting from long-term remedial extraction, and the overall length of the TCE plume. Hydraulic conductivities from the ISPFS and TCE plume data were calculated utilizing water-table gradients as derived from water-level data. The hydraulic conductivity measured by all of these data sets was between $7-10(\mathrm{ft} / \mathrm{d})\left(2.5-3.5 \times 10^{-5} \mathrm{~m}\right.$ $\mathrm{s}^{-1}$ ). The results of contaminant depth-profiling using permeable diffusion samplers (PDSs) indicate little variation in horizontal conductivity with depth. Analysis of waterlevel responses to changes in recharge rate indicate that the vertical conductivity at the site is also relatively uniform, and approximately the same or slightly less than the horizontal conductivity. The results from the ISPFSs and the TCE plume shape indicate there is no significant anisotropy in the unconfined aquifer. Therefore the hydraulic conductivity is remarkably uniform in all directions as well as across spatial scales, from the few feet around an ISFPS at the smallest scale to the thousands of feet of the entire TCE plume at the largest scale.

\section{Water-table Response to Early-1998 Precipitation}

Historically high precipitation occurred at the site in early 1998. As described in Oldenburg et al. (2002), the water table rose 6-12 ft $(1.8-3.7 \mathrm{~m})$ in response to this precipitation event. This rise was unprecedented in the available water-level records and is the dominant feature of all the OU 1 well hydrographs. In response to this recharge event, the gradient in the mid- to distal portion of the TCE plume rotated approximately $20^{\circ}$ counterclockwise from its previous orientation of north to northwest to just northwest. The effect of this was to rotate the gradient towards the edge of the FO-SVA and thereby reconfigure the water table for more efficient transmission of the increased quantity of groundwater through the unconfined A-aquifer.

The time to peak water level in each well following the early-1998 precipitation varied throughout OU 1. Water levels in the TCE plume area downgradient of the remedial extraction wells were relatively depressed prior to 1998. The water levels in these wells peaked later than in most other wells. This appears to be due to the long amount of time required to refill this area with groundwater in order to allow for the aforementioned gradient rotation. Outside of this area, water levels in wells located above the center and edge of the FO-SVA peaked earlier than in wells midway between these two locations. Near the center of the FO-SVA, groundwater flow increased due to the increased transmissivity, however the input of water returned to normal after the 1998 recharge event, and water levels began declining. Near the edge of the FO-SVA, the gradient increased markedly after the initial recharge event due to the constant discharge elevation of the edge of the FO-SVA. This increase in gradient more than compensated for the increase in groundwater throughput, so water levels decreased after the initial recharge. Midway between the center and edge of the FO-SVA, after the initial recharge event the gradient remained the same but groundwater inputs from areas upgradient continued to increase due to drainage of stored water. Therefore water levels continued to increase long after the recharge event thus increasing transmissivity. 


\section{TCE Plume Evolution}

At the time Oldenburg et al. (2002) was written, the earliest available groundwater chemistry data were from a few years after the beginning of groundwater extraction, treatment, and recharge. TCE concentrations west and northwest (transgradient) of the FDA were increasing at this time. Oldenburg et al. (2002) analyzed a number of hypotheses to explain this increase, and concluded that the high recharge rate of treated water likely was flushing residual contaminant from the vadose zone to the west of the FDA into the saturated zone in this area.

The availability of additional groundwater chemistry data for the present analysis alters this prior conclusion. Oldenburg et al. (2002) assumed the treated-water recharge area was upgradient of the head of the groundwater contaminant plume and not directly over an area of soil contamination. This assumption was supported by the earliest chemistry data available at the time (from 1992) that indicated low to non-detectable concentrations of TCE in the groundwater in the vicinity of the treated-water recharge area. So, while the recharge altered gradients locally, including rotating gradients beneath the western portion of the FDA toward the west, Oldenburg et al. (2002) concluded that the gradient rotation was not sufficient to cause the observed TCE concentration increases to the west and northwest of the FDA.

Groundwater chemistry data covering the period back to 1986 were available for the analyses performed in this report. These data indicate that shortly after commencement of treated-water recharge, TCE concentrations in a well upgradient of the recharge area increased by two orders of magnitude. Water levels in this well also respond to the changes in the treated water recharge rate more than in any other well. The mixture of contaminant compounds in the groundwater from this upgradient well suggests that the treated water recharge area overlies residual contamination in the vadose zone, and that this contamination was mobilized to the groundwater by the recharge. Therefore the locus of contaminant flushing appears not to have been to the west of the FDA as suggested in Oldenburg et al. (2002), but rather to the south of the FDA.

Once flushed to the groundwater, the contaminated water from the vadose zone combined with the diverging gradients caused by the high rate of treated water recharge to spread the head of the plume. In particular, contaminated water began to flow around the west side of the FDA along the gradient arc created by the recharge area/extraction well dipole. As of nine years after commencement of treated-water recharge, the contamination introduced by this activity had almost completely advected away from beneath the recharge area. As of approximately 15 years after commencement, the contamination had almost completely advected past the western side of the FDA and out from beneath the FDA. Contamination was located primarily to the northwest.

Ten years after the start of pump, treat, and recharge, chemistry results from a well network sufficient to characterize the full plume extent became available. These results indicated that the plume extended to the north-northwest of the pumping wells by a couple of thousand feet. In the subsequent five years, the axis of the plume tail has shifted southwestward approximately $200 \mathrm{ft}(61 \mathrm{~m})$. This shift correlates with the gradient rotation surmised to have occurred in the area as a result of water-level changes 
following the early-1998 precipitation event. The rotation in gradient at the tail of the TCE plume along with the shift in the TCE plume axis is causing the plume to move off of the monitoring well grid. Therefore, installation of new wells must be considered in order to maintain adequate characterization of the plume. The design and planned installation location of remedial systems must also be considered in light of the shift in direction of the plume. 
This page left intentionally blank. 


\section{INTRODUCTION}

This report presents a continuation of analysis of the hydrogeology, In-Situ Permeable Flow Sensor (ISPFS) results, aquifer response, and changes in the trichloroethylene (TCE) groundwater plume at Operational Unit 1 (OU 1) at the former Fort Ord Army Base, located on Monterey Bay in northern Monterey County. These analyses benefited from the availability in digital form of more recent, as well as older, groundwater chemistry records as well as treatment system totalizer data than were available at the time of Oldenburg et al. (2002). By way of introduction, we provide below a brief synopsis of the setting and history of OU 1, greater details of which can be found in Oldenburg et al. (2002).

OU 1 and environs are vegetated by grasslands and coastal scrub. The local geomorphology is hummocky, consisting of low hills and closed basins, with no developed drainages. Unconsolidated dune sands extend from the surface to a depth of $90-130 \mathrm{ft}(27-40 \mathrm{~m})$. The sand dunes were likely active in the area relatively recently in geologic time.

Beneath the dune sands are alternating layers of dune sand and clay. Some of the clay layers are laterally extensive, while others terminate in the vicinity of OU 1 . These clay layers are apparently due to a marine transgression 100-130 thousand years ago during the interglacial period following the Tahoe glaciation. Collectively, the clay layers are apparently over $70 \mathrm{ft}(20 \mathrm{~m})$ thick.

Hydrostratigraphically, the clay layers form the Fort Ord-Salinas Valley Aquitard (FOSVA). This aquitard separates the overlying, unconfined A-aquifer consisting of dune sand from deeper, confined, aquifers consisting of dune sand, and near-shore and fluvial deposits. The shallowest of these deeper confined aquifers is called the 180 -foot aquifer. The water-table depth of the A-aquifer ranges from approximately 70-100 $\mathrm{ft}(21-30 \mathrm{~m})$ bgs.

The former Fritzsche Army Airfield is located in the northernmost portion of the former Fort Ord Army Base. The airport fire department trained at a Fire Drill Area (FDA) adjacent to the airport. Fuels and solvents were placed in the burn pit and combusted for fire suppression training from 1962 to 1985. These activities resulted in soil and groundwater contamination in the A-aquifer with petroleum hydrocarbons, trichloroethylene (TCE), methyl ethyl ketone (MEK), and 1,1,1-trichloroethane (1,1,1TCA). The area contaminated by these compounds was subsequently designated Operable Unit 1 (OU 1).

In the late 1980's, near-surface contaminated soil was excavated and deeper contaminated soils were bioremediated. Subsequent soil sampling confirmed that the soil cleanup was successful. Shortly thereafter, a groundwater extraction and treatment system was installed to capture and treat the contaminated groundwater. This system significantly reduced all of the contaminant concentrations. By the early 1990's, contaminants other than TCE were generally below the Maximum Contaminant Levels (MCLs) set by the U.S. EPA for drinking water. However, sampling at new wells in the mid 1990's indicated groundwater downgradient of the extraction wells contained aboveMCL concentrations of TCE. Analysis of groundwater samples from wells subsequently installed through the late 1990's and early 2000's indicated the TCE groundwater plume 
was $3000 \mathrm{ft}(900 \mathrm{~m})$ long, or approximately four times the originally characterized length.

\section{DATA AND DATA TRANSFER}

The company MacTec (Oakland, CA) provided well, water-level, and chemistry data in electronic form. New well coordinates for all the wells, including wells installed after those analyzed in Oldenburg et al. (2002), were provided based upon a new state plane. Additional water levels from the period from the second quarter of 2000 through the last quarter of 2003, inclusive, were provided. Groundwater chemistry data were provided that extended the period of coverage from the beginning of 1986 to the end of 2003. The earliest chemistry records analyzed in Oldenburg et al. (2002) were from the second quarter of 1992, and the most recent were from 2000.

The well coordinates used in Oldenburg et al. (2002) were apparently surveyed relative to two different state planes depending upon when the well was installed. Wells surveyed to the earlier state plane were resurveyed relative to the newer state plane and new coordinates provided. Comparison of the old and new well coordinates revealed that the coordinates for extraction wells EW-OU1-17-A and -18-A apparently had not been updated to the new state plane. Comparison of the other early OU 1 wells revealed a relatively consistent difference in the coordinate values. This difference $(+22.80$ easting, -8.52 northing) was applied to the extraction well coordinates in order to place them in the proper position relative to the other wells.

The former well PZ-OU1-31-A was changed to MW-OU1-31-A to conform to MacTec's naming convention.

Water-level and chemistry data were imported into GIS $\backslash$ Key ${ }^{\mathrm{TM}}$ using utilities provided with the program. These utilities perform a variety of integrity checks. Any errors resulting from these checks must be resolved prior to import. We analyzed the data and made figures using GIS $\backslash$ Scout ${ }^{\mathrm{TM}}$ and AutoCAD ${ }^{\mathrm{TM}}$.

Totalizer data (cumulative volume of water produced) for the extraction wells from the second quarter of 1999 through the end of 2003 were provided by AGSC (Ahtna Governmental Services Corporation). These data were stored in Excel ${ }^{\mathrm{TM}}$, from which graphs depicting average flow from each well through time were developed.

\section{PRECIPITATION}

Precipitation data from the Fritzsche AAF meteorological station are only available for the years 1969 to 1978 . The least squares fit of the annual precipitation at this station versus the Monterey station is shown on Figure 3.1-1. This shows that the precipitation at OU 1 (adjacent to the Fritzsche AAF station) is generally $86 \%$ of the Monterey precipitation minus one inch $(0.025 \mathrm{~m})$. Rather than apply this correction to the Monterey data, the Monterey totals are assumed to apply to OU 1 throughout this report.

Monthly precipitation totals for the period January 2001 to August 2003 were downloaded from the National Oceanic and Atmospheric Administration data server for the Monterey meteorological station. An updated hydrologic year precipitation total 
chart for the Monterey station is shown on Figure 3.1-2. The hydrologic year is July $1^{\text {st }}$ to June $30^{\text {th }}$.

\section{HYDROSTRATIGRAPHIC MODEL}

Elements of the hydrostratigraphic model presented in Oldenburg et al. (2002) are occasionally referenced in this report. Briefly, this hydrostratigraphic model consists of four sand layers and three clay layers. The clay layers collectively comprise the Fort Ord-Salinas Valley Aquitard (FO-SVA). The sand and clay layers are numbered independently from the deepest to the shallowest. The clay layers range up to $12 \mathrm{ft}(3.6$ $\mathrm{m})$ thick and average approximately $5 \mathrm{ft}(1.5 \mathrm{~m})$ thick. Sands 1, 2, 3, and 4 average 15, 6, 8 , and $92 \mathrm{ft}(4.6,1.8,2.4$, and $28 \mathrm{~m})$ thick, respectively.

The deepest layer in the model is Clay 1. Clays 1 and 2 and intervening Sand 1 are continuous throughout the area. Clays 3 and 4 are discontinuous and consist of two patches each within OU 1, as shown on Figure 4.0-1. The northwestern patch of Clay 4 is sometimes referred to as the "Airfield Clay." Sands 2 and 3 are discontinuous and pinch out between the adjacent clay layers in places. Sand 4 is continuous throughout OU 1.

\section{WATER-TABLE EVOLUTION}

\subsection{Water Table}

As discussed in Oldenburg et al. (2002), water levels in the A-aquifer rose significantly in response to the precipitation in early 1998. As of December 2000 (the latest water levels included in Oldenburg et al. (2002)), the water levels in all of the OU 1 wells and many of the other wells were still increasing or were at their peak in response to the early-1998 precipitation event. The most complete water-table map presented in the Oldenburg et al. (2002) report was for the second quarter of 2000. These maps are reproduced as Figures 5.1-1 and 5.1-2. Figures 5.1-3 and 5.1-4 show the water-table map for the second quarter of 2002. Comparison of the maps reveals that the gradient direction is changing to the southwest and north of the Fire Drill Area (FDA) and steepening near the edge of the FOSVA. Comparison of these maps also reveals that the water-table elevation is decreasing in some areas and increasing in others. Finally, the greater well coverage southwest of the FDA in 2002 shows that the gradient upgradient of the edge of Clay 4 is steeper than downgradient, which tends to confirm the hydrostratigraphic model presented in Oldenburg et al. (2002).

\subsection{Change in Gradient Direction}

To the north and southwest of the FDA, the gradient was mapped as north- to northwestdirected in 2000, and northwest-directed in 2002. In the former area, the gradient rotated approximately $20^{\circ}$ counterclockwise, and well coverage did not change appreciably from 2000 to 2002, suggesting the change is real and not due to additional data from new wells. In the latter area, the change is due in part to greater well coverage in 2002, however some component of this change is probably real. This is demonstrated by the 
comparison of well hydrographs shown on Figure 5.2-1.

The wells in Figure 5.2-1 lie on northeast-southwest transect A-A' to the northwest of the FDA as shown on Figure 5.1-3. In general, the water level in each well increases less than in the wells to the northeast and more than in the wells to southwest along the transect. This is demonstrated on a more regional scale by comparing the hydrographs for MW-B-12-A and MW-OU1-31-A, and on a more local scale by comparing the hydrographs for MW-OU1-09-A and -22-A. The effect of this pattern is to rotate the gradient toward the west, which is the location of the edge of the FO-SVA. Therefore, this response appears to be a result of the aquifer's adjustment to transmitting more groundwater after the early-1998 precipitation event.

The well coverage prior to late 1998 is insufficient to resolve the water table north of the FDA during this period. Given the change in gradient direction during the period from 2000 to 2002, however, the actual gradient rotation since 1997 is probably even greater. This supports the conclusion in Oldenburg et al. (2002) that the gradient from the FDA was directed to the north during much of the time contaminants were being released at OU 1.

\subsection{Time to Peak Water Level}

The variation in the time to peak water levels after the early-1998 precipitation event, as shown on Figures 5.3-1 and 5.3-2, provides another perspective on the aquifer's adjustment to the early-1998 precipitation event. The distribution of peak times appears to consist of two patterns. One pattern is related to the treated recharge system at OU 1. Water levels in the downgradient area north to northwest of the FDA were apparently depressed prior to 1998 due to evapotranspiration losses from the treated-water sprinkler recharge system (Oldenburg et al., 2002). The time to the peak-water level throughout this region is relatively long compared to the rest of the aquifer. This is probably due to the longer time required to refill this area with stored water so that the gradient could rotate from alignment along the depression created by the recharge losses to across the depression to optimize the discharge of the increased flow resulting from the early-1998 precipitation event. Figures 5.3-3 and 5.3-4 confirm this hypothesis by showing that the water-level increase in the downgradient area north to northwest of the FDA was greater than throughout the rest of the aquifer on both an absolute basis and as a percentage of the pre-1998 saturated thickness.

The other pattern in the peak-water-level timing is a result of the increased recharge throughout the rest of the aquifer. Figure 5.3-5 shows this pattern by comparing hydrographs from wells throughout the aquifer outside of the region impacted by the OU1 pump, treat, and recharge activities. The water levels near the center and edge peak earlier than in the areas midway between them. This can be understood conceptually by imagining the early-1998 precipitation event as the instantaneous addition of a uniform thickness of groundwater on top of the pre-existing A-aquifer water table, which was in equilibrium with the background recharge rate. After the instantaneous groundwater addition, no further inputs above the background recharge rate occur. This conceptual model is justified by the relatively uniform arrival time of the early-1998 precipitation recharge at the water-table surface, and by the relatively uniform water-level rise of 2-3 
$\mathrm{ft}(0.60-1.8 \mathrm{~m})$ in the six months and 4-6 ft $(1.2-1.8 \mathrm{~m})$ in the year following the early1998 precipitation event (Oldenburg et al., 2002).

As shown in Figure 5.3-6, the water table in the vicinity of OU 1 can be viewed conceptually as a portion of a dome. The gradient remains unchanged on the dome after an instantaneous addition of water as shown on Figure 5.3-7. However, the transmissivity increases a constant amount initially throughout the dome, and the gradient at the edge of the dome increases due to the constant-discharge elevation (the top of the FO-SVA). At the center of the dome, where there is no long-term increase in flow above the background rate, the increase in transmissivity causes the water levels to decline after the instantaneous addition. Away from the center of the dome, the flow rate remains above the background rate for some time after the instantaneous addition due to drainage of the additional water stored in the upgradient areas. Therefore the water level away from the dome center will decline more slowly than the level at the center or may actually increase.

At the edge of the dome, the gradient increases after the instantaneous addition due to the constant discharge elevation (in this case the water table beyond the edge of the FO$\mathrm{SVA}$ ). As the transmissivity increase in this region is the same as in the upgradient area, the flow increase is greater at the edge of the dome than within the dome. Therefore the water levels decline more rapidly than in the area upgradient of the edge.

\section{FO-SVA AND 180-FOOT AQUIFER RESPONSES}

\subsection{Response Due to A-Aquifer Weight Increase}

Oldenburg et al. (2002) (Section 8.6) surmised that the water-level increases in MWOU1-11-SVA and the wells screened in the 180-foot aquifer following the historically high early (January/February) 1998 precipitation were due in part to precipitation recharge. This conjecture was based upon the increased water levels in these wells less than a year after the precipitation event.

Analyses in the present project suggest that the water-level increase in the 180 -foot aquifer following the early-1998 precipitation is probably primarily a result of the increased weight of the A-aquifer due to increased water storage. This conjecture assumes that the FO-SVA mechanically transmitted the change in total vertical stress from the A-aquifer to the 180-foot aquifer, but did not hydraulically transmit the change in head from the former to the latter. This interpretation appears plausible for a number of reasons. First, the water-level increases in the deeper, confined aquifers were a fraction of the water-level increases in the A-aquifer as shown on Figure 6.1-1 and, to a lesser extent, Figure 6.1-2 which compare the responses in the deeper aquifer wells MWOU1-11-SVA (screened across several sand layers within the FO-SVA) and MW-B-13180 to those in the nearby A-aquifer wells PZ-OU1-16-A and MW-B-14-A. Second, Figures 6.1-1 and 6.1-2 illustrate that the water levels in wells in the deeper aquifers increased through the second quarter of 1998, the only time this has occurred (water levels decreased in the second quarter in all other years). Water levels in the A-aquifer had just started increasing at the time of the second quarter of 1998. The figures also show that water levels in the deeper aquifer wells decreased in the third quarter of 1998 
to approximately the highest dry-season levels ever recorded in these wells. At this time only half or less of the water-level increases in the A-aquifer had occurred. Furthermore, the water-level increases and peaks in the deeper aquifers occurred predominantly within about six months of the early-1998 precipitation, while the increases and peaks in the Aaquifer occurred within about 18 months. This timing of the deeper aquifer water-level change is rapid, consistent with the timing of the increase in weight of the A-aquifer, which would have been essentially simultaneous with the precipitation (which extended into May of 1998). In contrast, the A-aquifer response is delayed, consistent with the time needed for infiltration to migrate through the vadose zone to the water table. If the A-aquifer were transmitting head changes to the 180-foot aquifer hydraulically, waterlevel increases in the deeper aquifers would have tracked or lagged the A-aquifer changes. Note that a more continuous water-level history would help resolve the timing better, but we are limited to the quarterly sampling intervals for this analysis.

Finally, the hydraulic conductivity of the clay layers in the FO-SVA appears to be much lower than the conductivity of the aquifer materials, as evidenced by the high (three and a half), downward-directed, hydraulic gradient through the FO-SVA coupled with the lack of OU 1 contaminants in the deeper aquifers. This low hydraulic conductivity would cause significant attenuation across the FO-SVA of hydraulic pressure changes occurring at the FO-SVA boundaries.

\subsection{Specific Yield and Porosity}

If the post-1997 water-level increases in the FO-SVA and 180-foot aquifers are due to the increased weight of the A-aquifer as argued above in Section 6.1, then these water-level responses can provide an estimate of the specific yield of the A-aquifer. This calculation is based upon comparing the water-level increases in the A-aquifer to those in the deeper aquifers.

The change in total vertical stress $\left(\Delta \sigma_{A}\right)$ at the base of the A-aquifer due to the waterlevel rise is

$$
\Delta \sigma_{A}=\rho g \Delta h_{A} S_{y}
$$

where $\rho$ is the density of water, $g$ is the acceleration of gravity, $\Delta h_{A}$ is the change in head in the A-aquifer, and $S_{y}$ is the specific yield of the A-aquifer. This change in total vertical stress causes a strain in the deeper aquifers. The strain $\left(\varepsilon_{w}\right)$ induced in the groundwater (assuming undrained conditions, e.g., no lateral drainage) in these aquifers by the total stress change is

$$
\varepsilon_{w}=-\beta \Delta P
$$

where $\beta$ is the compressibility of water and $\Delta P$ is the change in water pressure due to $\Delta \sigma_{\mathrm{A}}$. The strain induced in the sediments $\left(\varepsilon_{S}\right)$ constituting the deeper aquifers is

$$
\varepsilon_{S}=-\alpha\left(\Delta \sigma_{A}-\Delta P\right)
$$

where $\alpha$ is the compressibility of the sediments. The strain induced in the groundwater and in the sediments are the same under undrained conditions. As the deeper aquifers are 
confined, the stress response can be approximated by an undrained condition on a short time scale. Setting $\varepsilon_{w}$ equal to $\varepsilon_{S}$ and solving for $\Delta P$ yields

$$
\Delta P=\frac{\alpha}{\alpha+\beta} \Delta \sigma_{A}
$$

Water is typically more than a thousand times stiffer than sand (Bowles, 1996), of which the A-aquifer consists. Therefore $\alpha \approx 1000 \beta$ which leads to $\Delta P \approx \Delta \sigma_{A}$. The change in pressure is given by

$$
\Delta P=\rho g \Delta h \approx \Delta \sigma_{A}
$$

where $\Delta h$ is the change in head in the deeper aquifers. Substituting Eq. 6-1 into 6-5 gives

$$
\rho g \Delta h_{A} S_{y} \approx \rho g \Delta h
$$

Solving for $S_{y}$ yields

$$
S_{y} \approx \Delta h / \Delta h_{A}
$$

Therefore the specific yield of the A-aquifer is approximately equal to the water-level increase in the deeper aquifers divided by the water-level increase in the A-aquifer.

This specific yield calculation rests on two main assumptions. First, the pressure change in the deeper aquifer is due entirely to the weight increase in the A-aquifer rather than other hydrologic changes in the deeper aquifer. Second, all of the weight increase in the A-aquifer can be accounted for by the water-level increase in the A-aquifer. The validity of these assumptions is addressed below.

MW-OU1-11-SVA and MW-B-13-180 are the only two sub-A-aquifer wells near Aaquifer wells which have water-level measurements before 1998. The water-level increase in MW-OU1-11-SVA was 1.5-2 ft $(0.45-0.61 \mathrm{~m})$ following the early-1998 precipitation event. This increase was sustained through 2003 as shown on Figure 6.1-1, indicating that the assumption of no pressure dissipation in the deeper aquifer (undrained condition) is approximately met. Additionally, analysis of the water levels in MW-OU111-SVA as compared to those in the A-aquifer and 180-foot aquifer at this location indicates that the aquifers screened by this well are not hydraulically connected to the Aaquifer above or the 180-foot aquifer below (Oldenburg et al., 2002).

The closest A-aquifer well to MW-OU1-11-SVA is PZ-OU1-16-A. The maximum water-level increase in PZ-OU1-16-A following the early-1998 precipitation was approximately $7.5 \mathrm{ft}(2.3 \mathrm{~m})$ (neglecting the increase due to discontinuation of pumping at EW-OU1-18-A). The same increase was measured at nearby A-aquifer well MWOU1-03-A. The increase in PZ-OU1-16-A was sustained from June 2000 to June 2002, which is sufficiently long after the precipitation event to support the assumption that the vadose zone has predominantly returned to pre-1998 moisture conditions (consistent with the sandy nature of the vadose zone) and therefore the water-level change accurately reflects the change in weight of the A-aquifer. The ratio of the water-level increases, and therefore the A-aquifer's specific yield, for the PZ-OU1-16-A/ MW-OU1-11-SVA well pair is $20-27 \%$.

The water-level increase in MW-B-13-180 after the early-1998 precipitation was $4 \mathrm{ft}(1.2$ 
$\mathrm{m}$ ) as shown on Figure 6.2-2. The maximum water-level increase in nearby MW-B-14-A following this event was $7 \mathrm{ft}(2.1 \mathrm{~m})$. The ratio of these water levels suggests an Aaquifer specific yield of $57 \%$, which is physically impossible. The maximum increase in MW-B-14-A occurred in August 1999 and was followed by declining water levels. The date of the maximum water level in this well was the fourth earliest of all the A-aquifer wells suggesting that drainage of the vadose zone to background conditions may not have been complete by the time of the water level maximum. Additionally, the water-level increase in the 180-foot aquifer may be due in part to recharge of the early-1998 precipitation directly to the 180-foot aquifer beyond the FO-SVA. Therefore the waterlevel increases from MW-B-14-A and MW-B-13-180 likely do not meet the two assumptions necessary for the specific yield calculation.

The specific yield of 20-27\% calculated from the MW-OU1-11-SVA and PZ-OU1-16-A water levels is in the center of the generally accepted range of $15-32 \%$ for mediumgrained sands (Fetter, 1994). The average volumetric moisture content of the OU 1 sand in the region $7.5 \mathrm{ft}(2.3 \mathrm{~m})$ above the water table is approximately $10 \%$ if we assume it is sand at field capacity (van Genuchten, 1980). Adding this to the specific yield estimate gives a total porosity estimate of $30-37 \%$, which is on the low side of the generally accepted porosity range of $25-50 \%$ for well-sorted sand (Fetter, 1994). However, we recognize that despite the plausible result obtained, the analysis is somewhat uncertain due to its being based on a single well pair.

\section{1997/98 PRECIPITATION RECHARGE}

As discussed above in Section 6.1, the change in total vertical stress after the early-1998 precipitation is due to the increase in weight of the A-aquifer resulting from the precipitation recharge. This can be expressed as

$$
\Delta \sigma_{A}=\rho g s
$$

where $s$ is the quantity of precipitation recharge. Substituting equation 6-5 into equation 7-1 gives

$$
\rho g \Delta h=\rho g s
$$

Cancelling terms gives

$$
\Delta h=s
$$

Therefore the water-level rise in the confined aquifers is equivalent to the quantity of precipitation recharge. The water-level increase in MW-OU1-11-SVA after the early1998 precipitation event likely indicates the total depth of water recharged to the aquifer during the 1997/1998 rain year was $1.5-2 \mathrm{ft}(0.46-0.61 \mathrm{~m})$. The total precipitation during this rain year was 47.15 in $(1.2 \mathrm{~m})$ at the Monterey meteorological station. Dividing $1.5-2 \mathrm{ft}(18-24 \mathrm{in}, 0.46-0.61 \mathrm{~m})$ by the total precipitation yields a very high recharge fraction of $38-51 \%$.

This high recharge fraction is possible because the early-1998 precipitation was an extreme event. Approximately 25 in $(0.63 \mathrm{~m})$ of the 1997/1998 rain year precipitation fell at Monterey during an approximately one-month period in January and February of 
1998. This rainfall was greater than the average annual total precipitation at Monterey. Such high precipitation rates could be expected to cause higher recharge rates at OU 1 for three reasons. First, the high precipitation rate overwhelms the normal evapotranspiration rate. Second, the high precipitation rate causes higher liquid saturation at the ground surface and in the vadose zone, which increases the effective hydraulic conductivity therefore creates a higher infiltration rate. Finally, the lack of developed drainages in the hummocky dunes at OU 1 prevents precipitation from flowing laterally away and leads to increased infiltration.

The $1997 / 1998$ recharge fraction of $38-51 \%$ is considerably higher than the $27 \%$ precipitation recharge fraction derived from an analysis of water-level changes during more typical rain years in Oldenburg et al. (2002). As explained above, the 1997/1998 hydrologic year was an extreme event and it makes sense that the recharge fraction would be significantly greater than for a typical rain-year.

\section{GROUNDWATER FLOW VELOCITY}

\subsection{ISPFS Instrumentation at OU 1}

Hydrotechnics In-Situ Permeable Flow Sensors (ISPFSs) are installed below the well screens in MW-OU1-36-A through -40-A. These instruments contain a heater and an array of 30 temperature sensors (thermistors). The temperature field produced by the heater is distorted by groundwater flow past the instrument. Temperatures measured by the thermistor array in each instrument are recorded once an hour. The software HTFlow95 provided by Hydrotechnics inverts the thermistor data to derive the Darcy groundwater velocity vector (vertical and horizontal velocity magnitudes and horizontal velocity azimuth). The inversion algorithm assumes isotropic hydraulic and thermal conductivity. Details of ISPFS installation and preliminary data analysis can be found in Oldenburg et al. (2002).

Three of the five installed ISPFSs have produced useful data. These are ISPFSs installed in MW-OU1-36-A, -37-A and -39-A. The heater power in the ISPFS in MW-OU1-39-A decreased on June 5, 2001. The analysis of data from this instrument has been improved since Oldenburg et al. (2002) by accounting for the change in heater power. Data from the ISPFSs installed in MW-OU1-38-A and MW-OU1-40-A have been more problematic. The heater in the ISPFS in MW-OU1-40-A failed due to an electrical short in January 2001. While the ISPFS in MW-OU1-38-A appears to be functional, a detailed examination of the thermistor data revealed an apparently non-uniform flow field around the sensor. When groundwater flow is homogeneous over the surface of the instrument, temperatures along the length of the sensor are highest towards the middle at all sensor azimuths, and the temperature around the sensor varies approximately sinusoidally at all distances along the sensor. The thermistor data from MW-OU1-38-A did not conform to either of these patterns, but rather to a pattern suggestive of flow twisting around the probe, perhaps due to borehole effects related to the installation. Therefore, consideration of the data in MW-OU1-38-A and -40-A is not included below.

The daily average of the hourly results inverted from the MW-OU1-36-A, -37-A and -39A ISPFS data from January 1, 2001 to November 28, 2003 are discussed below. 


\subsection{Horizontal Velocity Azimuth}

The inverted horizontal flow azimuths from the ISPFSs are shown along with the extraction rates from EW-OU1-17-A and -18-A on Figure 8.2-1. Counterclockwise gradient rotations in MW-OU1-37-A and -39-A on a weekly time scale correlate to pumping-rate decreases from EW-OU1-18-A. Such rapid rotations are not observed in MW-OU1-36-A, perhaps due to its position in the region dominated by changes in the treated water recharge rate (Oldenburg et al., 2002). Pumping-rate decreases at EWOU1-18-A would tend to cause counterclockwise gradient rotation toward EW-OU1-17A at this well. Recharge decreases would tend to cause clockwise gradient rotation at this well due to realignment with the regional gradient. Therefore the azimuth perturbations due to pumping and recharge rate changes would tend to cancel each other. The horizontal flow azimuths have also rotated counterclockwise on a yearly time scale as shown on Figure 8.2-1. These rotations are likely due to continuing adjustments to the cessation of pumping from EW-OU1-18-A in June 2001 and the water-level increases due to the early-1998 precipitation. The rotation at MW-OU1-36-A is the greatest and at MW-OU1-37-A is the least.

Table 8.2-1 compares the azimuths inverted from the ISPFS data to that measured from the water-table gradient. The discrepancies between the gradient azimuth and that measured by the flow sensor could be due to sensor installation error, sensor measurement error, borehole effects, actual differences between the gradient direction and the flow field due to anisotropy or heterogeneity, or error in the contoured watertable gradient. The comparison on Table 8.2-1 indicates that the ISPFS azimuths for MW-OU1-36-A and 37-A are too westerly by $17^{\circ}$ to $27^{\circ}$ (the MW-OU1-39-A comparison is probably inaccurate due to gradient-azimuth errors caused by insufficient well coverage along the edge of the Airfield Clay near EW-OU1-17-A). This is in accord with the ISPFS azimuth ranges shown on Figure 8.2-1, which appear too westerly given the position of the instrument wells relative to the extraction wells and the treated water recharge area. The consistency of the discrepancy could be due to a northwest/southeastoriented anisotropy, however the contaminant plume shape (discussed below in Section 11) does not suggest such an anisotropy. A more likely explanation is an error during installation that resulted in a consistent misalignment (e.g., bad measurement of magnetic north, or error in accounting for magnetic declination). 
Table 8.2-1. Comparison of azimuths during the second quarter, 2003.

\begin{tabular}{|l|c|c|c|}
\hline Source & MW-OU1-36-A & MW-OU1-37-A & MW-OU1-39-A \\
\hline ISPFS & $316^{\circ}$ & $311^{\circ}$ & $298^{\circ}$ \\
\hline gradient & $333^{\circ}$ & $338^{\circ}$ & $270^{\circ}$ \\
\hline
\end{tabular}

\subsection{Horizontal Velocity Magnitude}

The inverted horizontal flow velocities from the ISPFSs are shown along with the extraction rates from EW-OU1-17-A and -18-A on Figure 8.3-1. This figure shows a clear correlation between the pumping state at EW-OU1-18-A and the horizontal velocities at the instruments. When extraction from EW-OU1-18-A ceases, the horizontal velocity at MW-OU1-36-A and -37-A decreases and at MW-OU1-39-A increases. This is readily explained by the location of the former generally upgradient of EW-OU1-18-A, and the position of the latter near the point of stagnation between the two extraction wells. The response at MW-OU1-37-A is greater than at -36-A due to its greater proximity to EW-OU1-18A in a more upgradient direction.

The absolute velocity values are divided by the gradient in Section 10.7 to estimate the hydraulic conductivity at each instrument. These values are compared against hydraulic conductivities measured via other methods. From these comparisons, it appears that the horizontal velocities measured by the ISPFSs are reasonable.

\subsection{Vertical Velocity Magnitude}

The inverted vertical flow velocities from the ISPFSs along with the extraction rates from EW-OU1-17-A and -18-A are shown in Figure 8.4-1. Comparison of Figures 8.3-1 and 8.4-1 indicates that the vertical velocities inverted from the ISFPS data are approximately the same as or much greater than the horizontal velocity at the same instrument, and are directed downward. Further, the inverted vertical velocities are approximately proportional to the horizontal velocities. This result is unexpected, and a complete analysis of the data is presented in the companion report ( $\mathrm{Su}$ et al., 2005), with a summary presented below.

The inverted vertical velocities are improbable due to the presence of the FO-SVA aquitard near the base of each instrument. This aquitard would prevent significant vertical flow at this position in the aquifer. Oldenburg et al. (2002) suggested that the temperature at the bottom of the sensor was elevated relative to the top due to the relatively lower thermal conductivity of clay, such as the FO-SVA, near the base of the sensors, as compared to sand, such as the A aquifer, which surrounds the sensors.

Non-isothermal flow simulation of various scenarios using TOUGH2 indicates that the thermal heterogeneity introduced by the immediate proximity of the sensor base to the FO-SVA clay could produce a temperature buildup at the bottom of the sensor that HTFlow95 would interpret as due to downward vertical flow ( $\mathrm{Su}$ et al., 2005). This effect rapidly dissipates as the sensor base is moved away from the clay however. The sensor base in MW-OU1-36-A, -37-A and -39-A is $1.5,0$, and $4 \mathrm{ft}(0.45,0$, and $1.2 \mathrm{~m})$, 
respectively, above the top of the FO-SVA, according to the well installation logs. The TOUGH2 modeling of Su et al. (2005) indicates that at a separation of 1.5-4 $\mathrm{ft}(0.45-1.2$ $\mathrm{m})$ from the clay, the thermal heterogeneity is too far away to create the necessary temperature buildup. This is further confounded by the significantly larger inverted vertical velocity in MW-OU1-36-A compared to those from the other wells, despite the fact that other wells have both greater and less separation between the bottom of the sensor and the FO-SVA clay.

One possible explanation is that the depth to the top of the FO-SVA is inaccurately represented on the drill logs for the sensor wells. Oldenburg et al. (2002) noted that comparison of the position of the top of the FO-SVA on drill logs and geophysical well $\operatorname{logs}$ for the four wells at OU 1 for which the latter data were available indicated discrepancies of up to $3.5 \mathrm{ft}(1.1 \mathrm{~m})$ between the two methods. Given this uncertainty, all of the ISFPSs in MW-OU1-36-A, -37-A, and -39-A may be in sufficiently close proximity to the FO-SVA to create the inverted vertical velocities.

Alternatively, the well completion method could have introduced thermal and permeability heterogeneities that would cause false inverted vertical velocities. The borings for the wells were initially piloted $2.5-4 \mathrm{ft}(0.76-1.2 \mathrm{~m})$ into the FO-SVA clay with a small auger. The borings were subsequently reamed with a larger auger to a target completion depth at or within $4 \mathrm{ft}(1.2 \mathrm{~m})$ of the top of the FO-SVA clay. The ISPFS was installed to the total depth of this larger boring.

Piloting into the FO-SVA would have caused smearing of clay for some distance up the borehole. This smear zone likely existed just below each ISPFS. The smear zone would introduce a thermal heterogeneity as well as a permeability heterogeneity. The TOUGH2 modeling indicated a thermal conductivity decrease of as little as $5 \%$ (from $2.1 \mathrm{~W} \mathrm{~m}^{-1} \mathrm{C}^{-1}$ to $2.0 \mathrm{~W} \mathrm{~m}^{-1} \mathrm{C}^{-1}$ ) near the bottom as compared to the thermal conductivity along the rest of the sensor could create a heat buildup sufficient to create the inverted vertical velocities (Su et al., 2005).

In short, we are left to speculate about the in situ conditions around the installed ISPFSs. However, TOUGH2 modeling demonstrates that thermal and permeability heterogeneities at the base of the ISPFSs are capable of creating apparent vertical velocities (Su et al., 2005). Thus we conclude that large components of downward vertical velocity in the A-aquifer are unlikely.

\section{PERMEABLE DIFFUSION SAMPLER RESULTS}

\subsection{Water Sampling Methods}

Water sampling from 51 of the wells at OU 1 from which chemistry data were available was changed from purge and sample (P\&S) to permeable diffusion sampling (PDS) at the end of 2001 as shown in Figure 9.1-1. Two wells outside of the area on Figure 9.1-1 have PDS results: MW-36-01-A to the east and MW-BW-18-A to the south. The wells without PDS results near the FDA are either piezometers, from which water samples are not collected, extraction wells, from which water samples are collected at the treatment system intakes, or wells connected to the real-time chemistry analysis system, from 
which samples are collected at the system intakes.

In $\mathrm{P} \& \mathrm{~S}$, a volume of water equivalent to a number of well-bore volumes is typically purged from a well and then a water sample is collected. The purpose of purging the well is to allow sampling of water representative of the groundwater in the formation rather than in the well. This is because the chemistry of the water in the well may change over time due to interaction with air, among other effects. Various water parameters such as temperature, $\mathrm{pH}$, and conductivity are typically monitored during the purging. Stabilization of these parameters provides a secondary check on whether the purging has been sufficient to bring water to the well representative of groundwater in the formation.

PDS involves placing a polymer bag filled with water (typically deionized) into the water column in the well. The PDS bag is left in place for some time, typically from one sampling event to the next, which is three months at OU 1. The concentration of organic contaminants in the water column in the well and in the water inside the bag equilibrates through diffusion.

Prior to switching the groundwater sampling methodology used at a well, MacTec conducted pilot studies for switching from P\&S to PDS. These studies included nearly contemporaneous samples collected via the two different methods; however these data and the pilot study reports were not available to LBNL. The analyses presented below are based entirely upon the analytical results of record for each well. Analysis of these records ultimately provides a better comparison of the methodologies due to the much greater number of PDS sample results for each well since the switch relative to the PDS results available during the pilot study analysis. A greater number of PDS results affords a more accurate and precise perspective on the concentrations and repeatability of these results, and therefore a better comparison to the P\&S results.

\subsection{Comparison of Purge and Sample to PDS results}

The 51 wells with PDS sampling can be broadly broken into three main groups based on the results from P\&S after June 2000 and PDS from late 2001 to early 2003. Contaminants were less than the detection limit in both the P\&S or PDS results from 17 of the 51 wells. Trichloroethylene (TCE) and its degradation compound cis-1,2 Dichoroethylene (cis-1,2 DCE) were consistently detected in the P\&S and/or PDS results from 19 of the 51 wells. Carbon tetrachloride (CT) and its potential degradation compounds were consistently detected in the P\&S and/or PDS results from 15 of the 51 wells. Chloroform, a possible degradation product of CT, and TCE or its potential degradation products were detected in two wells, MW-OU-01-A and-23-A. These two wells are included in both the CT and TCE groups. Two wells had consistently detected contaminants other than those listed above. Freon 113 was detected in MW-40-01-A and MEK and Toluene were detected in MW-B-11-A. Neither of these wells is included in the three main groups.

In general, the contaminant concentrations from samples collected by P\&S and PDS were consistent. There was a clear difference between the two result sets for only four of the 19 wells in the TCE group, as summarized in Table 9.2-1. For three of the wells, the result sets are different by a factor of two or less, assuming non-detects are near the detection limit, and so are not very significant. The only significant difference is in the 
result sets from MW-OU1-10-A. The difference in these result sets is an order of magnitude and, due to the position of this well, these differences would alter the interpretation of plume shape. For this reason, the PDS results from this well were discounted for plume contouring.

Table 9.2-1. Comparison of chemistry results from purge and sample and PDS.

\begin{tabular}{|c|c|c|c|}
\hline \multirow{2}{*}{ Well } & \multirow{2}{*}{ Contaminant } & \multicolumn{2}{|c|}{ Concentrations } \\
\cline { 3 - 4 } & cis-1,2 DCE & P\&S $(>6 / 00)$ & PDS \\
\hline $\begin{array}{c}\text { MW-OU1-02- } \\
180\end{array}$ & $<0.5 \mathrm{ug} / \mathrm{L}$ & $\begin{array}{c}0.59-1.4 \mathrm{ug} / \mathrm{L} \text { in greater than } \\
\text { half of } 184 \mathrm{ft} \text { bgs samples; } \\
\text { not detected at other depths }\end{array}$ \\
\hline MW-OU1-10-A & TCE & $3-7 \mathrm{ug} / \mathrm{L}$ & $\begin{array}{c}\text { typically }<0.5 \mathrm{ug} / \mathrm{L} ; \text { where } \\
\text { detected, } 0.5-0.6 \mathrm{ug} / \mathrm{L}\end{array}$ \\
\hline MW-OU1-32-A & TCE & $0.5-0.7 \mathrm{ug} / \mathrm{L}$ & $0.6-1.5 \mathrm{ug} / \mathrm{L}$ \\
\hline MW-OU1-33-A & TCE & typically $<0.5 \mathrm{ug} / \mathrm{L}$ & typically $0.6-0.8 \mathrm{ug} / \mathrm{L}$ \\
\hline
\end{tabular}

$\mathrm{ug} / \mathrm{L}=$ micrograms/liter

Result sets from some of the other TCE-group wells contained more subtle differences, however these differences could not be clearly assigned to the different sampling methodologies versus changing contaminant concentrations with time. The difficulty differentiating these two possibilities was in part because the first PDS data available from a well were two and a half months or more after the last P\&S data, with two exceptions. Therefore contaminant concentrations were not available for samples collected simultaneously by the two methodologies.

The focus of this report is on the OU 1 plume, and thus the TCE-group wells. The CTgroup well results are compared here simply as an additional comparison of the P\&S and PDS methods. Of the 15 wells in this group, there was no significant difference between the P\&S and PDS results for seven of the wells, the PDS results were significantly less than the P\&S results for five of the wells, and the PDS results were significantly higher than the P\&S results for three of the wells. The difference between the result sets was a factor of two to six generally. Therefore while no well in the CT group had as significant a difference between the result sets as MW-OU1-10-A in the TCE group, the fraction of wells showing a variance between the two groups was much higher in the CT group (approximately half) than the TCE group (approximately a fifth).

\subsection{PDS Depth Profiling Results}

At OU 1, the initial sampling event using PDS typically involved sampling from multiple depths in the water column to characterize the concentration profile. Thereafter sampling was carried out at the depth with the maximum concentrations. In wells where the initial sampling depths were widely spaced, and the contaminant concentrations were not uniform with depth, a subsequent sampling event was often undertaken to resolve the concentration gradients better. In some wells where the concentrations were uniform across a significant portion of the water column, the single sample depth after the initial 
multi-depth characterization was varied from event to event across the uniform region. In only one well, MW-OU1-27-A, sampling was carried out at more than one depth after the initial depth characterization sampling. These results are shown on Figures 9.3-1 and 9.3-2. These figures show that although the contaminant concentrations changed through time, the concentrations within the initially identified uniform region generally remained uniform through time. Note that the bottom of the well is above the depth given for some of the PDS results, presumably due to an error in the PDS depths.

The contaminant concentrations were relatively constant with depth in 39 of the 51 wells sampled by PDS. Of the 39 wells with constant concentrations with depth, the results from 17 wells were uniformly non-detect. Therefore the actual concentration profile in these wells may not be uniform. The contaminant concentrations from approximately two-thirds of the wells in both the TCE group and the CT group were constant with depth. Contaminant concentrations varied with depth in six of the 19 wells in the TCE group. The initial, multi-depth results from these wells are shown on Table 9.3-1. Contaminant concentrations increased with depth in four of the six wells. In three of these wells, no contaminants were detected in the shallowest PDS sample(s). Contaminant concentrations decreased with depth in only one well and were highest toward the middle of the depths sampled in only one well. 
Table 9.3-1. Non-uniform, contaminant concentration depth profiles.

\begin{tabular}{|c|c|c|c|c|}
\hline Well & $\begin{array}{l}\text { Consistently } \\
\text { detected con- } \\
\text { taminant(s) }\end{array}$ & $\begin{array}{l}\text { Water } \\
\text { column } \\
\text { (ft bgs) }\end{array}$ & $\begin{array}{c}\text { PDS } \\
\text { depths } \\
\text { (ft bgs) }\end{array}$ & $\begin{array}{l}\text { Concen- } \\
\text { tration } \\
(\mathrm{ug} / \mathrm{L})\end{array}$ \\
\hline MW-OU1-02-180 & cis-1,2 DCE & $141-195$ & $\begin{array}{l}179 \\
184 \\
189 \\
194\end{array}$ & $\begin{array}{l}<0.5 \\
0.59 \\
<0.5 \\
<0.5\end{array}$ \\
\hline MW-OU1-23-A & $\begin{array}{c}\mathrm{TCE} \\
\text { cis-1,2 DCE }\end{array}$ & $98-128.5$ & $\begin{array}{l}103 \\
108 \\
113 \\
118 \\
123 \\
128 \\
\end{array}$ & $\begin{array}{c}24,0.56 \\
24,0.55 \\
25,0.59 \\
25,0.58 \\
\quad<0.5 \\
1.6,<0.5\end{array}$ \\
\hline MW-OU1-27-A & $\begin{array}{c}\mathrm{TCE} \\
\text { cis-1,2 DCE }\end{array}$ & $56-85.5$ & $\begin{array}{l}60 \\
65 \\
70 \\
75 \\
80 \\
85\end{array}$ & $\begin{array}{c}<0.5 \\
4.2,<0.5 \\
49,7.2 \\
40,6.4 \\
43,6.7 \\
47,7.7\end{array}$ \\
\hline MW-OU1-29-A & TCE & $59-90$ & $\begin{array}{l}64 \\
88\end{array}$ & $\begin{array}{c}<0.5 \\
26\end{array}$ \\
\hline MW-OU1-32-A & TCE & $83-100$ & $\begin{array}{l}89 \\
94 \\
99\end{array}$ & $\begin{array}{c}0.76 \\
0.79 \\
1.5\end{array}$ \\
\hline MW-OU1-43-A & TCE & $65-96$ & $\begin{array}{l}73 \\
78 \\
83 \\
88 \\
93 \\
98\end{array}$ & $\begin{array}{c}<0.5 \\
<0.5 \\
0.52 \\
4.2 \\
18 \\
23\end{array}$ \\
\hline
\end{tabular}

As mentioned, the focus of this report is on the TCE-group wells. The CT-group well results are compared here simply as an additional comparison of the P\&S and PDS methods. Of the 15 wells in this group, the contaminant concentrations were relatively constant with depth in nine of the wells. In the other six wells, the contaminant concentrations typically increased with depth. In four of these wells, the concentration increased through the upper third of the water column and was relatively constant below.

As indicated, concentrations from slightly less than one third of the wells in the TCE group and slightly more than one third of the wells in the CT group were not constant with depth. Two possible explanations for these variations with depth are (1) varying horizontal flow velocities and volatilization or (2) other perturbations near the air/water interface. These variations in TCE concentrations with depth listed in Table 9.3-1 are generally more consistent with varying horizontal flow velocities with depth than with 
volatilization at the air/water interface. The concentration variations in the CT wells, as described, are generally more consistent with volatilization or other perturbations near the air/water interface.

\section{A-AQUIFER HYDRAULIC CONDUCTIVITY}

\subsection{Introduction}

The horizontal hydraulic conductivity of the A-aquifer is estimated below from the aquifer scale to the sub-well scale from the plume length, steady-state drawdowns, shortterm pumping tests, and ISPFS results. The unsaturated vertical hydraulic conductivity at the vadose-zone scale is estimated across the site from precipitation and treated-water recharge responses. The variation in hydraulic conductivity was investigated using all of these methods as well as the PDS results. The result of this analysis is that the vertical and horizontal conductivities are roughly equivalent, are in the range of 5.0 to $10.0 \mathrm{ft} / \mathrm{d}$ $\left(1.8-3.6 \times 10^{-5} \mathrm{~m} \mathrm{~s}^{-1}\right)$, are relatively uniform and isotropic, and are consistent across scales and across the site as described below.

\subsection{Plume Length and Alignment}

The gradient from above the recharge mound at the southeast corner of the FDA to the tail of the TCE plume in the second quarter of 2000 was 0.007 (Oldenburg et al., 2002). The total plume length in 2000, 39 years after the start of fire suppression training in the FDA, was $2000 \mathrm{ft}(600 \mathrm{~m})$. Assuming an effective porosity of $25 \%$ and no retardation, the implied average linear velocity from the start of training through 2000 is $0.14 \mathrm{ft} / \mathrm{d}(4.9$ $\mathrm{x} 10^{-7} \mathrm{~m} \mathrm{~s}^{-1}$ ). From these values, the calculated hydraulic conductivity across the entire plume is $5.0 \mathrm{ft} / \mathrm{d}\left(1.8 \times 10^{-5} \mathrm{~m} \mathrm{~s}^{-1}\right)$. As the OU 1 aquifer materials probably have low total organic carbon, retardation of TCE is probably low and therefore the actual hydraulic conductivity at the plume scale is probably only slightly greater than this value. Note further that this estimate is based on the tip of the plume and therefore is the maximum hydraulic conductivity for the plume.

Oldenburg et al. (2002) noted that the plume was aligned with the likely pre-1998 gradient, and with the depression in the water table downgradient of the FDA apparently created by evapotranspiration losses during recharge of the treated water. These alignments indicate that the flow direction is coincident with the gradient direction. Therefore it is unlikely there is significant anisotropy in the hydraulic conductivity in the A-aquifer at $\mathrm{OU} 1$.

\subsection{Early-1998 Precipitation Event}

Water levels shallower than $60 \mathrm{ft}(18 \mathrm{~m})$ started to increase $0.5-1.5$ months after the early-1998 precipitation event (Oldenburg et al., 2002). Therefore the recharge front advected through this portion of the vadose zone at a rate of $1.3-4 \mathrm{ft} / \mathrm{d}\left(4.6-14 \times 10^{-6} \mathrm{~m} \mathrm{~s}^{-}\right.$ $\left.{ }^{1}\right)$. The elapsed time from the precipitation event to the start of the water-level increase for water levels deeper than $60 \mathrm{ft}(18 \mathrm{~m})$ was proportional to the thickness of the vadose zone below $60 \mathrm{ft}(18 \mathrm{~m})$ (Oldenburg et al., 2002). The proportionality between elapsed 
time to water-level increase and thickness of the vadose zone below $60 \mathrm{ft}(18 \mathrm{~m})$ indicates the recharge front advected at a rate of $0.7 \mathrm{ft} / \mathrm{d}\left(2.5 \times 10^{-6} \mathrm{~m} \mathrm{~s}^{-1}\right)$ (Oldenburg et al., 2002). The decreasing advection rate of the recharge front with depth could be due to higher relative saturation in the upper portion of the vadose zone resulting from precipitation events earlier in the 1997/1998 rain year. Alternatively, the decreasing advection rate of the recharge front with depth could be due to a decrease in the hydraulic conductivity with depth.

Assuming a unit gradient, the advection rates for the recharge front are equivalent to the unsaturated hydraulic conductivity. Therefore the unsaturated vertical hydraulic conductivities are $0.7-4 \mathrm{ft} / \mathrm{d}\left(2.5-14 \times 10^{-6} \mathrm{~m} \mathrm{~s}^{-1}\right)$. The correlation of the recharge front arrival time at the water table to the thickness of the vadose zone at each well also indicates the vertical hydraulic conductivity throughout the vadose zone is relatively uniform with depth.

\subsection{PDS Results}

The PDS sample results from most of the A-aquifer wells indicate that contaminant concentrations typically do not vary with depth. Vertical mixing in these wells should generally be minimal due to Darcy flow and the horizontal to near-horizontal layering of the hydrostratigraphic units at the site. Therefore, the predominance of constant contaminant concentrations with depth indicates that within the A-aquifer at OU 1 there is typically little variation in the flow velocity, and therefore the horizontal permeability, with depth in the sandy portion of the A aquifer.

\subsection{Steady-State Drawdown}

Continuous groundwater extraction from EW-OU1-17-A commenced in early 1988 and has continued through 2003. Continuous groundwater extraction from EW-OU1-18-A occurred from early 1988 to June 2001. The water levels in these wells and nearby wells MW-OU1-03-A and PZ-OU1-13-A to -16-A reflect the steady-state response of the aquifer to pumping. The water levels in these wells allow estimation of the hydraulic conductivity in the vicinity of the extraction wells by employing the Thiem equation for steady-state radial flow to a well in an unconfined aquifer (e.g., Bouwer, 1978).

The unconfined aquifer version of the Thiem equation rests on the following assumptions:

1) The aquifer is unconfined.

2) Pumping well and observation wells fully penetrate the aquifer.

3) Pumping rate is constant.

4) Flow has reached steady state.

5) Water-table position is not changing with time.

6) Aquifer is homogeneous and isotropic.

7) Water table is horizontal prior to pumping. 
8) Aquifer is underlain by a horizontal aquitard.

9) Pumping well is $100 \%$ efficient.

The first assumption is obviously correct and second assumption is correct for the wells under consideration. Available totalizer data indicate the pumping rate for both wells is constant at approximately 8.5 gallons per minute (gpm), thereby in accordance with the third assumption. Figures 10.5-1 and 10.5-2 show the hydrographs for the wells under consideration. The applicability of the fourth assumption is reflected by the constant pumping rate, the constancy of the water levels in various time periods, and the constant to gradually changing water level differences between the wells. The fifth assumption is valid because measurements presented in Oldenburg et al. (2002) indicate that the time to rebound after the shutdown EW-OU1-18-A was approximately one month, which is much shorter than any similar magnitude natural changes in the water-table elevation occurring at these wells with the exception of the period from early 1998 to mid-2000. Therefore, the Thiem equation can be applied to water levels outside of this time period.

The applicability of the sixth assumption is suggested by the materials which make up the A-aquifer. The homogeneous, isotropic nature of this material is further confirmed by the alignment of the TCE plume with the water-table gradient and the pre-1998 watertable depression presumably due to evapotranspiration losses resulting from the method of recharge of the treated water.

Comparison of water levels after shutdown of EW-OU1-18-A indicates that the nonpumping water-table elevation in this well is the same as PZ-OU1-15-A, approximately $0.1 \mathrm{ft}(0.03 \mathrm{~m})$ above MW-OU1-03-A, and approximately $0.2 \mathrm{ft}(0.06)$ above PZ-OU116-A. The variances from the assumption for the latter two wells are relatively small compared to the drawdowns of 0.9 and $1.2 \mathrm{ft}(0.27$ and $0.37 \mathrm{~m})$ at these wells, respectively, prior to the shutdown. Therefore the seventh assumption is valid for EWOU1-18-A and the three observation wells.

Comparison of water levels during apparent pumping shutdowns of EW-OU1-17-A, as well as consideration of the position of this well and the two observation wells relative to the surrounding water table and hydrogeologic features, indicates that the non-pumping water-table elevation in this well is effectively the same as PZ-OU1-13-A, given the approximately $1.3-2.0 \mathrm{ft}(0.40-0.61 \mathrm{~m})$ drawdown at this observation well during pumping. Therefore the seventh assumption appears to be met for this well pair. The non-pumping water-table elevation at PZ-OU1-14-A appears to be approximately $0.5 \mathrm{ft}$ $(0.15 \mathrm{~m})$ lower than at the other wells, which is in accord with its position farther from the edge of the Airfield Clay portion of Clay 3 (see Oldenburg et al. (2002) for a hydrostratigraphic description of OU 1). This is a significant fraction of the total typical drawdown at this well of 1.2-2.0 ft $(0.37-0.61 \mathrm{~m})$. Due to the smaller drawdowns at the observation wells, this deviation from the seventh assumption will introduce a large error into the hydraulic conductivity estimated from the observation well pair. The $0.5 \mathrm{ft}(0.15$ $\mathrm{m})$ deviation at PZ-OU1-14-A is small relative to the drawdown of 4-10 $\mathrm{ft}(1.2-3.0 \mathrm{~m})$ at EW-OU1-17-A, however, so the deviation will cause only slight underestimation of the hydraulic conductivity from this well pair. Therefore, the hydraulic conductivity will not be estimated from the observation well pair, but rather only from pumping 
well/observation well pairs.

The eighth assumption is valid for EW-OU1-17-A and PZ-OU1-13-A and -14-A as the top of the FO-SVA varies little compared to the observation well drawdowns as shown on Figure 10.5-3. Note that the elevation of the top of the FO-SVA in this figure does not match those in Oldenburg et al. (2002) at all wells. In the former document, the top of the FO-SVA was taken at the base of angled contacts shown on well logs. In this document, the top of the FO-SVA is taken at the midpoint of the angled contacts shown on logs, as is standard in the geotechnical industry.

The eighth assumption is problematic for EW-OU1-18-A, MW-OU1-03-A, and PZ-OU115-A and -16-A as the top of the FO-SVA varies by $10 \mathrm{ft}(3 \mathrm{~m})$ as shown in Figure 10.53 , which is an order of magnitude more than the drawdown at the observation wells. This error introduces large errors in the hydraulic conductivities estimated using the actual saturated thicknesses from the well pairs using the Thiem equation as shown on Figure 10.5-4 and in Table 10.5-1. These errors are due to the large errors-even reversals--in the estimation of the gradient. The gradient can be preserved by treating the aquitard elevation as constant. This will in turn introduce errors into the saturated thickness. However these errors will always be smaller than those where the saturated thickness is preserved and the gradient is altered, and the error introduced will be bounded as described below.

Table 10.5-1. Erroneous estimates of hydraulic conductivity (ft/d) from EW-OU1-18-A.

\begin{tabular}{|l|l|l|l|l|}
\hline $\begin{array}{c}\text { 3 October 1994 } \\
\text { 4 June 2001 }\end{array}$ & EW-OU1-18-A & PZ-OU1-15-A & PZ-OU1-16-A & MW-OU1-03-A \\
\hline EW-OU1-18-A & & 2.9 & 4.3 & -29.2 \\
\hline PZ-OU1-15-A & 2.0 & & -2.0 & -0.5 \\
\hline PZ-OU1-16-A & 2.9 & -1.7 & & -0.8 \\
\hline MW-OU1-03-A & -56.3 & -0.4 & -0.6 & \\
\hline
\end{tabular}

There are two components to the deviation from the eighth assumption. The first component is the variance of the aquitard elevation in the radial direction from the pumping well. The second component is the variation of the aquitard elevation in the tangential direction around the pumping well. This variation will cause tangential gradients inconsistent with the radial-flow-only corollary to the sixth, seventh and eighth assumptions.

The error introduced by setting the FO-SVA elevation constant around EW-OU1-18-A can be bounded by estimating the end-member hydraulic conductivity for each well pair as shown on Figure 10.5-4. One estimate of saturated thickness uses the higher aquitard elevation from the well pair, while the other is based upon the lower aquitard elevation from the well pair. The first method will overestimate the hydraulic conductivity due to the artificial reduction in saturated thickness. The second method will underestimate the hydraulic conductivity due to the artificial increase in saturated thickness. The actual hydraulic conductivity will be between these two estimates.

The tangential variability of the aquitard can be accounted for by only estimating 
hydraulic conductivity from well pairs along the same azimuth from the pumping well, and by estimating hydraulic conductivity at different azimuths that capture the range of variability in the aquitard. The first strategy eliminates misestimation of hydraulic conductivities due to tangential flow and gradients caused by differing aquitard elevations between observation wells on different azimuths. As none of the OU 1 observation wells are on the same azimuth, this necessitates only analyzing well pairs consisting of the pumping well and an observation well. The second strategy develops a range of estimates that will bracket the actual hydraulic conductivity value. This is because the tangential variability in the aquifer leads to different contributions to the pumping rate from different sectors of the aquifer. The Thiem equation will therefore over- or under-estimate the hydraulic conductivity along a particular azimuth depending upon whether the contribution of that sector of the aquifer is above or below the average. If hydraulic conductivity estimations are made along a number of azimuths, then the variance in the flow contributions will average out between them, as will the hydraulic conductivity estimates. The three EW-OU1-18-A/observation well pairs are along approximately evenly spaced azimuths, as shown on Figure 10.5-3, so this approach is valid.

The ninth assumption overestimates the efficiency of any real well. However, the actual efficiency of EW-OU1-17-A and -18-A is probably reasonably high given the lack of fines in the formation and the use of stainless steel, wire-wrapped screens in their construction. Therefore, while there are certainly head losses across the well screen, they are likely a small fraction of the total drawdown. To the extent these losses exist, use of water levels from these wells will underestimate the hydraulic conductivity because use of these water levels overestimates the gradient toward the well. The impact of a less than perfect well efficiency on the hydraulic conductivity estimates is approximated below.

Hydraulic conductivity estimates were developed using water levels from periods of relatively stable pumping (for which data were available from June 2000 through December 2003) and/or water-level stability. Estimates were developed for one pre-1998 and one-post-1998 water-level data set. Table 10.5-2 presents the hydraulic conductivity estimates for the EW-OU1-17-A/observation well pairs. Due to the slight variation in the elevation of the top of the FO-SVA between EW-OU1-17-A and PZ-OU1-13-A, and for the sake of consistency, this table presents end-member (calculated based on minimum and maximum elevations of the FO-SVA for each well pair) hydraulic conductivity estimates. Table 10.5-3 presents the end-member hydraulic conductivity estimates for the EW-OU1-18-A/observation well pairs. 
Table 10.5-2. Hydraulic conductivity estimates (ft/d) from EW-OU1-17-A pumping.

\begin{tabular}{|l|c|c|c|c|}
\hline \multicolumn{1}{|c|}{ EW-OU1-17-A } & \multicolumn{2}{|c|}{ pumping well clay elevation } & observation well clay elevation \\
\hline & PZ-OU1-14-A & PZ-OU1-13-A & PZ-OU1-14-A & PZ-OU1-13-A \\
\hline 11 November 1994 & 6.8 & 7.0 & 6.8 & 6.9 \\
\hline$\sim 80 \%$ efficient & 8.4 & 8.6 & 8.4 & 8.3 \\
\hline 3 June 2002 & 9.0 & 8.4 & 9.0 & 7.8 \\
\hline$\sim 80 \%$ efficient & 14.0 & 12.0 & 14.0 & 10.7 \\
\hline
\end{tabular}

Table 10.5-3. Hydraulic conductivity estimates (ft/d) from EW-OU1-18-A pumping.

\begin{tabular}{|l|c|c|c|c|c|c|}
\hline EW-OU1-18-A & \multicolumn{2}{|c|}{ pumping well clay elevation } & \multicolumn{3}{c|}{ observation well clay elevation } \\
\hline & $\begin{array}{c}\text { PZ-OU1- } \\
16-A\end{array}$ & $\begin{array}{c}\text { PZ-OU1- } \\
\text { 15-A }\end{array}$ & $\begin{array}{c}\text { MW-OU1- } \\
\text { 03-A }\end{array}$ & $\begin{array}{c}\text { PZ-OU1- } \\
16-\mathrm{A}\end{array}$ & $\begin{array}{c}\text { PZ-OU1- } \\
\text { 15-A }\end{array}$ & $\begin{array}{c}\text { MW-OU1- } \\
\text { 03-A }\end{array}$ \\
\hline 3 October 1994 & 5.0 & 5.8 & 5.8 & 4.3 & 5.2 & 6.8 \\
\hline$\sim 80 \%$ efficient & 6.9 & 7.9 & 7.6 & 5.9 & 7.2 & 9.0 \\
\hline 4 June 2001 & 8.2 & 9.9 & 9.7 & 6.7 & 8.5 & 12.4 \\
\hline 80\% efficient & 11.3 & 13.8 & 12.9 & 9.3 & 12.0 & 16.4 \\
\hline
\end{tabular}

The June 2001 drawdown at EW-OU1-18-A is known directly from measurements following the pump shutdown. The drawdown at the extraction wells for the other dates is calculated by presuming that water-level peaks at nearby dates on the hydrographs shown on Figures 10.5-1 and 10.5-2 are due to short pump shutdowns. This presumption is reasonable as the water level in the extraction wells rises to nearly the same level as in the observation wells on these dates. The extraction well drawdowns were used to develop the hydraulic conductivity estimates assuming a pumping well efficiency of $80 \%$. The hydraulic conductivity estimates assuming $80 \%$ well efficiency range from $30 \%$ to $60 \%$ higher than the estimates assuming $100 \%$ well efficiency for the single well pair estimates. This is a fairly small error given the natural variability in hydraulic conductivity.

The variation in the end-member hydraulic conductivity estimates for each well pair is less than $25 \%$ using the average of the estimates as the basis. The average variation of the end-member hydraulic conductivity estimates is $3 \%$ and $17 \%$ for the EW-OU1-17-A and EW-OU1-18-A well pairs, respectively. The higher variation in the EW-OU1-18-A well pairs is expected due to the greater variation in the FO-SVA elevation around this well.

The average of all the hydraulic conductivity estimates assuming $100 \%$ well efficiency (no head loss across the well screen) is $7.7 \mathrm{ft} / \mathrm{d}\left(2.7 \times 10^{-5} \mathrm{~m} \mathrm{~s}^{-1}\right)$ and $7.4 \mathrm{ft} / \mathrm{d}\left(2.6 \times 10^{-5} \mathrm{~m}\right.$ $\mathrm{s}^{-1}$ ) for EW-OU1-17-A and EW-OU1-18-A, respectively. Assuming 80\% well efficiency ( $20 \%$ head loss across the well screen), the average of all the estimates is $10.6 \mathrm{ft} / \mathrm{d}(3.7 \mathrm{x}$ $\left.10^{-5} \mathrm{~m} \mathrm{~s}^{-1}\right)$ and $10.8 \mathrm{ft} / \mathrm{d}\left(3.8 \times 10^{-5} \mathrm{~m} \mathrm{~s}^{-1}\right)$ for EW-OU1-17-A and EW-OU1-18-A, respectively.

The hydraulic conductivity estimates for every well pair were $30 \%$ to $80 \%$ greater during the increased water levels after 1998 than before, suggesting the hydraulic conductivity 
decreases slightly with depth. This relatively small variation is consistent with the typically constant contaminant concentrations with depth from the PDS results. The average of the hydraulic conductivity estimates for the EW-OU1-17-A well pairs, assuming $100 \%$ efficiency, are $6.9 \mathrm{ft} / \mathrm{d}\left(2.4 \times 10^{-5} \mathrm{~m} \mathrm{~s}^{-1}\right)$ and $8.5 \mathrm{ft} / \mathrm{d}\left(3.0 \times 10^{-5} \mathrm{~m} \mathrm{~s}^{-1}\right)$ for 1994 and 2002, respectively. The water levels during the 1994 estimate were 14-19 ft (4.3-5.8 m) lower than during the 2002 estimate, and the water level in EW-OU1-17-A was approximately $6 \mathrm{ft}(1.8 \mathrm{~m})$ and $25 \mathrm{ft}(7.6 \mathrm{~m})$ above the top of the FO-SVA in 1994 and 2002, respectively. The average of the hydraulic conductivity estimates for the EWOU1-18-A well pairs, assuming 100\% efficiency, are $5.5 \mathrm{ft} / \mathrm{d}\left(1.9 \times 10^{-5} \mathrm{~m} \mathrm{~s}^{-1}\right)$ and 9.2 $\mathrm{ft} / \mathrm{d}\left(3.2 \times 10^{-5} \mathrm{~m} \mathrm{~s}^{-1}\right)$ in 1994 and 2001, respectively. The water levels during the 1994 estimate were 7-8 $\mathrm{ft}(2.1-2.4 \mathrm{~m})$ lower than during the 2001 estimate, and the water level in EW-OU1-18-A was approximately $20 \mathrm{ft}(6.1 \mathrm{~m})$ and $27 \mathrm{ft}(8.2 \mathrm{~m})$ above the top of the FO-SVA in 1994 and 2001, respectively. Therefore, the variation in hydraulic conductivity with depth appears to be less at EW-OU1-17-A than at EW-OU1-18-A, particularly considering the much larger water-level changes at the former compared to the latter.

The range of well-pair averaged estimates assuming $100 \%$ efficiency is $6.8-7.0 \mathrm{ft} / \mathrm{d}$ $\left(2.4-2.5 \times 10^{-5} \mathrm{~m} \mathrm{~s}^{-1}\right)$ and 7.8-9.0 ft/d (2.7-3.2 x 10-5 $\left.\mathrm{m} \mathrm{s}^{-1}\right)$ for the EW-OU1-17-A well pairs in 1994 and 2002, respectively. The range of well-pair averaged estimates assuming $100 \%$ efficiency is $4.3-6.8 \mathrm{ft} / \mathrm{d}\left(1.5-2.4 \times 10^{-5} \mathrm{~m} \mathrm{~s}^{-1}\right)$ and $6.7-12.4 \mathrm{ft} / \mathrm{d}(2.4-4.3$ $\mathrm{x} 10^{-5} \mathrm{~m} \mathrm{~s}^{-1}$ ) for the EW-OU1-18-A well pairs in 1994 and 2001, respectively. The ranges of hydraulic conductivity estimates from EW-OU1-18-A are greater than that from EW-OU1-17-A, probably due to the greater variability in the elevation of the top of the FO-SVA around EW-OU1-18-A.

\subsection{Treated Groundwater Recharge Response}

Water-level changes in wells MW-OU1-01-A, -02-A, -06-A and -12-A followed changes in the treated water recharge rate by 20 days to a month (Oldenburg et al., 2002). As the vadose zone is approximately $70 \mathrm{ft}(21.3 \mathrm{~m})$ thick in this area, the linear velocity through the partially to nearly saturated vadose zone beneath the recharge area is between 2.3 and $3.5 \mathrm{ft} / \mathrm{d}\left(1.2 \times 10^{-5} \mathrm{~m} \mathrm{~s}^{-1}\right)$. Assuming a unit hydraulic gradient and an effective porosity of $25 \%$, the unsaturated vertical hydraulic conductivity in the vadose zone is $0.6-0.9 \mathrm{ft} / \mathrm{d}$ $\left(2.1-3.2 \times 10^{-6} \mathrm{~m} \mathrm{~s}^{-1}\right)$.

\subsection{Short-Duration Pump Tests}

Short-duration pumping tests were conducted at wells MW-OU-07-A, 08-A, 10-A, and 29-A. The results of these tests were analyzed using the Dupuit-Forcheimer equation to arrive at hydraulic conductivities of $3.1,3.4,43$, and $7.1 \mathrm{ft} / \mathrm{d}\left(1.1,1.2,15\right.$, and $2.5 \times 10^{-5}$ $\mathrm{m} \mathrm{s}^{-1}$ ) (Oldenburg et al., 2002). Oldenburg et al. (2002) used the harmonic mean of these conductivities $\left(5.1 \mathrm{ft} / \mathrm{d}\left(1.8 \times 10^{-5} \mathrm{~m} \mathrm{~s}^{-1}\right)\right)$ for estimating average linear velocities and simple flow modelling used to analyse ISPFS response. The harmonic mean is appropriate for estimating conductivities in one-dimensional flow perpendicular to a series of layers with different conductivities. However, the geometric mean provides a more accurate estimation of average conductivity from point measurements in a two- 
dimensional domain containing non-layer-dependent conductivity variations (de Marsily, 1986). The geometric mean of the hydraulic conductivities inverted from the shortduration pump tests is $7.5 \mathrm{ft} / \mathrm{d}\left(2.6 \times 10^{-5} \mathrm{~m} \mathrm{~s}^{-1}\right)$.

\subsection{ISPFS Results}

Inversion of the temperature data from the three ISPFS instruments with functioning heaters and conforming temperature data yields a Darcy flow velocity vector in the vicinity of the instrument, as previously described. The apparent vertical Darcy velocities measured by the instruments at OU 1 are likely artifacts of the thermal heterogeneity and borehole skin around the instruments as discussed in Section 8.3 and in $\mathrm{Su}$ et al. (2005). However, the horizontal Darcy velocities appear reasonable. Dividing these velocities by the gradient yields an estimate of the hydraulic conductivity around each sensor. Table 10.8-1 lists the inverted velocity and the gradient measured from the June 2003 water table in the vicinity of the ISPFSs along with the estimated hydraulic conductivities.

Table 10.8-1. Hydraulic conductivity estimates from ISPFS $V_{h}$ and gradient.

\begin{tabular}{|l|c|c|c|}
\hline & $\begin{array}{c}\text { MW-OU1-36- } \\
\text { A }\end{array}$ & $\begin{array}{c}\text { MW-OU1-37- } \\
\text { A }\end{array}$ & $\begin{array}{c}\text { MW-OU1-39- } \\
\text { A }\end{array}$ \\
\hline Vh from ISPFS (ft/day) & 0.028 & 0.093 & 0.13 \\
\hline Gradient & 0.0058 & 0.0090 & 0.027 \\
\hline Hydraulic Conductivity (ft/day) & 4.8 & 10.3 & 4.8 \\
\hline
\end{tabular}

\subsection{Summary Hydraulic Conductivity Comparison}

Table 10.9-1 summarizes and compares all of the hydraulic conductivity estimates as well as information regarding heterogeneity and anisotropy. The estimates made by a wide variety of methods are in excellent agreement, falling primarily between $5-10 \mathrm{ft} / \mathrm{d}$ $\left(1.8-3.5 \times 10^{-5} \mathrm{~m} \mathrm{~s}^{-1}\right)$. This is a remarkable result given the range of scales over which these estimates are made. Scales range from the length of the entire plume (approximately $3000 \mathrm{ft}(900 \mathrm{~m})$ ) to the bore-hole scale (ISPFS results). Further, the analyses indicated that the A-aquifer is relatively homogeneous and isotropic with perhaps a slight decline in conductivity with depth. The unsaturated vertical conductivities range from $0.6-4 \mathrm{ft} / \mathrm{d}\left(2.1-14 \times 10^{-6} \mathrm{~m} \mathrm{~s}^{-1}\right)$. Given that unsaturated conductivities are less than saturated conductivities for the same material, this range appears reasonable relative to the horizontal, saturated hydraulic conductivities. 
Table 10.9-1. Comparison of hydraulic conductivity estimates.

\begin{tabular}{|c|c|c|c|}
\hline estimate source data & K type & $\begin{array}{c}\mathrm{K} \\
(\mathrm{ft} / \mathrm{d})\end{array}$ & Notes \\
\hline plume length & $\begin{array}{c}\text { horizontal, } \\
\text { saturated }\end{array}$ & 5.0 & $\begin{array}{c}\text { Actual value probably higher } \\
\text { due to retardation }\end{array}$ \\
\hline plume alignment & $\begin{array}{c}\text { horizontal, } \\
\text { saturated }\end{array}$ & NA & $\begin{array}{c}\text { Alignment suggests no } \\
\text { heterogeneity or anisotropy. }\end{array}$ \\
\hline $\begin{array}{l}\text { early-1998 recharge - vadose } \\
\text { zone above } 60 \text { feet deep }\end{array}$ & $\begin{array}{l}\text { Vertical, near } \\
\text { saturation? }\end{array}$ & $1.3-4$ & $\begin{array}{l}\text { No significant heterogeneity } \\
\text { in vadose zone above } 60 \text { feet }\end{array}$ \\
\hline $\begin{array}{l}\text { Early-1998 recharge - vadose } \\
\text { zone below } 60 \text { feet deep }\end{array}$ & $\begin{array}{c}\text { Vertical, } \\
\text { unsaturated? }\end{array}$ & 0.7 & $\begin{array}{l}\text { No significant heterogeneity } \\
\text { in vadose zone below } 60 \text { feet }\end{array}$ \\
\hline Treated groundwater recharge & $\begin{array}{l}\text { Vertical, near } \\
\text { saturation? }\end{array}$ & $\begin{array}{c}0.6- \\
0.9\end{array}$ & \\
\hline PDS results & $\begin{array}{c}\text { horizontal, } \\
\text { saturated }\end{array}$ & NA & $\begin{array}{l}\text { horizontal conductivity does } \\
\text { not vary greatly with depth }\end{array}$ \\
\hline $\begin{array}{l}\text { EW-OU1-17-A and -18A } \\
\text { drawdown }\end{array}$ & $\begin{array}{c}\text { horizontal, } \\
\text { saturated }\end{array}$ & $\begin{array}{l}7.4- \\
7.7\end{array}$ & $\begin{array}{c}\text { Assumes } 100 \% \text { pumping well } \\
\text { efficiency }\end{array}$ \\
\hline $\begin{array}{l}\text { EW-OU1-17-A and -18A } \\
\text { drawdown }\end{array}$ & $\begin{array}{c}\text { horizontal, } \\
\text { saturated }\end{array}$ & $\begin{array}{c}10.6- \\
10.8\end{array}$ & $\begin{array}{c}\text { Assumes } 80 \% \text { pumping well } \\
\text { efficiency }\end{array}$ \\
\hline $\begin{array}{l}\text { EW-OU1-17-A and -18A } \\
\text { drawdown }\end{array}$ & $\begin{array}{c}\text { horizontal, } \\
\text { saturated }\end{array}$ & NA & $\begin{array}{c}\text { Slight decrease in } \\
\text { conductivity with depth, no } \\
\text { anisotropy }\end{array}$ \\
\hline Short-duration pump tests & $\begin{array}{c}\text { horizontal, } \\
\text { saturated }\end{array}$ & $3.1-43$ & Geometric mean is 7.5 \\
\hline $\begin{array}{l}\text { Water-table gradients and } \\
\text { ISPFS velocity measurements }\end{array}$ & $\begin{array}{c}\text { horizontal, } \\
\text { saturated }\end{array}$ & $\begin{array}{l}4.8- \\
10.3\end{array}$ & \\
\hline
\end{tabular}

\section{TCE PLUME EVOLUTION}

\subsection{TCE Plume History}

The TCE plume is shown in late 1993, late 1997, and late 1999 in Oldenburg et al. (2002), which nearly covered the temporal extent of the chemistry data analyzed in that report. The chemistry data analyzed in the present report cover the time period from the beginning of 1986 to the end of 2003. Figure 11.1-1 shows the head of the TCE plume in late 1986. Note that the location of the FDA is more accurately depicted as compared to the depiction in Oldenburg et al. (2002) and now includes the flammable materials offloading, storage, and transfer areas as well as the burn pit. The depiction shown is based upon HLA (1986) and an unreferenced vertical aerial photograph available from the Fort Ord Data Integration System (http://www.fodis.net). This photo was included in the web site to show the mosaic pattern of grassland, coast live oak woodland and central maritime chaparral at Fort Ord. The photo also happened to show the FDA in the period between cessation of fire training activities and the remedial soil excavation. 


\subsection{Plume Prior to Remediation}

The head of the TCE plume shown in Figure 11.1-1 was approximately colocated with the FDA. The shape of the plume head suggests a single area of contaminant release with subsequent advection and dispersion with the possible exception of an additional release of contaminants near MW-OU1-03-A, which has the highest TCE concentrations. The axis of the plume trended approximately 15 degrees west of north which matched the estimate of the pre-extraction gradient direction in Oldenburg et al. (2002). Up to late 1986, TCE was not detected in the transgradient wells MW-OU1-05-A, -06-A, -08-A and -09-A, nor in upgradient wells MW-OU1-01-A and 02-A.

\subsection{Plume After Soil Remediation}

The TCE plume head in late 1987 is shown on Figure 11.3-1. This apparently post-dates soil remediation activities at the FDA. TCE concentrations at MW-OU1-03-A, -04-A and -07-A diminished relative to 1986. The concentrations at the MW-OU1-03-A were the highest and did not decrease as significantly as the concentrations in the other two wells, further suggesting an additional, past contaminant release near this well. TCE was detected at upgradient well MW-OU1-01-A for the first time during this period. The timing of this detection suggests that the soil remediation activities between late 1986 and late 1986 may have moved TCE to the south of the FDA, either by reversing the groundwater flow or by introducing TCE into or mobilizing TCE through the vadose zone in this area. TCE was still not detected at the transgradient wells.

\subsection{Plume After Commencement of Pump, Treat and Recharge}

In mid-1988, extraction of contaminated groundwater from EW-OU1-17-A and -18-A commenced. The extraction rate from each well was approximately 8 gallons per minute (gpm) $\left(0.5 \mathrm{~L} \mathrm{~s}^{-1}\right)$. The water was treated by an on-site granular activated-charcoal system and then spread on the ground surface by sprinkler in the general area shown on Figure 11.4-1. Based upon Figure 11.3-1, the recharge area appears to overlie a portion of the TCE plume. The recharge area is approximately 10 degrees east of south from EW-OU118-A, which is almost directly upgradient of this extraction well. Oldenburg et al. (2002) estimated that the recharge rate was $70 \%$ of the total extraction rate, which is $40 \%$ greater than the extraction rate from a single well. Given these relative rates and the spatial relationship between EW-OU1-18-A and the recharge area, it is likely that some of the flow from the recharge area bypassed EW-OU1-18-A to the east.

Figure 11.4-1 also shows the TCE plume head in late 1990. Concentrations continued to generally decrease within the plume core. The concentration at MW-OU1-03-A was still the highest. The TCE concentration in transgradient well MW-OU1-10-A declined, presumably due to flow of TCE-free groundwater from beyond the plume boundary to EW-OU1-17-A (throughout the rest of this section, transgradient will be used to refer to wells that were cross-gradient from the TCE plume location in 1986).

In late 1990, the TCE concentration in upgradient well MW-OU1-01-A increased approximately two orders of magnitude relative to the concentration prior to 
commencement of treated-water recharge. Oldenburg et al. (2002) demonstrated that the water levels in this well had the greatest response to this recharge. The TCE concentration increase was likely due to some effect of the treated water recharge. This could be due to placement of the recharge area over a portion of the plume with subsequent reversal of groundwater flow. This reversal would cause TCE-contaminated groundwater to advect southward toward MW-OU1-01-A. However flow reversal would likely have brought groundwater contaminated with 1,2 Dichloroethylene (1,2 DCE) to the well also. 1,2 DCE is a degradation product of TCE which is present throughout the head of the TCE plume prior to remedial activities in late 1986. 1,2 DCE was not detected in MW-OU-01-A. Therefore a more likely mechanism for the TCE increase at MW-OU1-01-A is mobilization of residual TCE in the vadose zone by the high rate of treated water recharge (which is several times the peak natural recharge rate (Oldenburg et al., 2002)).

Figure 11.4-1 shows TCE was also detected at transgradient wells MW-OU1-05-A and 08-A where TCE had generally not been detected prior to treated water recharge. This is likely a result of the transgradient plume dimension increasing due to divergent flow of contaminated groundwater beneath the treated-water recharge area. Specifically, a slight change in the trajectory of contaminated groundwater along west of the FDA and in the vicinity of MW-OU1-03-A would cause the observed increases.

\subsection{Plume Six Years After Commencing Pump, Treat, and Recharge}

The concentration of TCE in the plume core continued to decrease through early 1994 as shown in Figure 11.5-1. The TCE concentration in transgradient well MW-OU1-05-A continued to increase. The TCE concentration in transgradient well MW-OU1-06-A increased above non-detect for the first time, probably due to advection of the contaminated water in the vicinity of MW-OU1-01-A in 1990. Meanwhile, the TCE concentration in MW-OU1-01-A decreased considerably suggesting that the source of the TCE at this well was significantly depleted by this time.

\subsection{Plume Prior to Early-1998 Recharge}

The concentration of TCE in the plume core generally continued to decrease through late 1997 as shown in Figure 11.6-1. The concentration in MW-OU1-01-A continued to decrease. The concentration decreased in nearby MW-OU1-06-A as well, probably due to advection along the west side of the plume of lower concentration groundwater which occurred in 1994 around MW-OU1-01-A. The concentration also decreased in MWOU1-08-A, probably due to advection of significantly lower concentration groundwater in the vicinity of MW-OU1-03-A along the east side of the plume.

The TCE concentrations in MW-OU1-04-A, -05-A and -19-A increased through late 1997. These increases appear to be due to continued advection along the west side of the plume of the higher-concentration groundwater which occurred in 1990 at MW-OU1-01A. The distance between MW-OU1-05-A and MW-OU1-06-A is approximately $400 \mathrm{ft}$ $(120 \mathrm{~m})$. From Oldenburg et al. (2002), the gradient west of the FDA is 0.011 . Using a hydraulic conductivity of $7.5 \mathrm{ft} / \mathrm{d}\left(2.6 \times 10^{-5} \mathrm{~m} \mathrm{~s}^{-1}\right)$ and a porosity of $25 \%$ yields a linear velocity of $0.33 \mathrm{ft} / \mathrm{d}\left(1.2 \times 10^{-6} \mathrm{~m} \mathrm{~s}^{-1}\right)$ or a travel time of 3.3 years between the two wells. 
This matches the apparent travel time of over two years between these two wells based upon a comparison of Figure 11.5-1 and 11.6-1.

\subsection{Plume Following Early-1998 Precipitation}

Following the historically high precipitation of early 1998, TCE concentrations in EWOU1-18-A, nearby wells and wells upgradient remained the same as shown on Figure 11.7-1. Concentrations in most of the other wells in which TCE had ever been detected increased. One explanation considered in Oldenburg et al. (2002) was that the record high water levels following precipitation caused entrainment of TCE-contaminated water at the base of the unsaturated zone. This water could have been stranded after past waterlevel declines. However, as presented in Oldenburg et al. (2002), the timing of the TCE concentration increases does not match the timing or magnitude of the water-level increases. Further, some of the wells that showed concentration increases, such as MWOU1-06-A and -05-A, do not appear to have been in the vicinity of contaminated groundwater during higher water-level periods. Other wells that were in the vicinity of the most contaminated groundwater during higher water-level periods, such as MWOU1-03-A and -07-A, do not show any concentration increase.

Oldenburg et al. (2002) suggested that mobilization of residual contamination west of the FDA could have caused a concentration increase that propagated down gradient. They noted that the concentration increase at MW-OU1-05-A occurred approximately three months after the increase in MW-OU1-06-A, which is too rapid for advection of a single concentration pulse. No other alternative explanations for the concentration increases following the early-1998 precipitation are currently available.

Concentration data from wells installed since early 1997 affords some perspective on the downgradient extent of the TCE plume in 1999 as shown on Figure 11.7-2. While the well field at this time does not characterize the full extent of the plume, the plume axis passes near PZ-OU1-35-A, and MW-OU1-29-A and -34-A at the tip of the plume.

\subsection{Plume in Early 2003}

The TCE plume in the vicinity of the extraction wells in early 2003 is shown in Figure 11.8-1 (note that the results at MW-OU1-10-A have been anomalously low since the switch to PDS in late 2001). At this time, the plume upgradient of the extraction wells has contracted and the concentrations have decreased since shortly after the early-1998 precipitation event. In the plume core immediately downgradient from the extraction wells, the concentrations have decreased. This is presumably due to the continued input of uncontaminated water from natural flows and treated water recharge upgradient of the plume.

The plume dimension transgradient to EW-OU1-17-A has increased. Concentrations within the areas newly occupied by the plume are at or below the Maximum Contaminant Level (MCL) of 5 parts per billion ( $\mathrm{ppb}$ ) for TCE in drinking water. Trends through late 2003 indicate the TCE concentration will not increase significantly above the MCL in the future.

The concentration increases to the northwest, west, and southwest of EW-OU1-17-A are 
most likely due to narrowing of the capture zone as indicated in Oldenburg et al. (2002). This narrowing is caused by sustaining the same pumping rate at this well despite the large water-level increases following the early-1998 precipitation. The water level in EW-OU1-17-A increased approximately $18 \mathrm{ft}(5.5 \mathrm{~m})$, which more than tripled the saturated thickness. The capture zone narrowing allowed the plume to spread in the vicinity of this well.

The plume expansion to the east/northeast of EW-OU1-17-A is likely due to a combination of factors. The capture zone around EW-OU1-18-A also narrowed after the early-1998 precipitation, although not as much as the narrowing at EW-OU1-17-A. The water level in EW-OU1-18-A increased approximately $7 \mathrm{ft}(2.1 \mathrm{~m})$, which increased the saturated thickness by approximately a third. Extraction from EW-OU1-18-A was shut down in mid-2001. Concentrations at MW-OU1-32-A were slightly higher after the switch to PDS.

The downgradient extent of the plume is shown on Figure 11.8-2. This figure shows the plume axis has shifted west/southwest and the tip of the plume has moved west from its position in late 1999 (shown on Figure 11.7-2). This is in accord with the gradient rotation following the early-1998 precipitation in the vicinity of the downgradient portion of the plume discussed in Section 5.2. This gradient rotation can be seen by comparing Figures 5.1-1 and 5.1-3.

\section{CONCLUSIONS}

\subsection{Water-table Evolution}

At of the end of 2003, the water table at OU 1 was still responding to the high quantity of precipitation that occurred 5 years earlier in early 1998. Water levels in all the wells analyzed in this report had peaked by this time. The water levels in the portion of the TCE plume downgradient of the extraction wells peaked the latest. The gradient in this area rotated approximately $20^{\circ}$ counterclockwise from north- to northwest-directed in 2000, and northwest-directed in 2002. Outside of the plume, water levels toward the center and edge of the FO-SVA peaked earlier than the water levels in the areas midway between. All of these responses can be understood conceptually as resulting from an instantaneous, uniform addition of water on top of the previously equilibrated water table of the A-aquifer, the extent of which is defined by the edge of the FO-SVA.

\subsection{Porosity}

Water-level responses to the early-1998 precipitation event in A-aquifer/deeper aquifer well pairs allow estimation of the porosity of the A-aquifer. The estimate of $30-37 \%$ porosity suggests that the effective porosity estimate of $30 \%$ used in Oldenburg et al. (2002) is perhaps 5\% too high. 


\subsection{Recharge}

The water-level increases in the A aquifer resulting from the early-1998 precipitation event allow estimation of the fraction of this precipitation that recharged to the water table. The estimate of a 38-51\% recharge fraction for this precipitation event is higher than the $27 \%$ recharge fraction derived from an analysis of water-level changes during more typical rain years in Oldenburg et al. (2002). The former should be higher than the latter primarily due to the lack drainages in the OU-1 area and greater relative ground saturation (causing higher vadose zone relative permeabilities). Therefore the estimated recharge fraction from the early-1998 precipitation is consistent with the recharge fraction estimate for typical rain years.

\subsection{ISPFS Results}

The groundwater flow azimuths measured by the ISPFSs were rotated counterclockwise relative to the gradients from water level contouring for unknown reasons. The shifts in gradient azimuth measured by the ISPFSs readily correlate to pumping rate changes from the extraction wells and the water-table response to the early-1998 precipitation event. The horizontal flow velocities measured by the ISPFSs match the regional velocities suggested by the water-table gradient and hydraulic conductivities from short-term pump tests. The changes in horizontal velocity readily correlate to pumping-rate changes from the extraction wells. Based upon instrument installation records and numerical modeling, the large, downward-directed vertical velocities measured by the ISPFSs could be due to either in-situ or drilling-induced thermal conductivity heterogeneities possibly in combination with drilling induced permeability heterogeneity.

\subsection{PDS Results}

The PDS results from a given well were generally similar to the P\&S results. With the exception of MW-OU1-10-A, PDS resulted in slightly higher TCE and 1,2 DCE concentrations in a few wells. In MW-OU1-10-A, PDS resulted in significantly lower concentrations. In general, the PDS and P\&S results were more similar for TCE and 1,2 DCE than for CT and Chloroform.

Depth-profiling of contaminant concentrations was performed with PDS in many wells. This profiling typically indicated that concentrations are uniform with depth or increased with depth as might be expected due to contaminant off-gassing at the water surface.

\subsection{A-Aquifer Hydraulic Conductivity}

The A-aquifer horizontal hydraulic conductivity estimates from the ISPFSs, shortduration pumping tests, drawdowns due to long-term extraction, and the entire TCE plume matched remarkably well, indicating unusual uniformity across scales. These estimates indicate the aquifer-scale hydraulic conductivities are likely between 7 and 10 $\mathrm{ft} / \mathrm{d}\left(2.5-3.5 \times 10^{-5} \mathrm{~m} \mathrm{~s}^{-1}\right)$. The results of the PDS depth profiling also qualitatively indicate little variation in the horizontal conductivity with depth through the A-aquifer. Vertical conductivities in the vadose zone estimated from water-level responses to surficial recharge changes matched the horizontal conductivity estimates well. Finally, 
flow information from the ISPFSs and the TCE plume shape indicates there is no significant anisotropy in the A-aquifer.

\subsection{TCE Plume Evolution}

Oldenburg et al. (2002) concluded high recharge rates had mobilized residual TCE in the vicinity of the FDA causing concentrations to increase in various locations transgradient to the plume. This conclusion was favored over changes in the groundwater flow field due to the treated water recharge because the available water-level data did not suggest that extraction and treated-water recharge had altered the flow field sufficiently to explain the changes. The conclusions of Oldenburg et al. (2002) were based upon chemistry data from mid-1992. The inclusion of earlier chemistry data in the analysis of the present report has altered the earlier conclusion. Now the likely cause of the transgradient concentration increases is mobilization of residual contamination south of the FDA combined with slight alteration of the flow of contaminated water northeast of the FDA. The earlier chemistry data indicates that the treated water recharge area partially overlay the TCE groundwater plume, thus causing the plume to spread. This stated, the transgradient increases as of 2003 are typically at or below MCLs. The pump-and-treat operation at the head of the OU-1 plume, which commenced in 1988, has significantly reduced contaminant concentrations and dissolved mass.

In the downgradient portion of the TCE plume, concentration data indicate the counterclockwise gradient rotation caused by the early-1998 precipitation is causing the contaminant advection to shift direction. The TCE plume is now advecting west/northwest, i.e., more westward than its pre-1998 axis. Therefore, any remedial effort based upon capturing or treating the plume as it advects through a transect, will have to change position and take place over a larger transect relative to the pre-1998 conditions. Furthermore, the slow return of groundwater flow to the pre-1998 conditions should also be taken into account when designing remedial systems.

Due to the gradient change at the tail of the plume, the plume is shifting off of the well network to some extent. This shift should be tracked carefully and new monitoring wells installed if necessary. Otherwise there might be a tendency to conclude that the plume is dissipating. The change in gradient direction may also have implications for the design of the remedial system for this portion of the plume. Whether a barrier or volumetric system is designed, the appropriate position for this installation appears to be shifting. In particular, note that in late 1999, the TCE concentration at MW-OU1-27-A was approximately the MCL (5 ug/L). As of early 2003, the TCE concentration is approximately 15 times the MCL, apparently due to a shift of the plume axis. 


\section{REFERENCES}

Bowles, J. E., 1996. Foundation Analysis and Design, $5^{\text {th }}$ Edition, MacGraw-Hill, New York, $\mathrm{xxx}$ pp.

Bouwer, H., 1978. Groundwater Hydrology, McGraw-Hill, New York, 480 pp.

Fetter, C. W., 1994. Applied Hydrogeology, $3^{\text {rd }}$ Edition, Prentice-Hall, Englewood Cliffs, New Jersey, xxx pp.

Harding Lawson Associates (HLA), 1986. Remedial Investigation/Feasibility Study of Soil Contamination, Fritzsche Army Airfield, Fire Drill Area, Fort Ord, California, Harding Lawson Associates, Novato, California, April 14.

de Marsily. G., 1986. Quantitative Hydrogeology, Groundwater Hydrology for Engineers, Academic Press, Orlando, Florida, 440 pp.

Oldenburg, C. M., P. F. Daley, B. M. Freifeld, J. Hinds, and P. D. Jordan, 2002. ThreeDimensional Groundwater Flow, Aquifer Response, and Treatment System Monitoring at Site OU 1, Fort Ord, California, Lawrence Berkeley National Laboratory Report, $L B N L-49586$, Lawrence Berkeley National Laboratory, February.

Su, G.W., B.M. Freifeld, C.M. Oldenburg, P.D. Jordan, and P.F. Daley, 2005. Data analysis and simulation of in-situ permeable flow sensors for measuring groundwater velocity, Lawrence Berkeley National Laboratory Report, $L B N L$ 57084, and Groundwater, submitted.

van Genuchten, M. Th., 1980. A closed-form equation for predicting the hydraulic conductivity of unsaturated soils, Soil Sci. Am. J., 44, 892-898. 


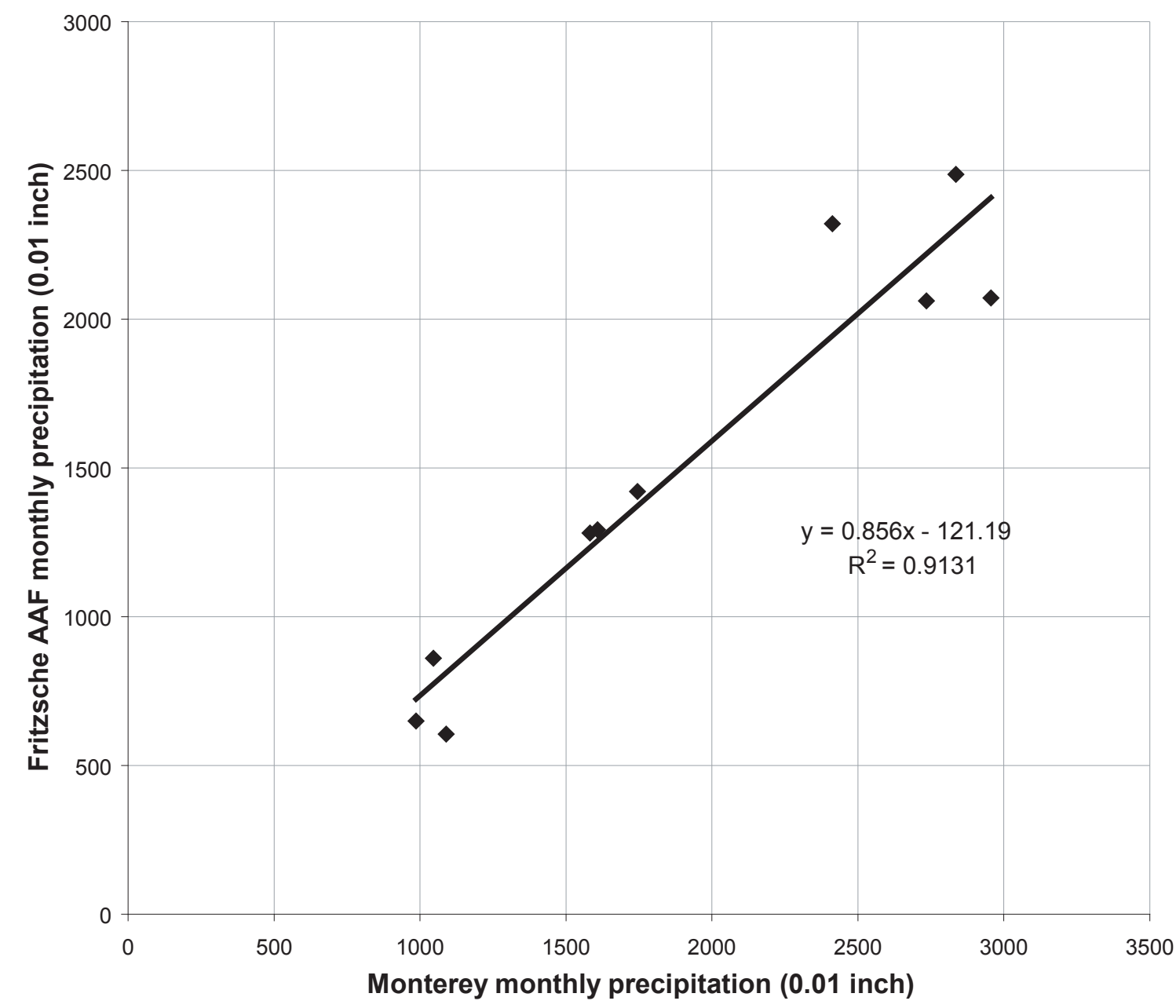

Figure 3.1-1. Comparison of precipitation totals at Monterey and Frizsche AAF meteorological stations. 


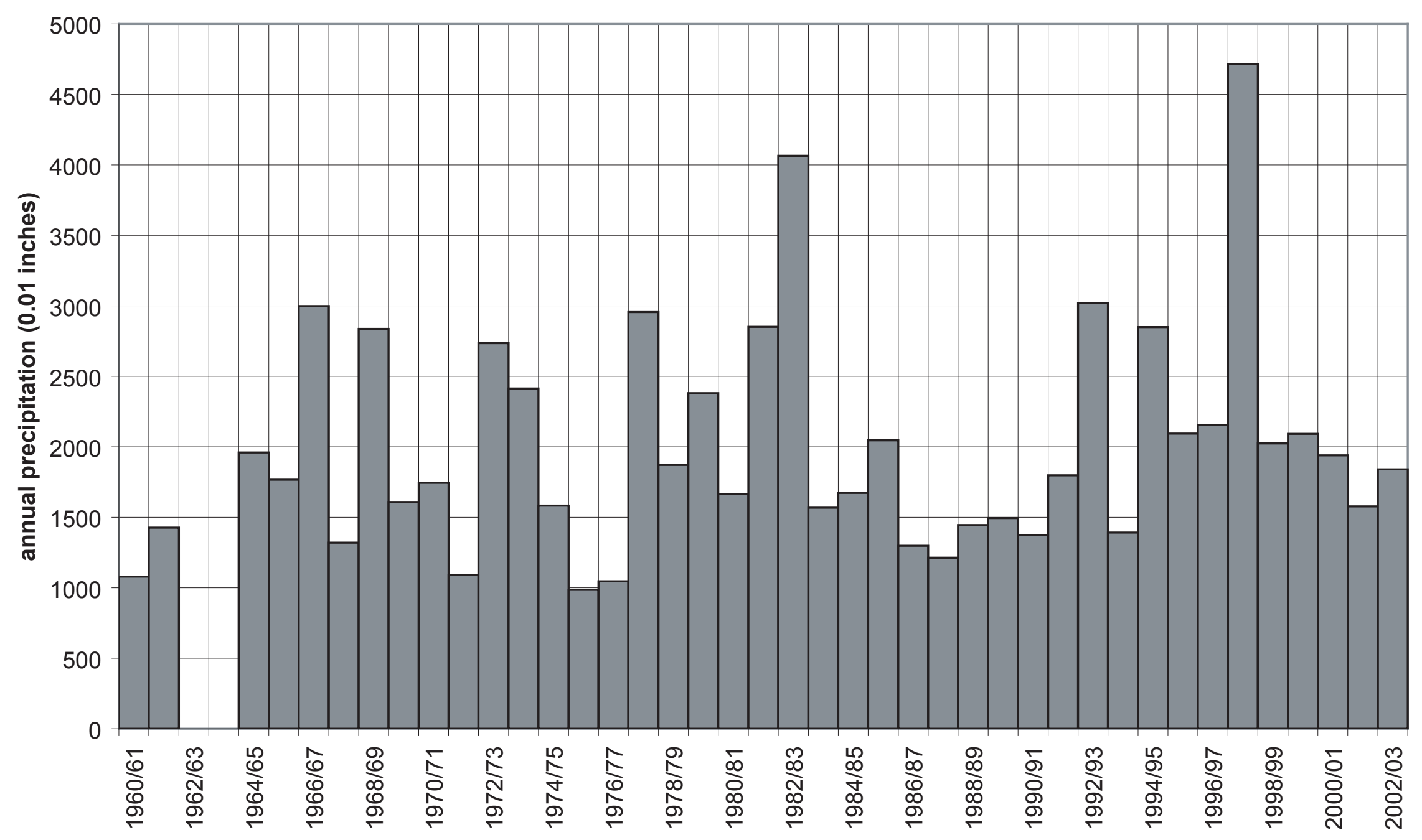

Figure 3.1-2. Hydrologic year (July 1st to June 30th) precipitation totals at Monterey meteorological station. 


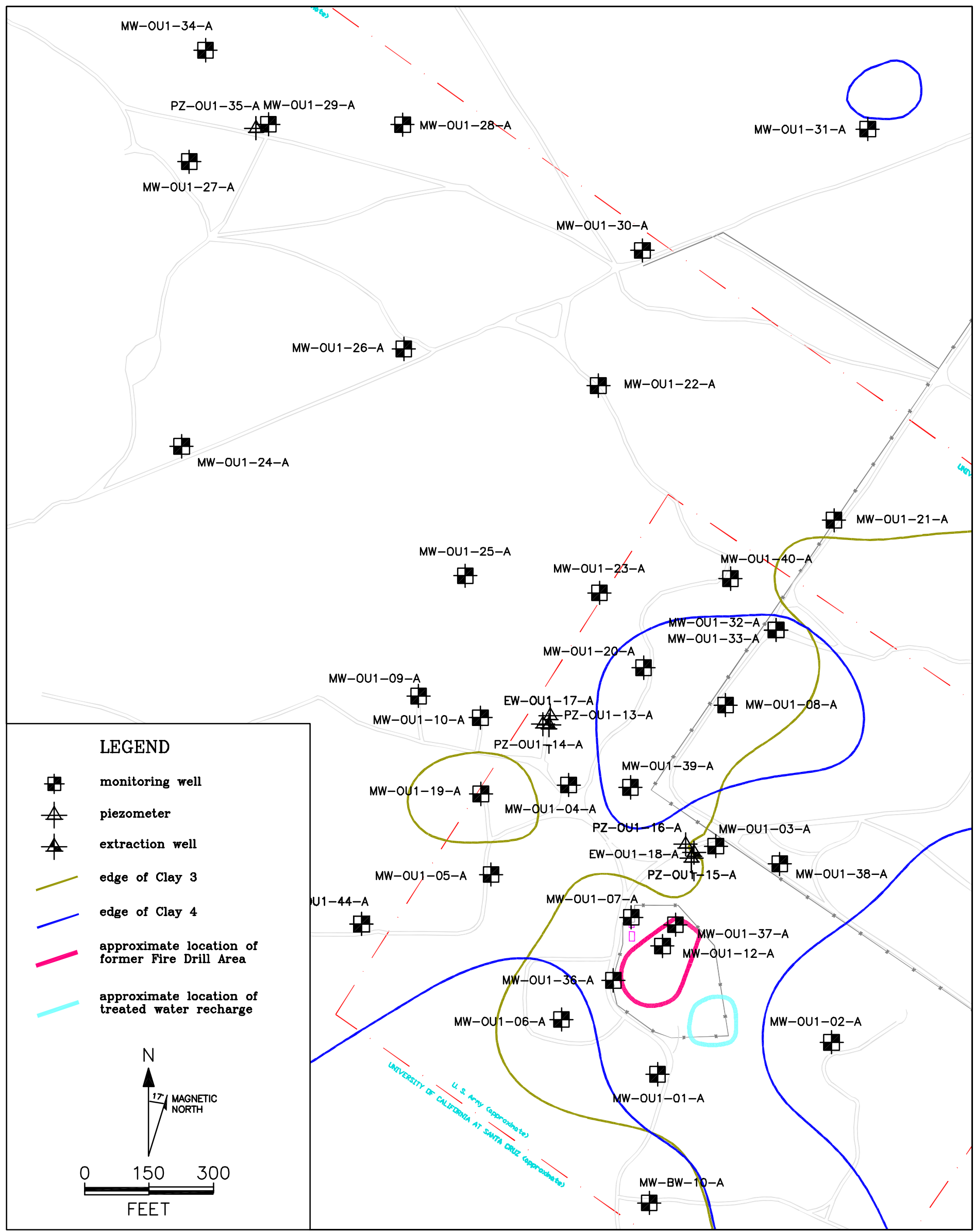

Figure 4.0-1. Edge of Clay 3 and 4 at OU-1. 


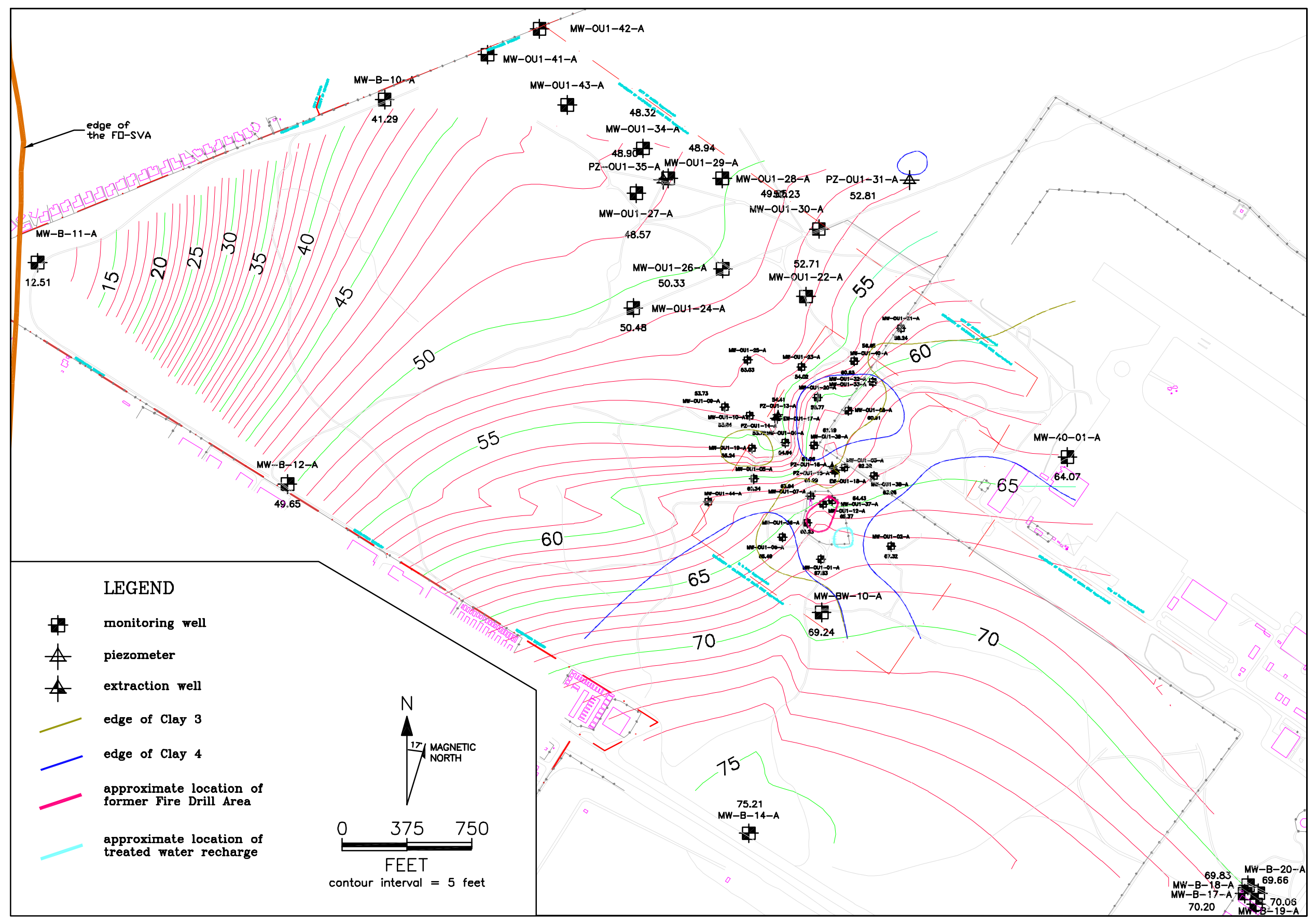

Figure 5.1-1. A-aquifer isopotentials for the second quarter, 2000 (modified from Oldenburg et al. (2002)). 


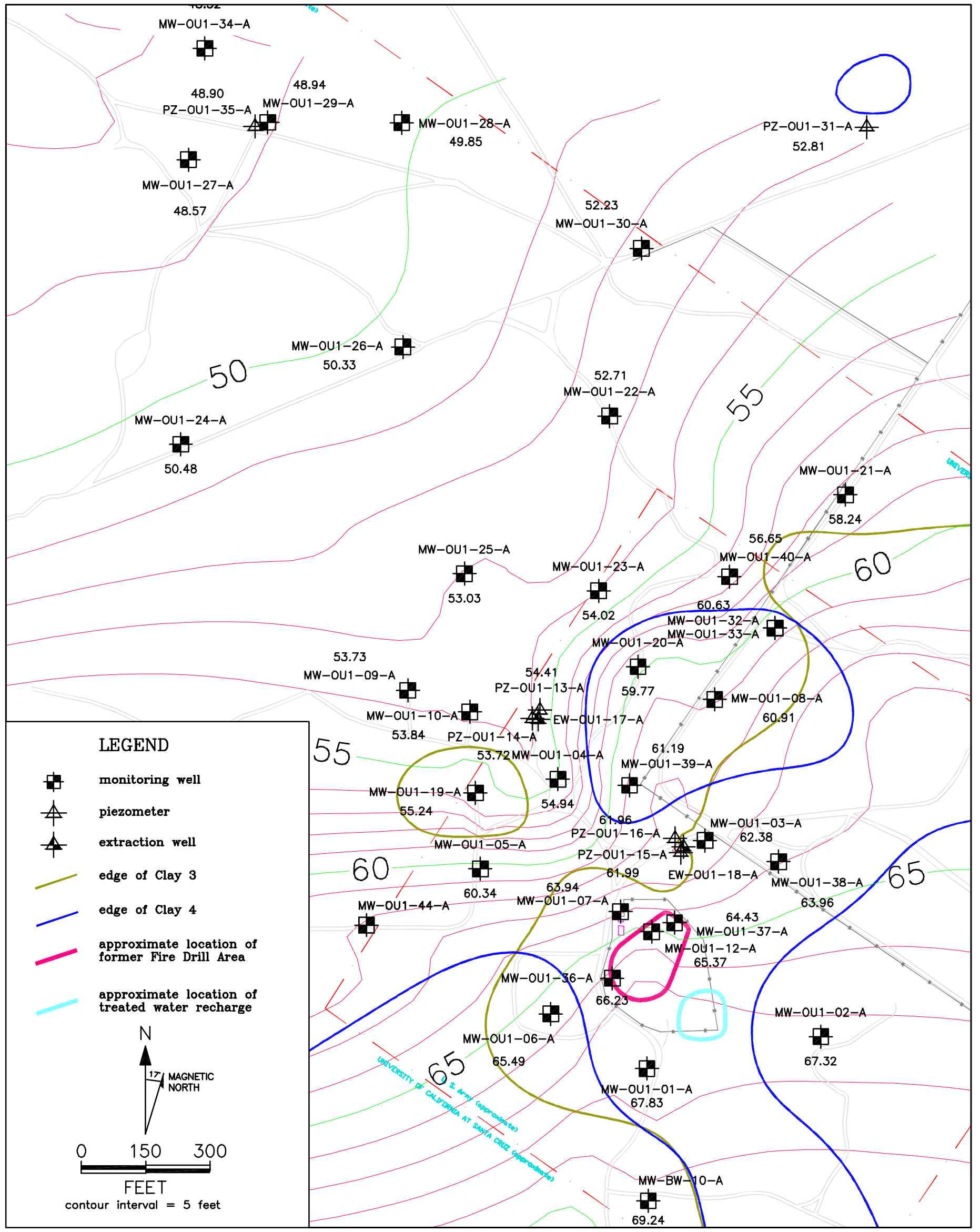

Figure 5.1-2. A-aquifer isopotentials for the second quarter, 2000 (modified from Oldenburg et al. (2002)). 


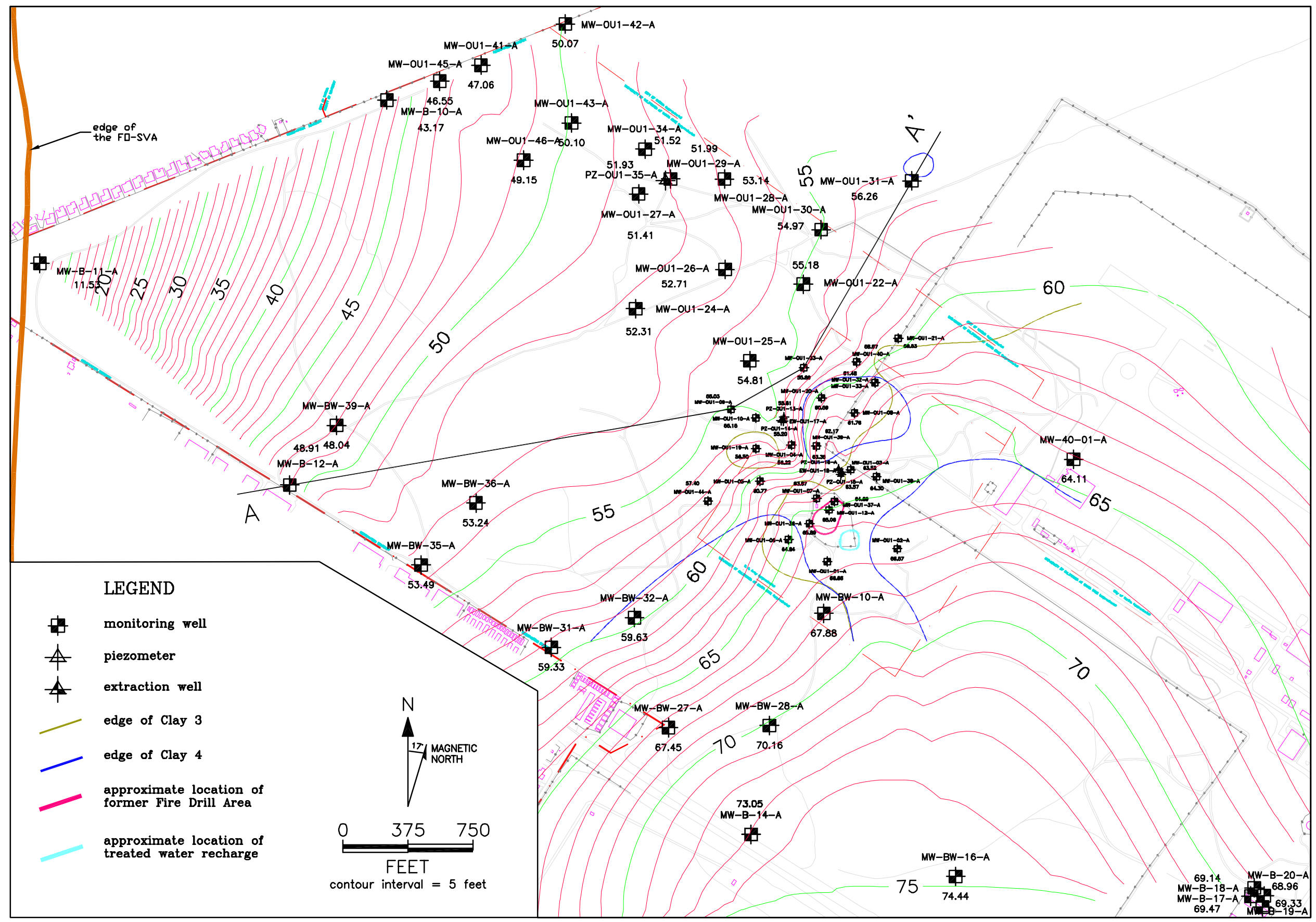

Figure 5.1-3. A-aquifer isopotentials for the second quarter, 2002. Location of Figure 5.2-1 hydrograph transect $A-A^{\prime}$ shown. 


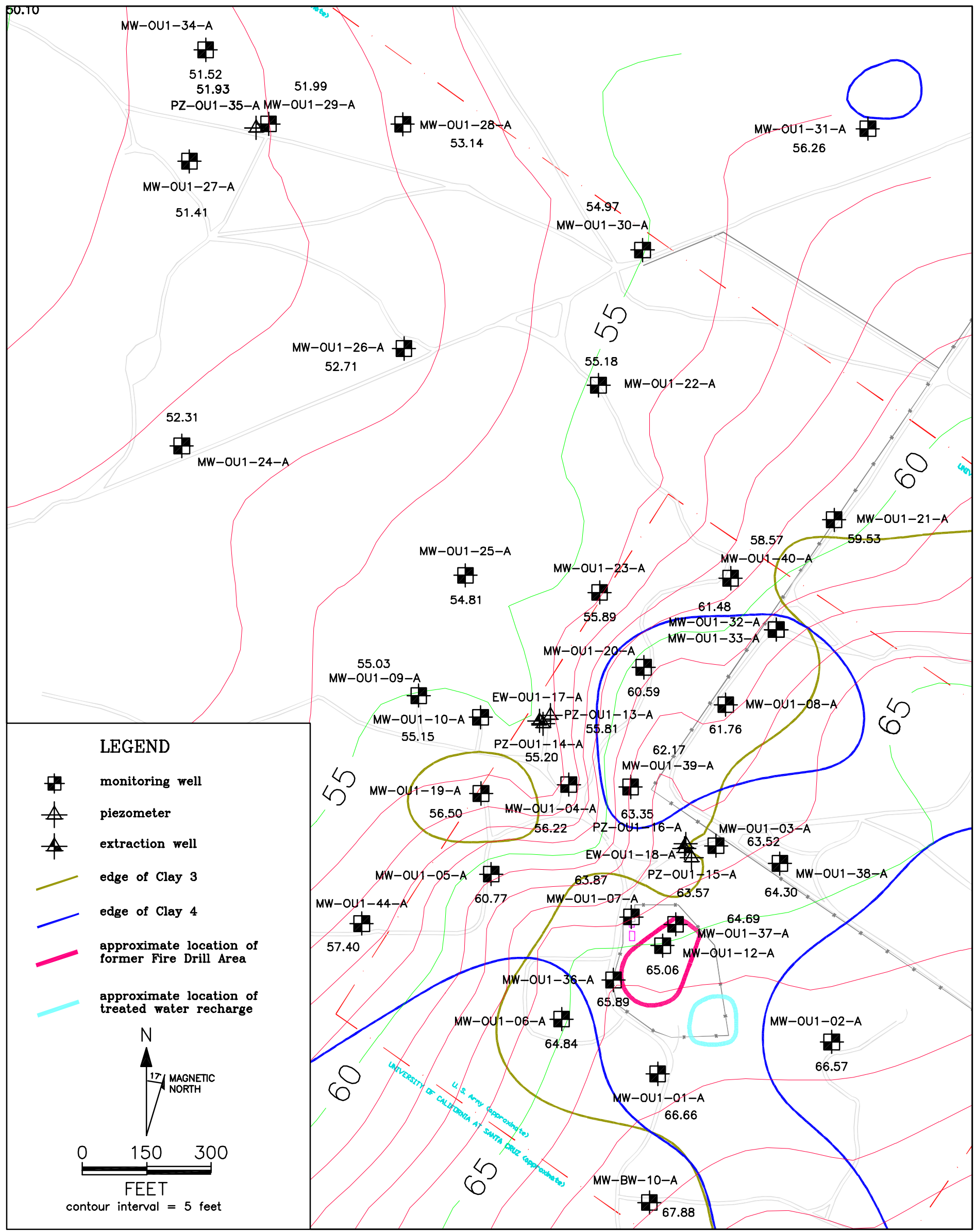

Figure 5.1-4. Detail of A-aquifer isopotentials for the second quarter, 2002. 


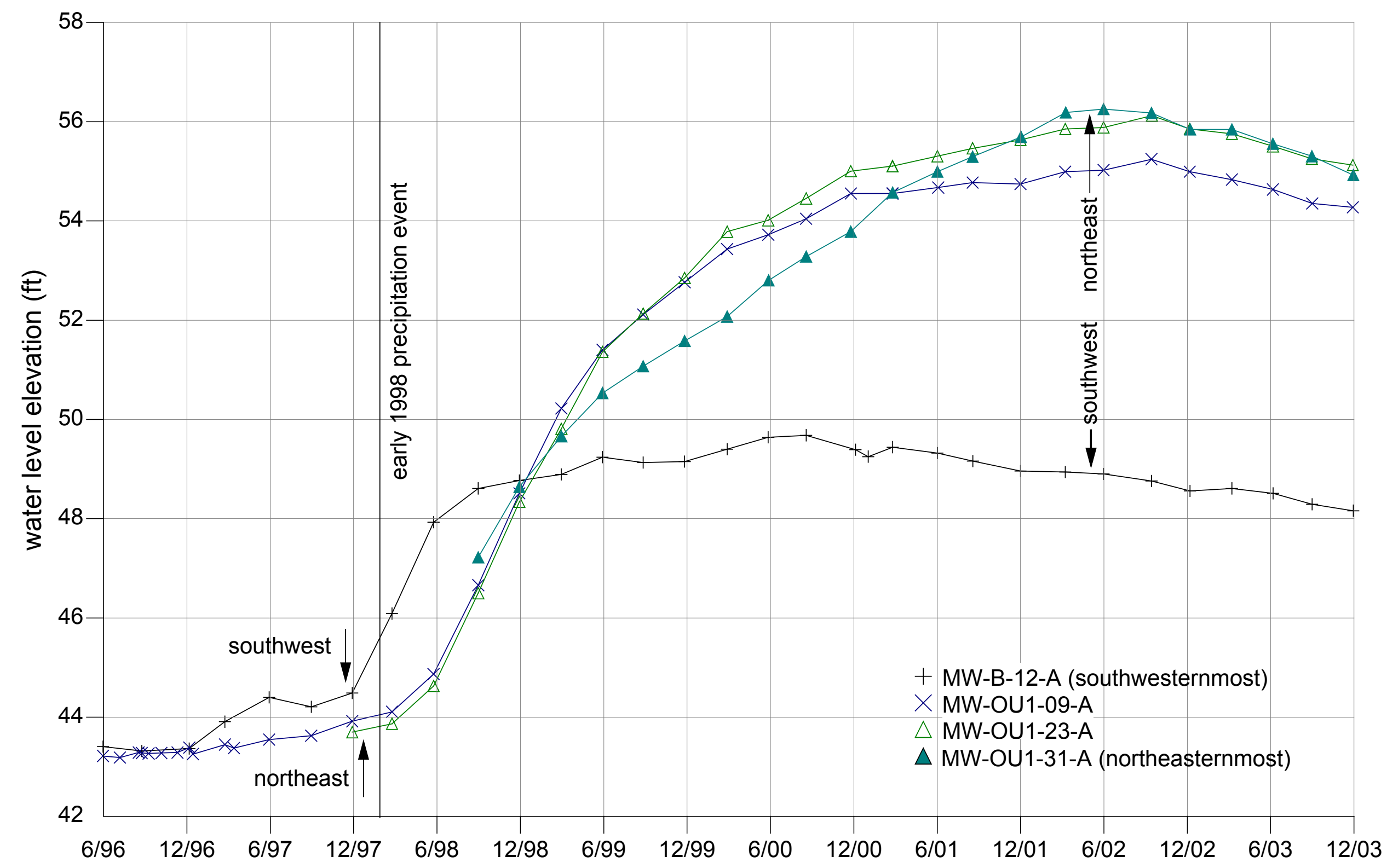

Figure 5.2-1. Hydrographs from wells on transect A-A' shown on Figure 5.0-3. 


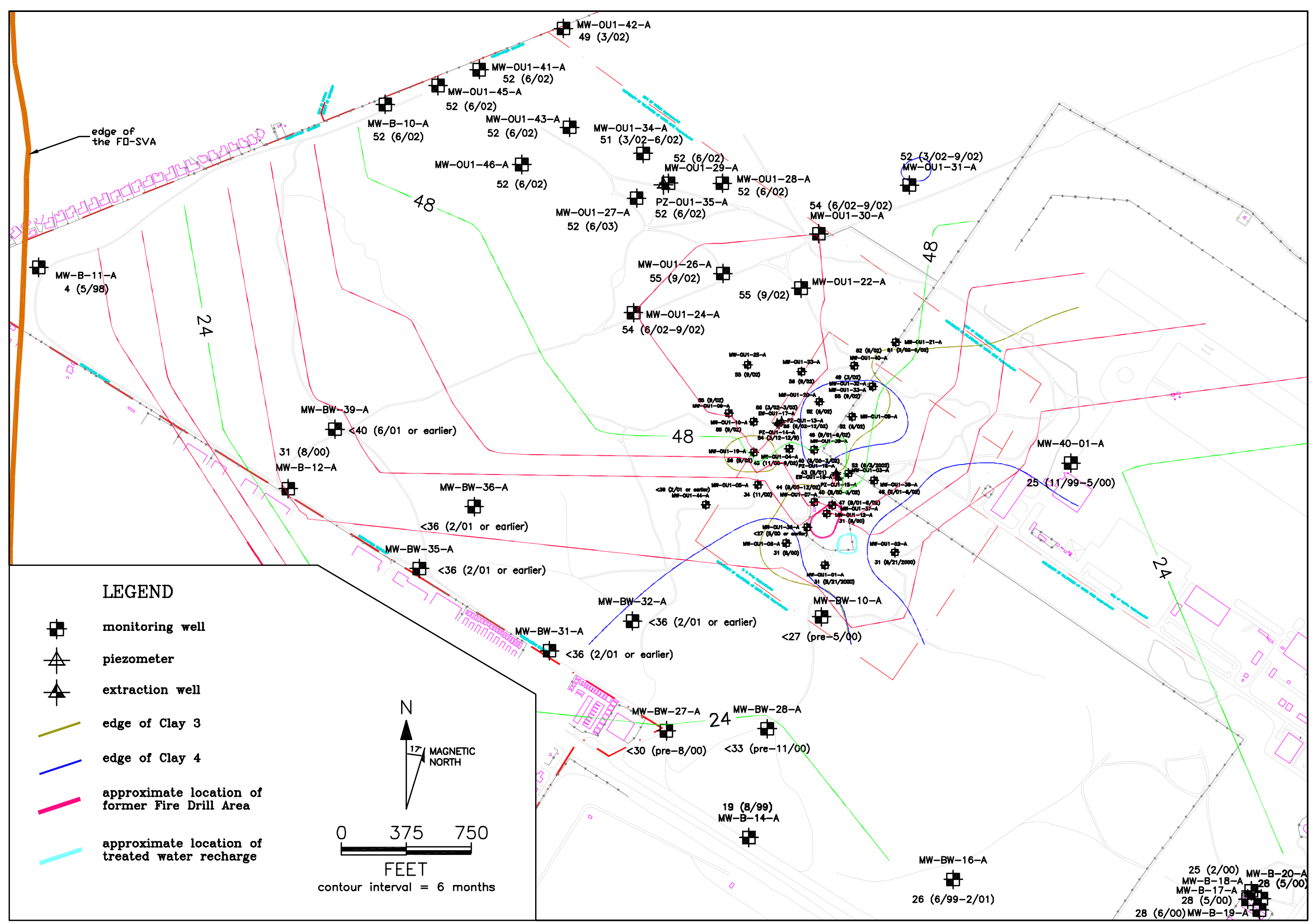

Figure 5.3-1. Isochrons (in months) of time to peak water level following the early 1998 precipitation. 


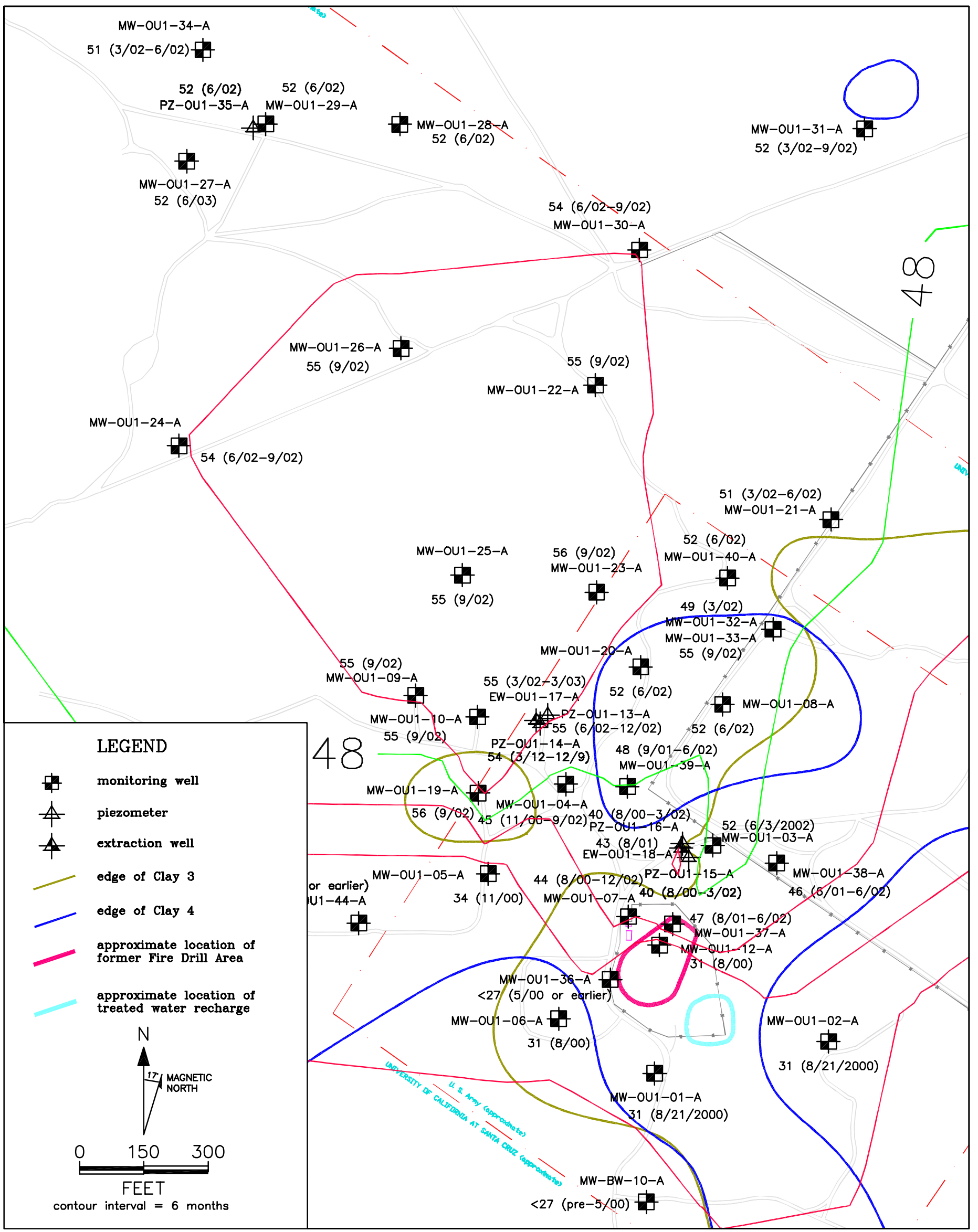

Figure 5.3-2. Detail of isochrons (in months) of time to peak water level following the early 1998 precipitation. 


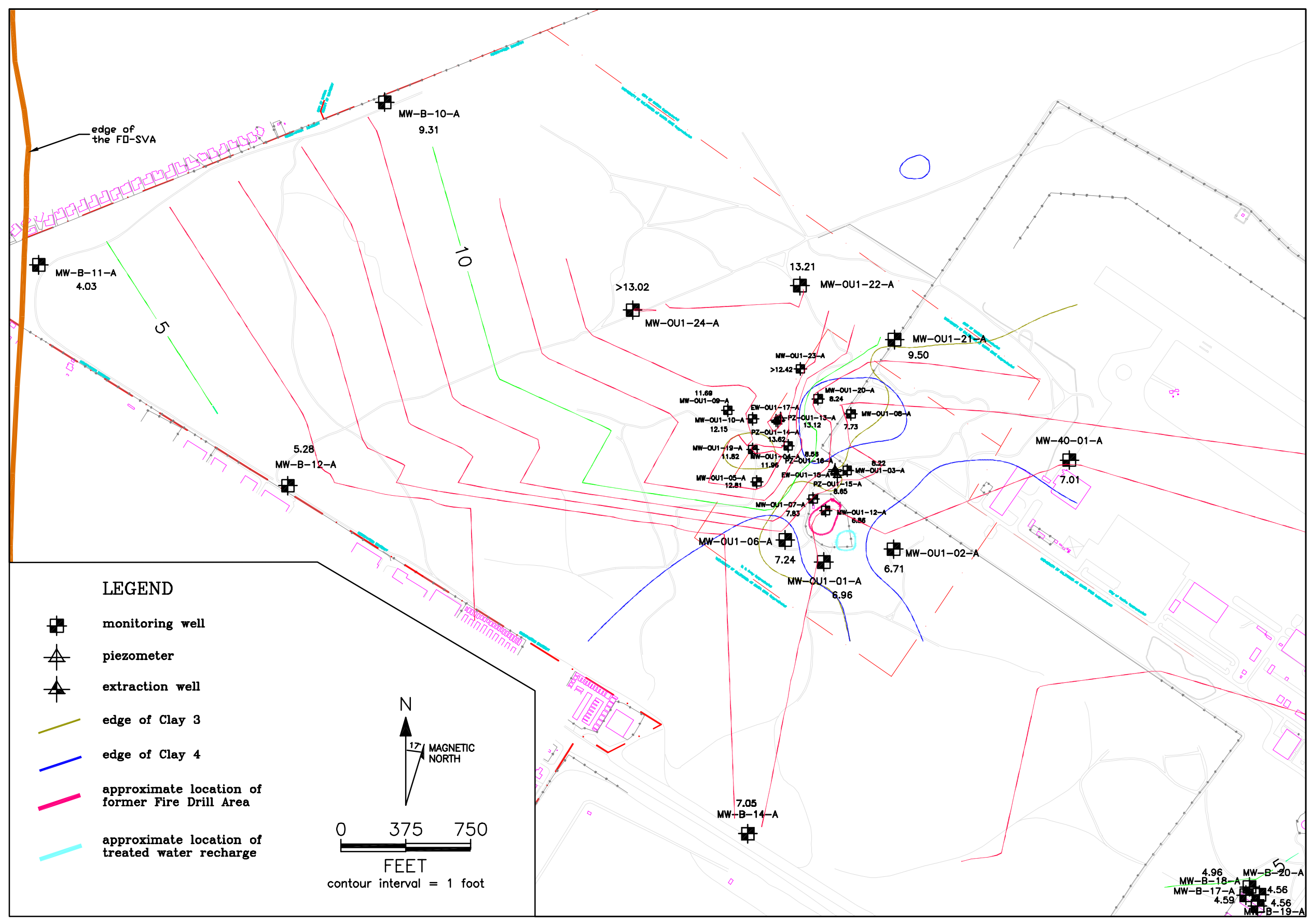

Figure 5.3-3. Contours of maximum water level increase following the early 1998 precipitation. 


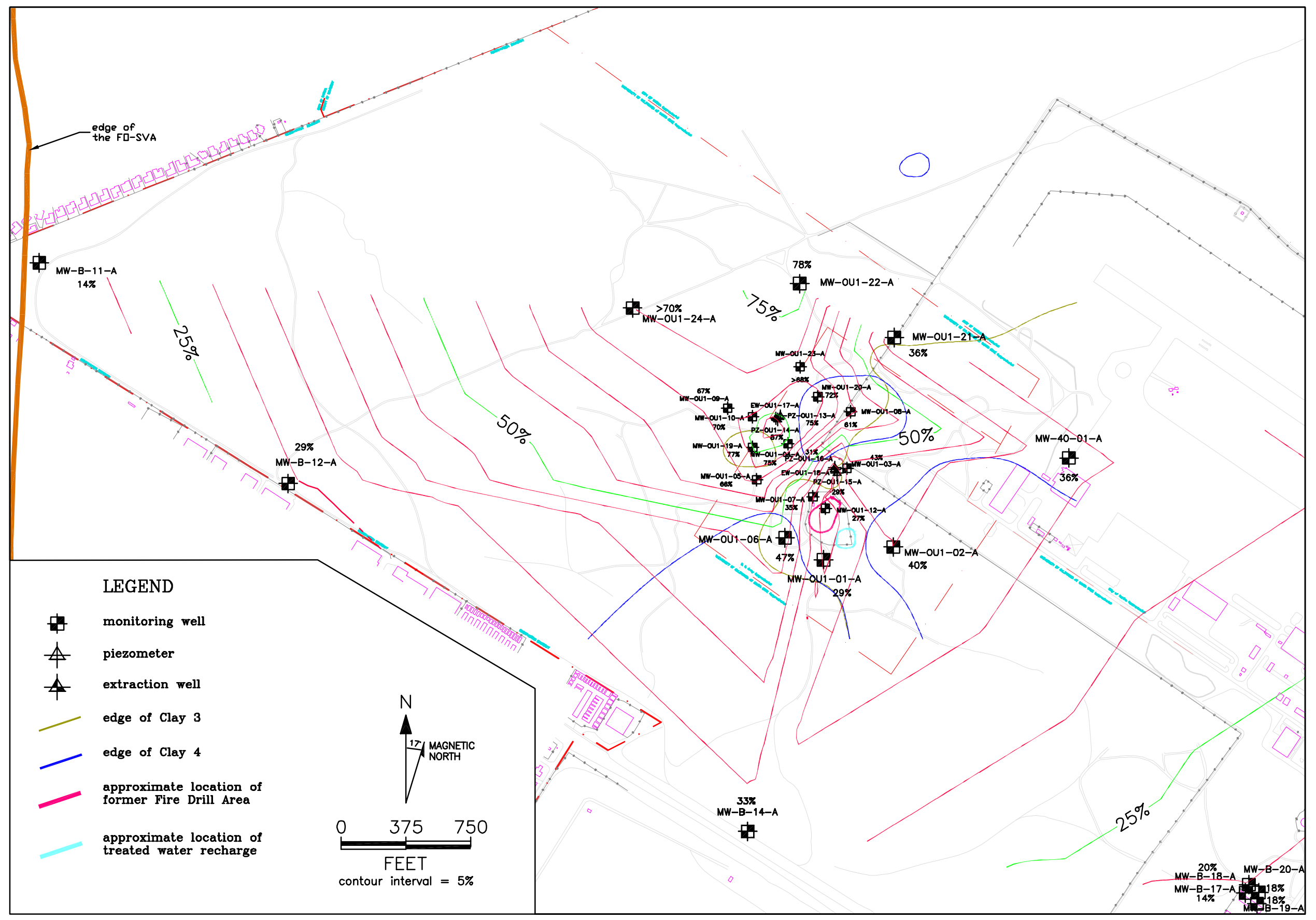

Figure 5.3-4. Contours of increase in saturated thickness as a percentage following the early 1998 precipitation. 


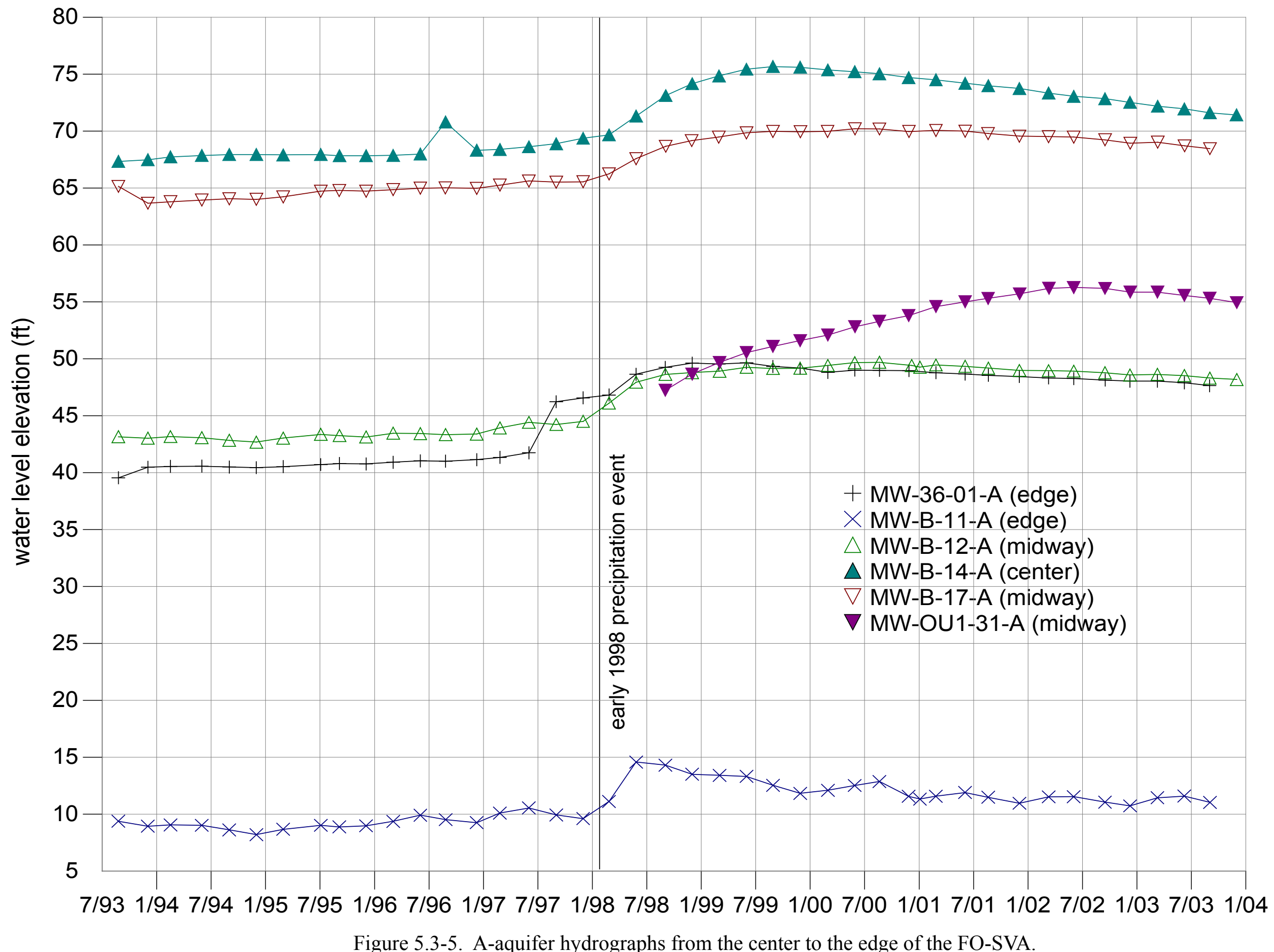

Figure 5.3-5. A-aquifer hydrographs from the center to the edge of the FO-SVA. 


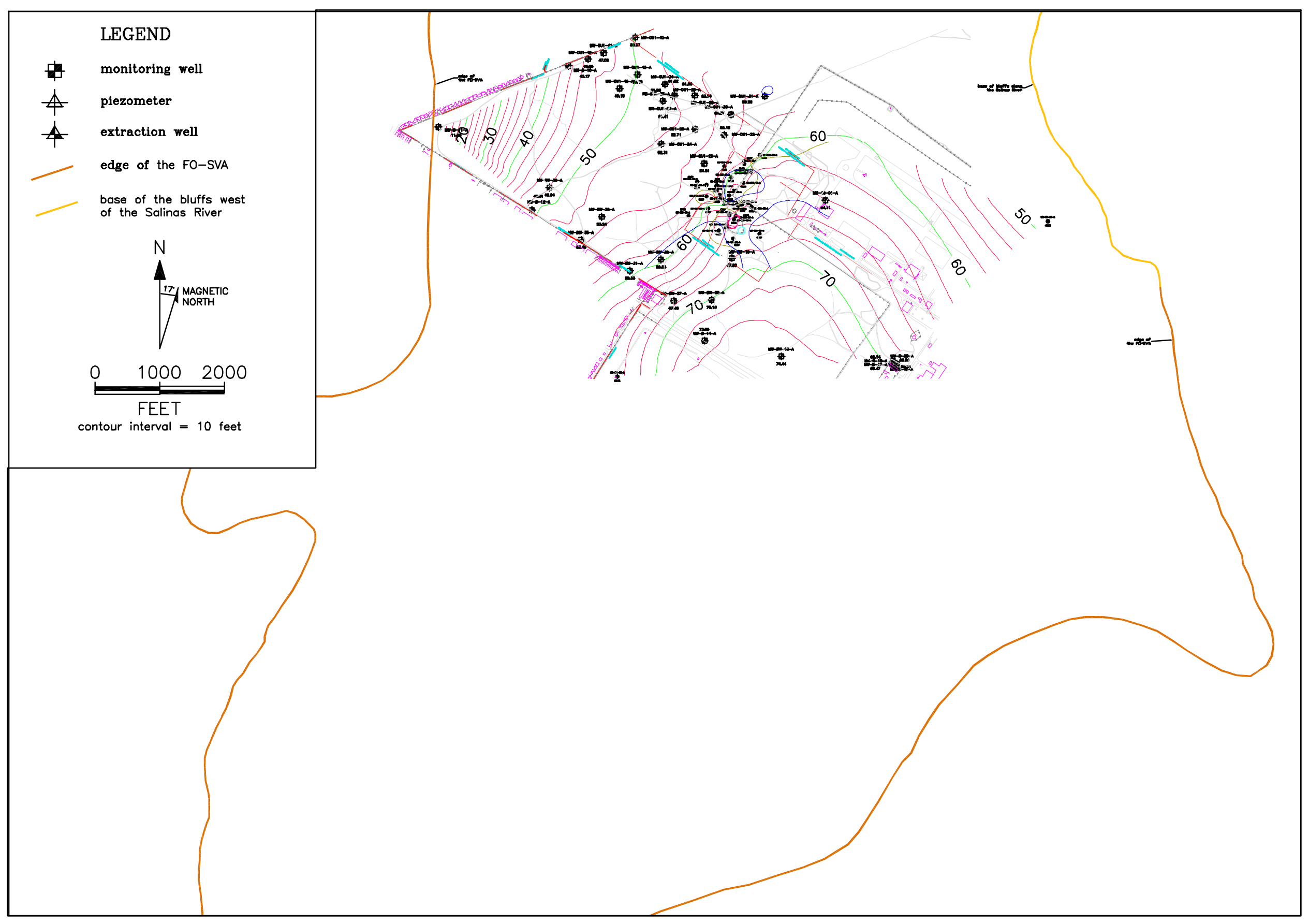

Figure 5.3-6. Overview of A-aquifer Isopotentials and FO-SVA boundaries in the second quarter, 2002. 


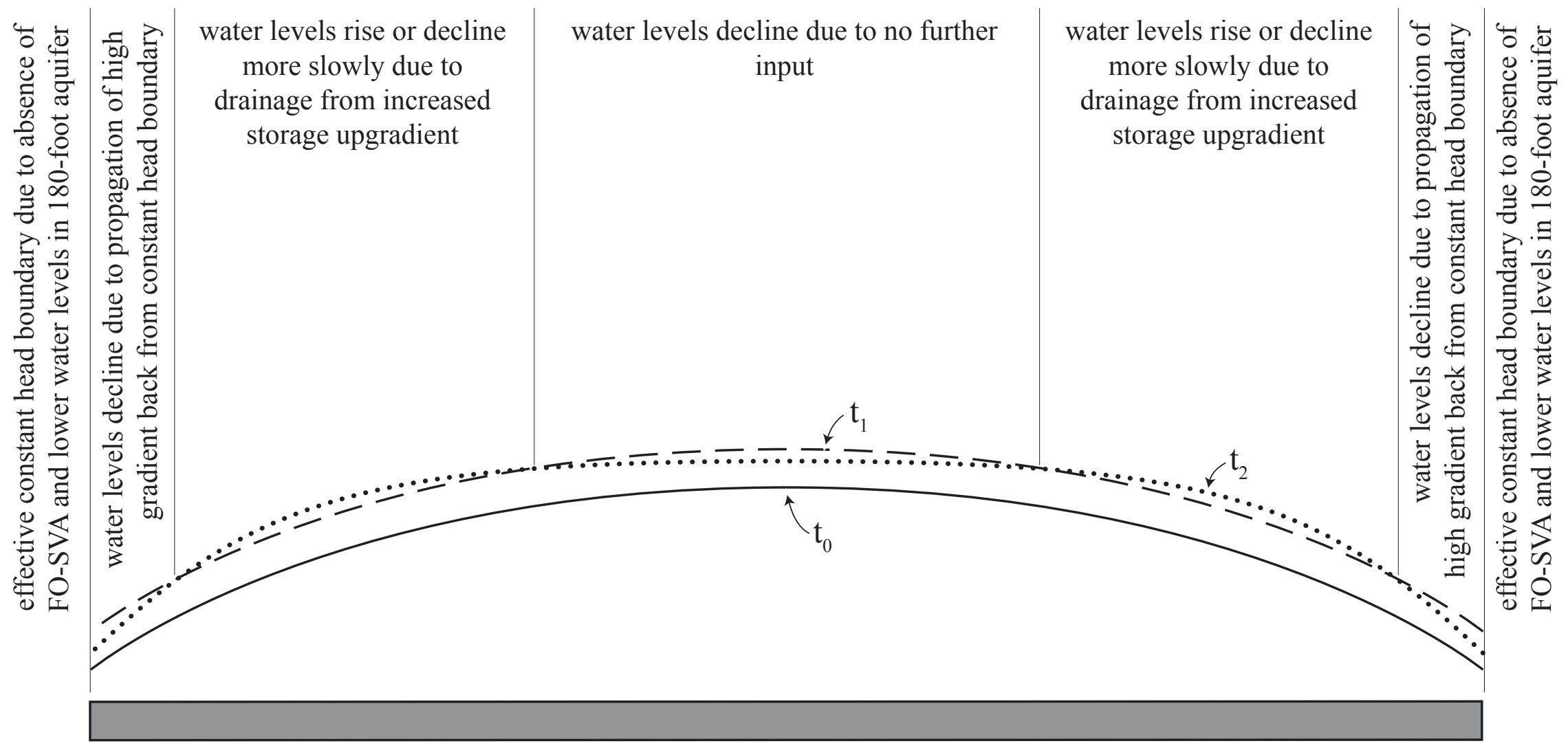

Figure 5.3-7. Conceptual model of A-aquifer response to early-1998 precipitation. 


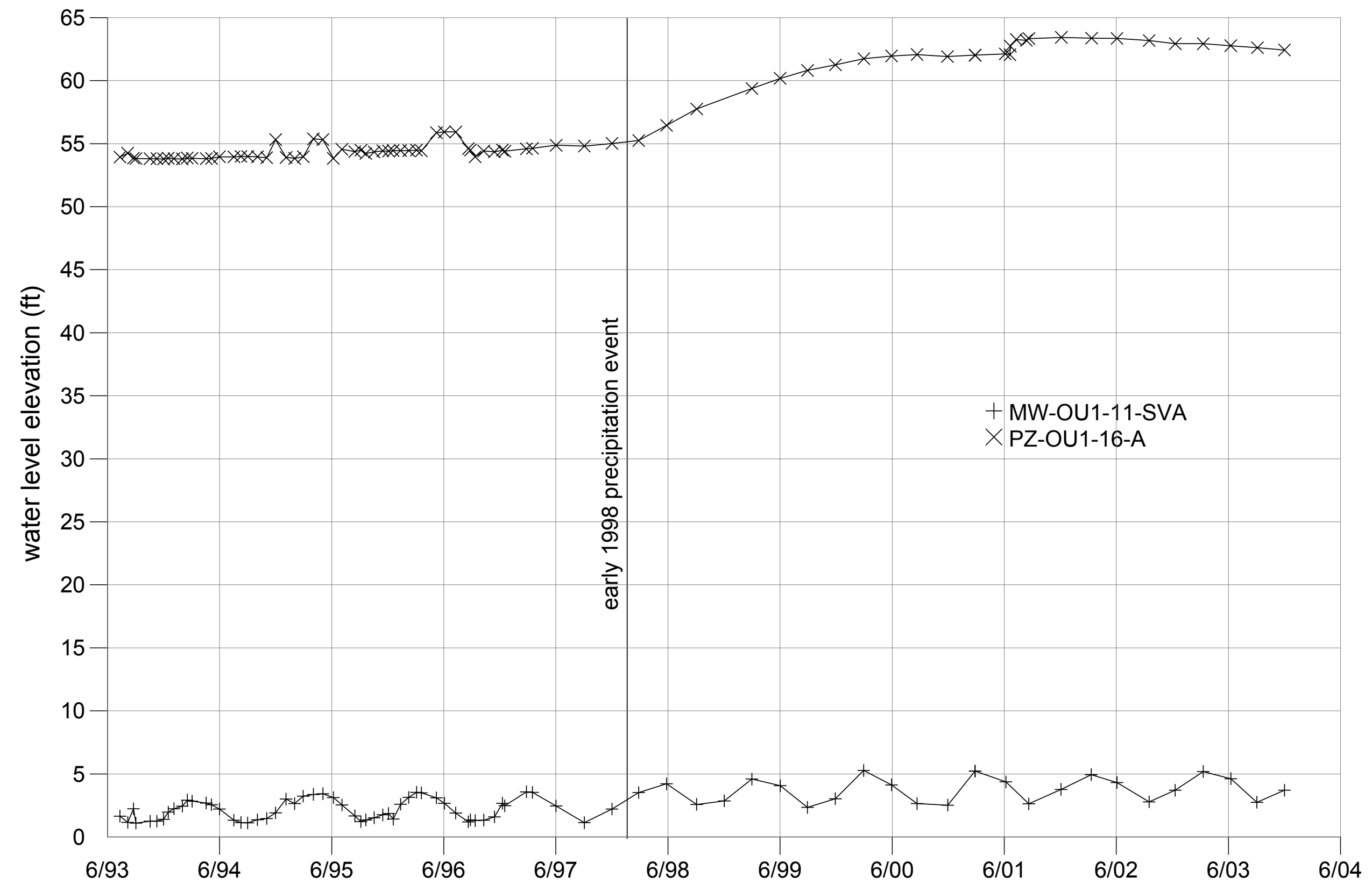

Figure 6.1-1. Hydrographs for MW-OU1-11-SVA and PZ-OU1-16-A. 


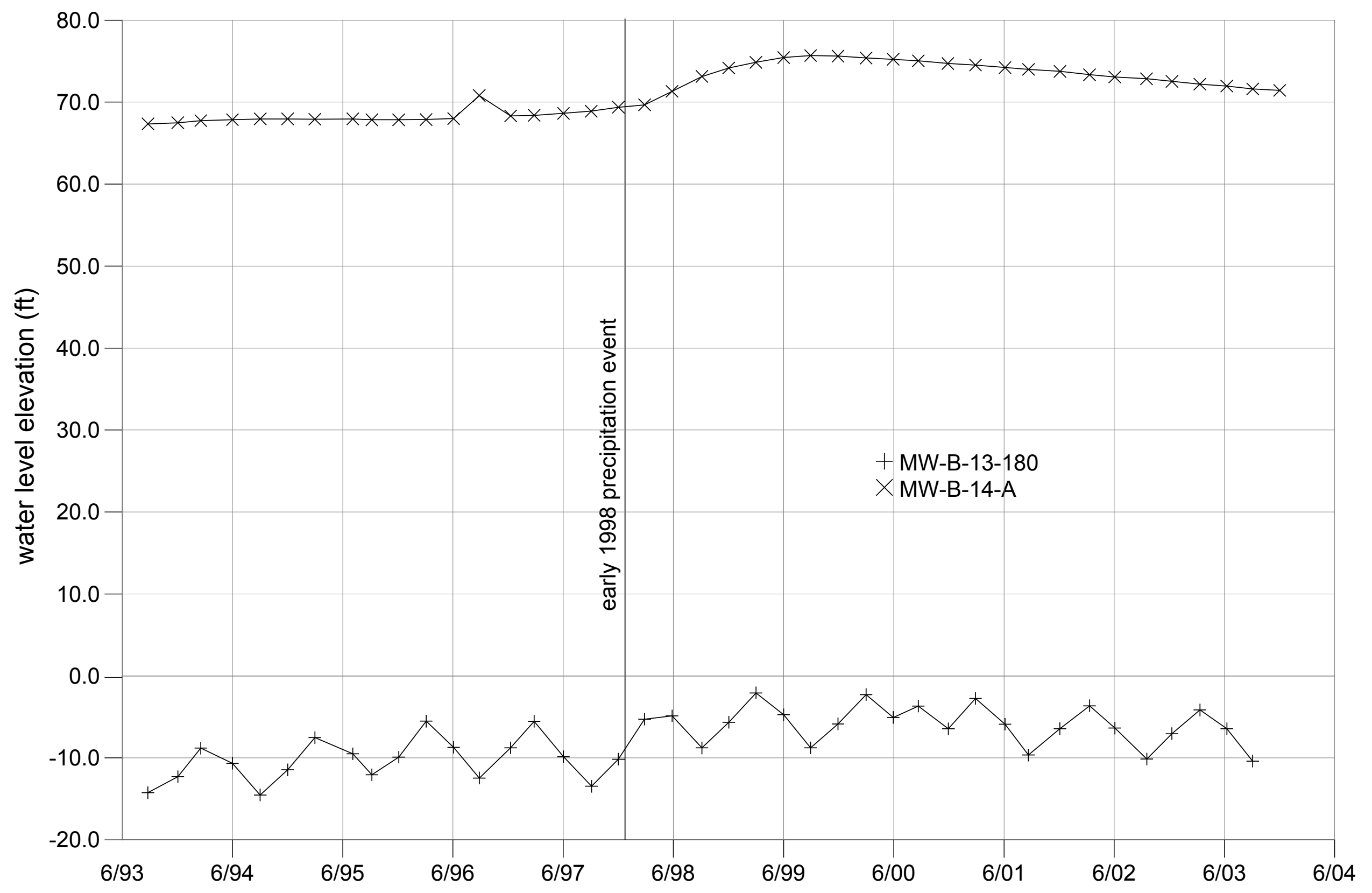

Figure 6.1-2. Hydrographs for MW-B-13-180 and MW-B-14-A. 


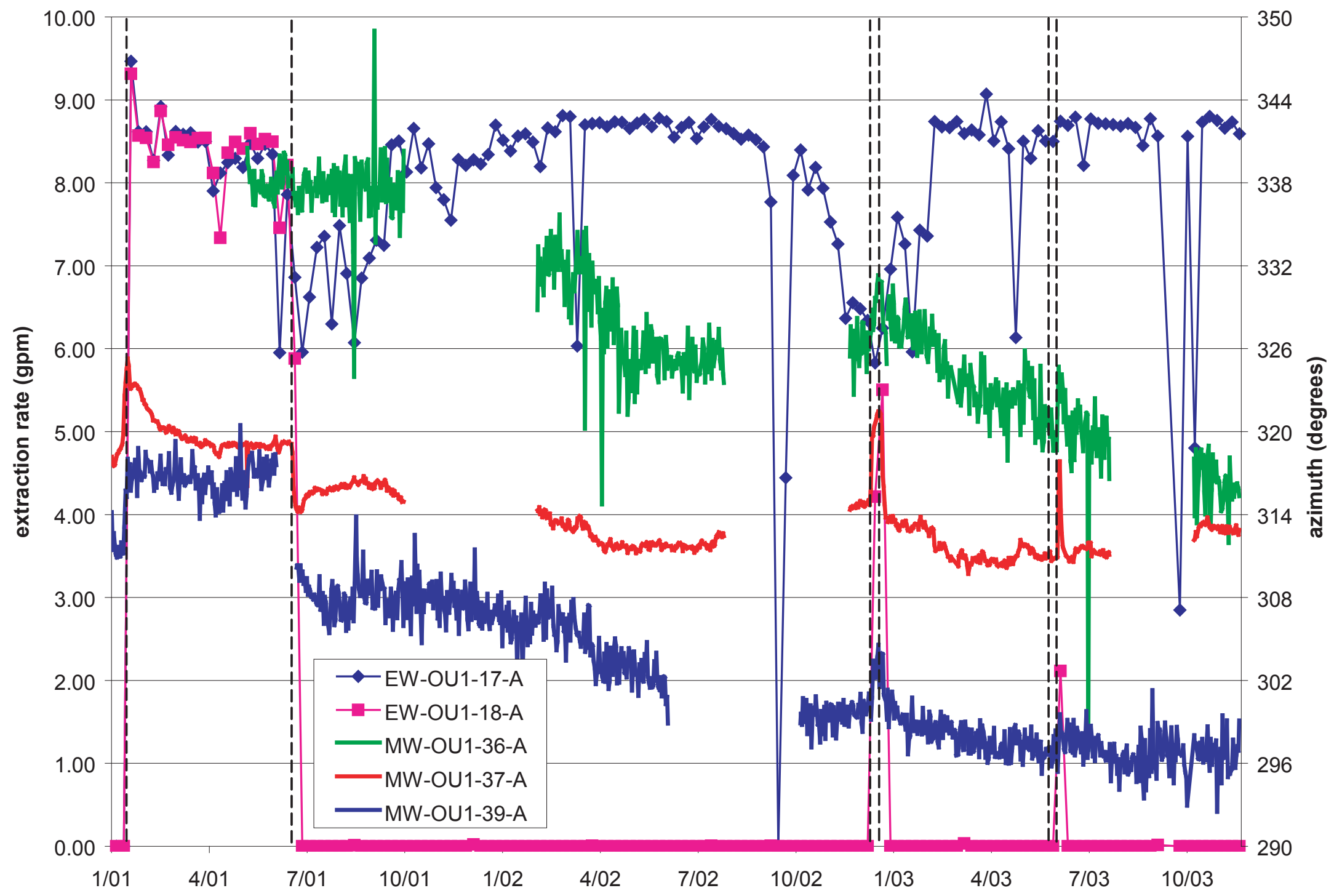

Figure 8.2-1. Inverted ISPFS azimuth compared to extraction rates. Dashed lines are EW-OU1-18-A pump switching. 


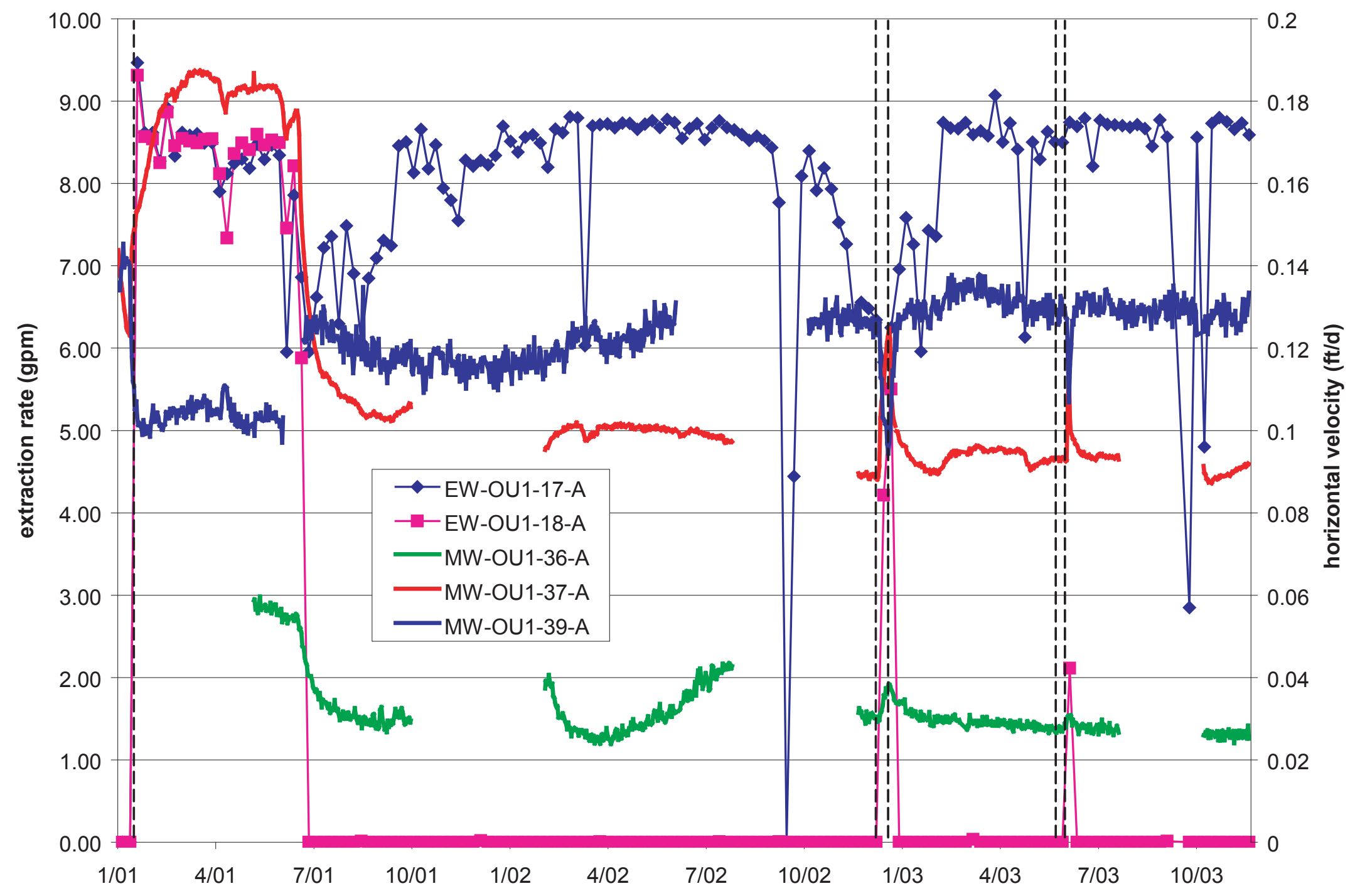

Figure 8.3-1. Inverted ISPFS horizontal velocities compared to extraction rates. Dashed lines are EW-OU1-18-A pump switching. 


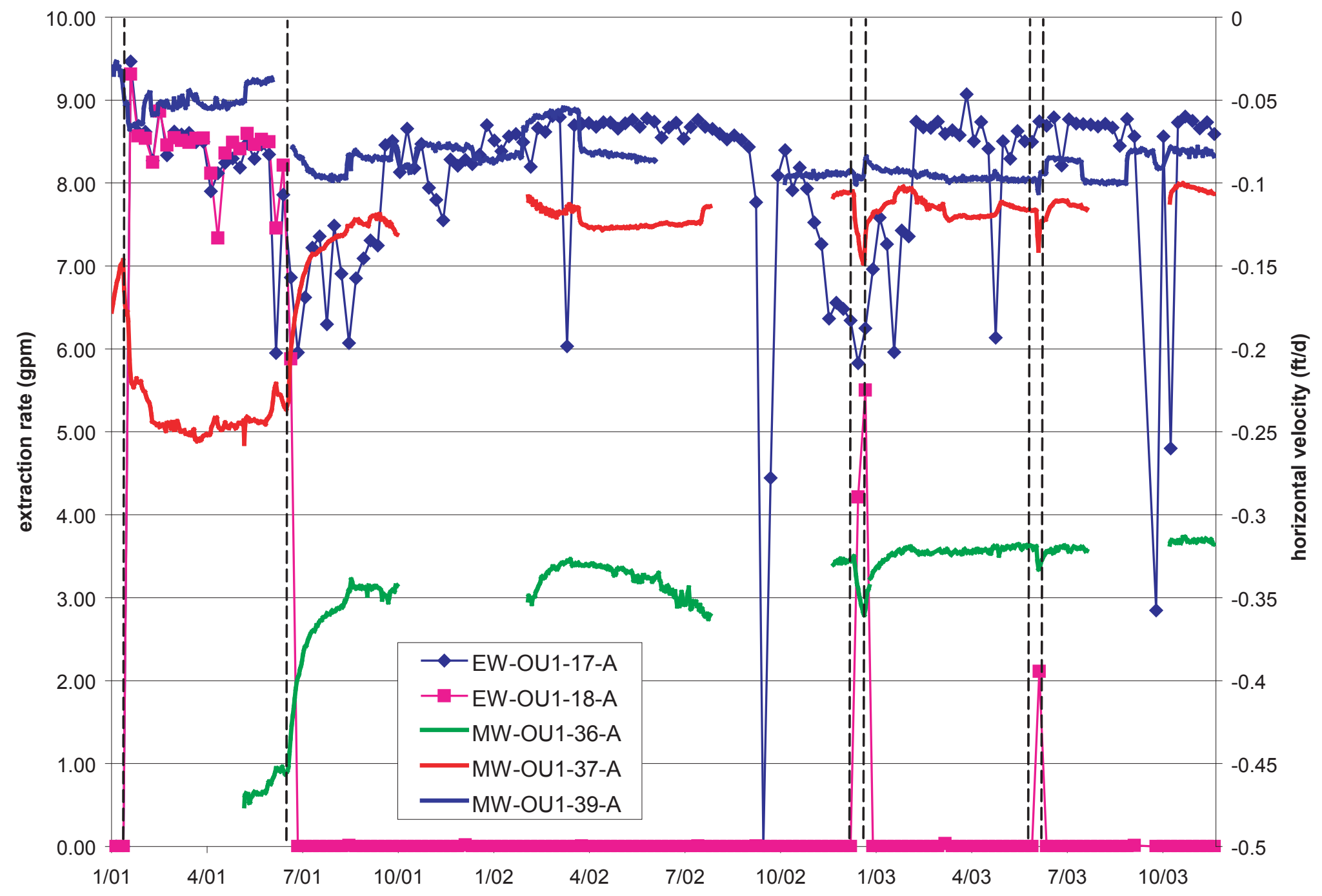

Figure 8.4-1. Inverted ISPFS vertical velocities compared to extraction rates. Dashed lines are EW-OU1-18-A pump switching. 


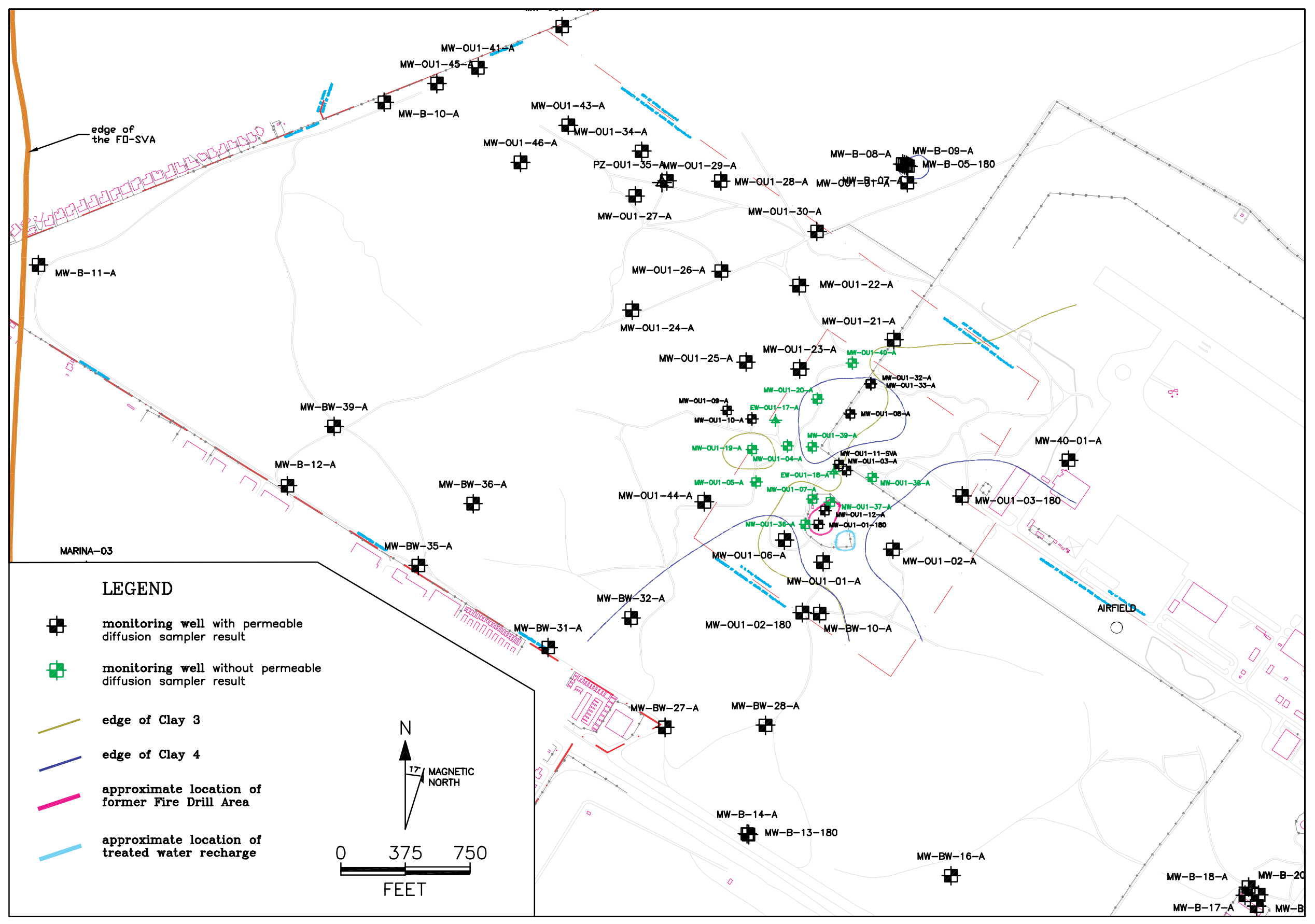

Figure 9.1-1. Wells with PDS results. 


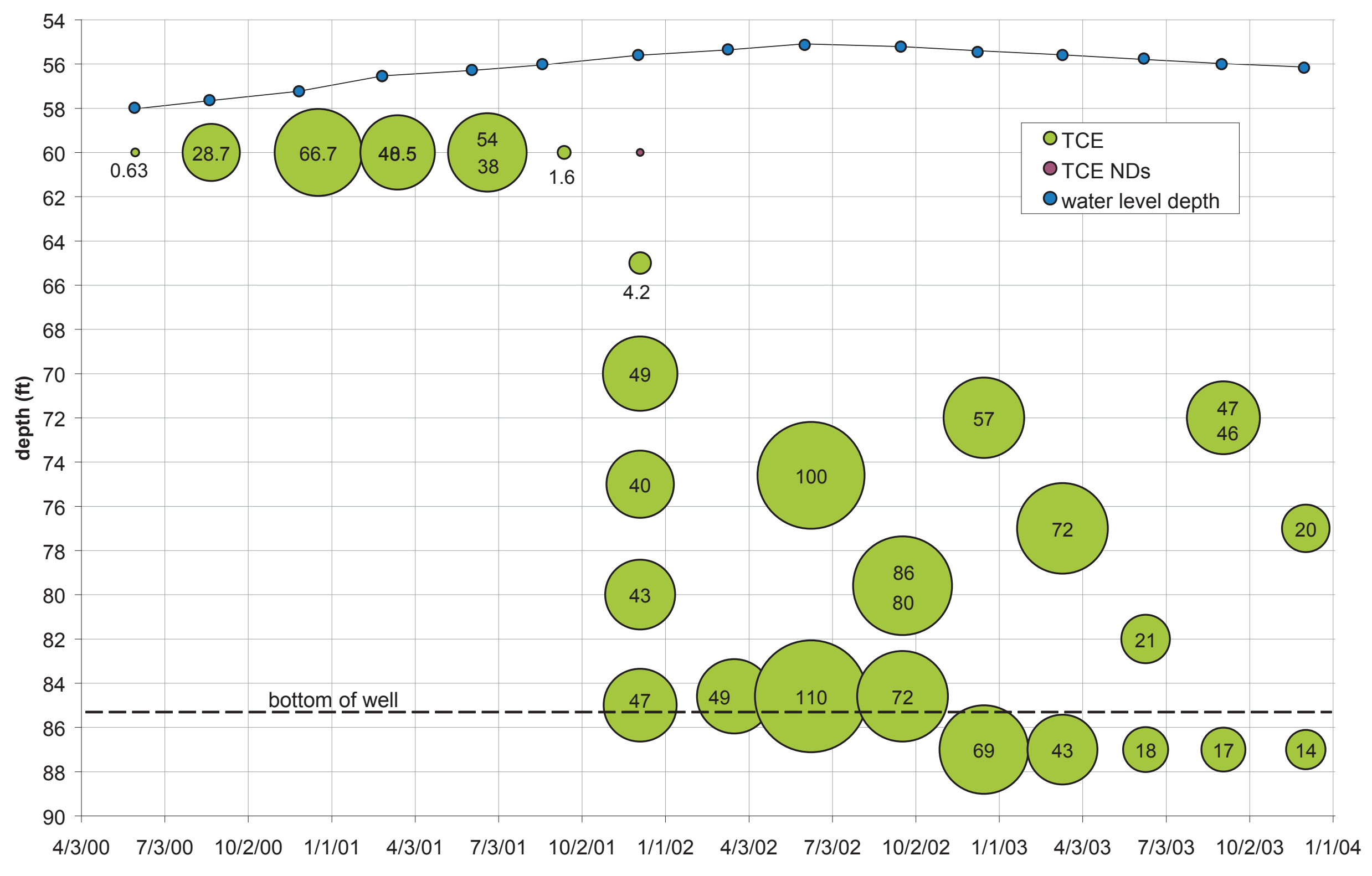

Figure 9.3-1. TCE PDS results from MW-OU1-27-A. 


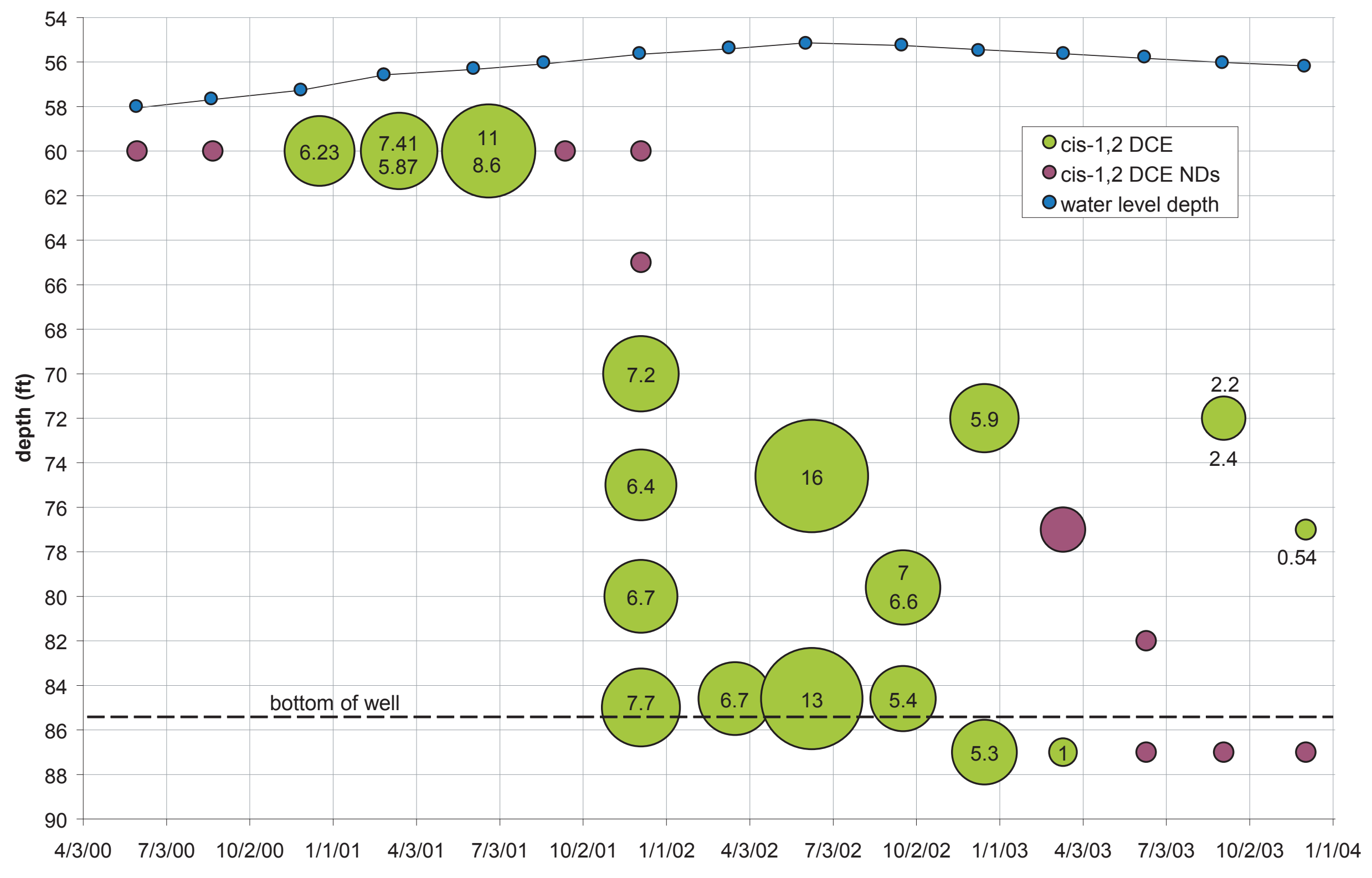

Figure 9.3-2. 1,2 DCE PDS results from MW-OU1-27-A. 


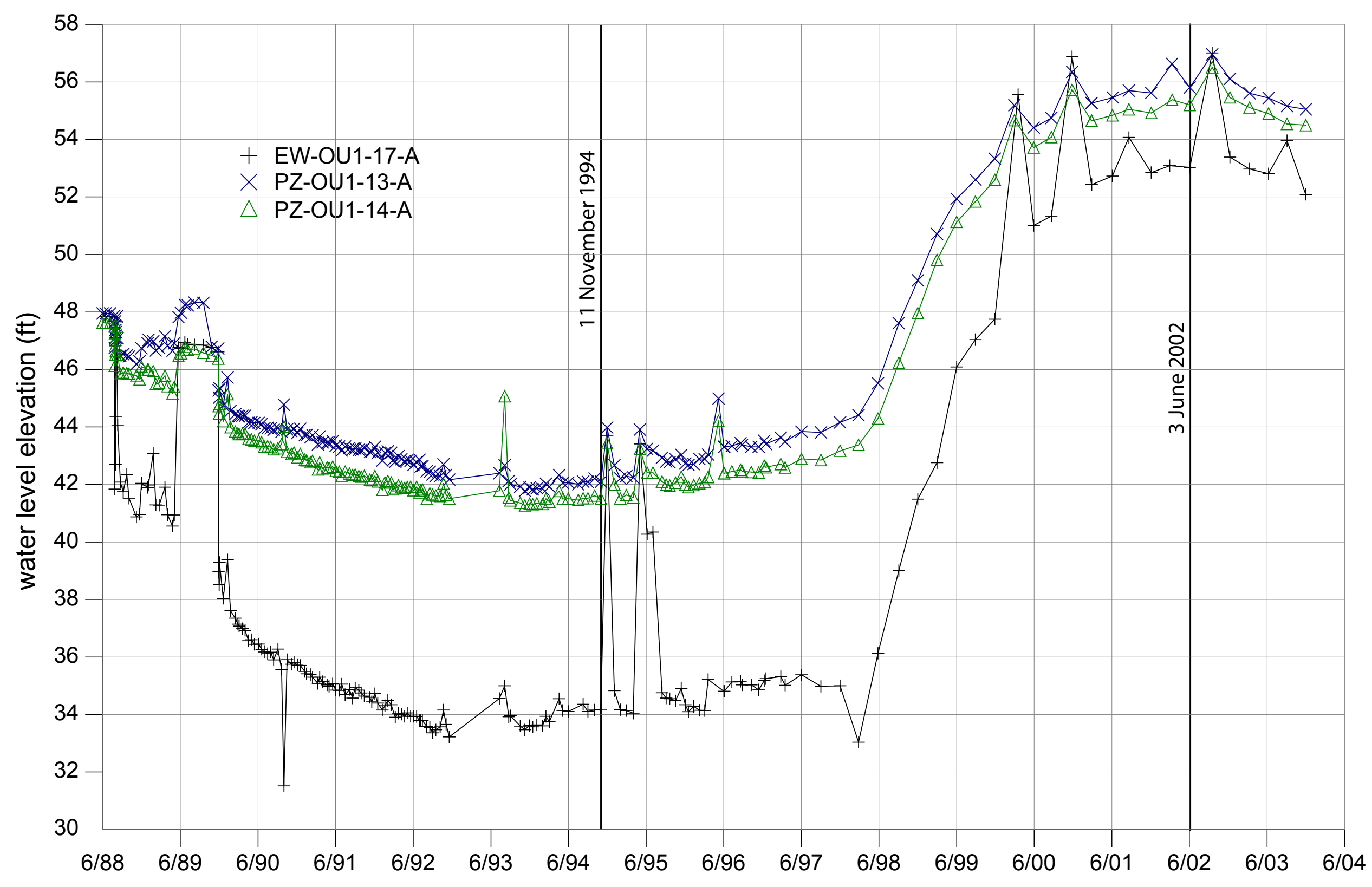

Figure 10.5-1. Hydrographs for EW-OU1-17-A, PZ-OU1-13-A and PZ-OU1-14-A. 


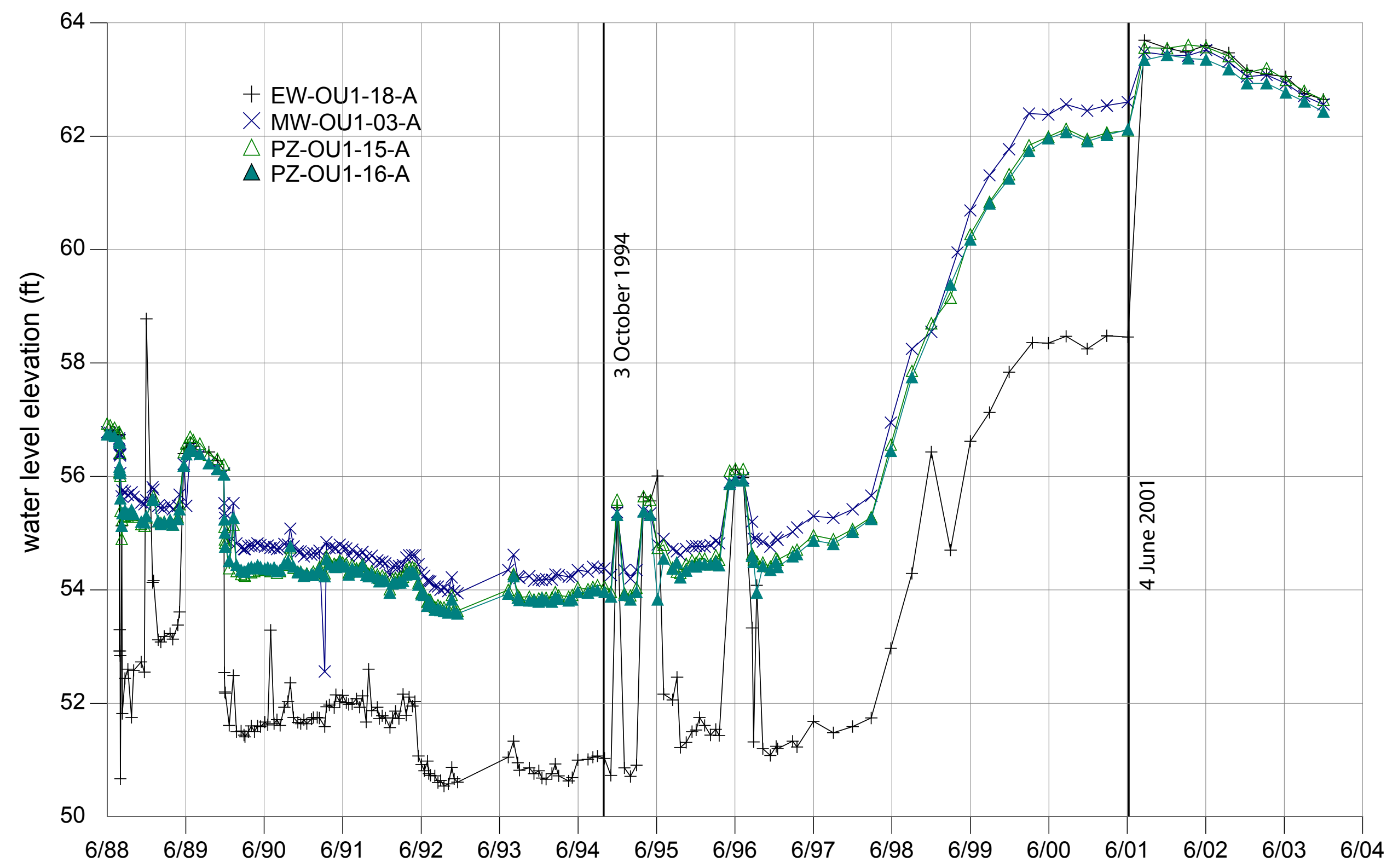

Figure 10.5-2. Hydrographs for EW-OU1-18-A, PZ-OU1-15-A and PZ-OU1-16-A. 


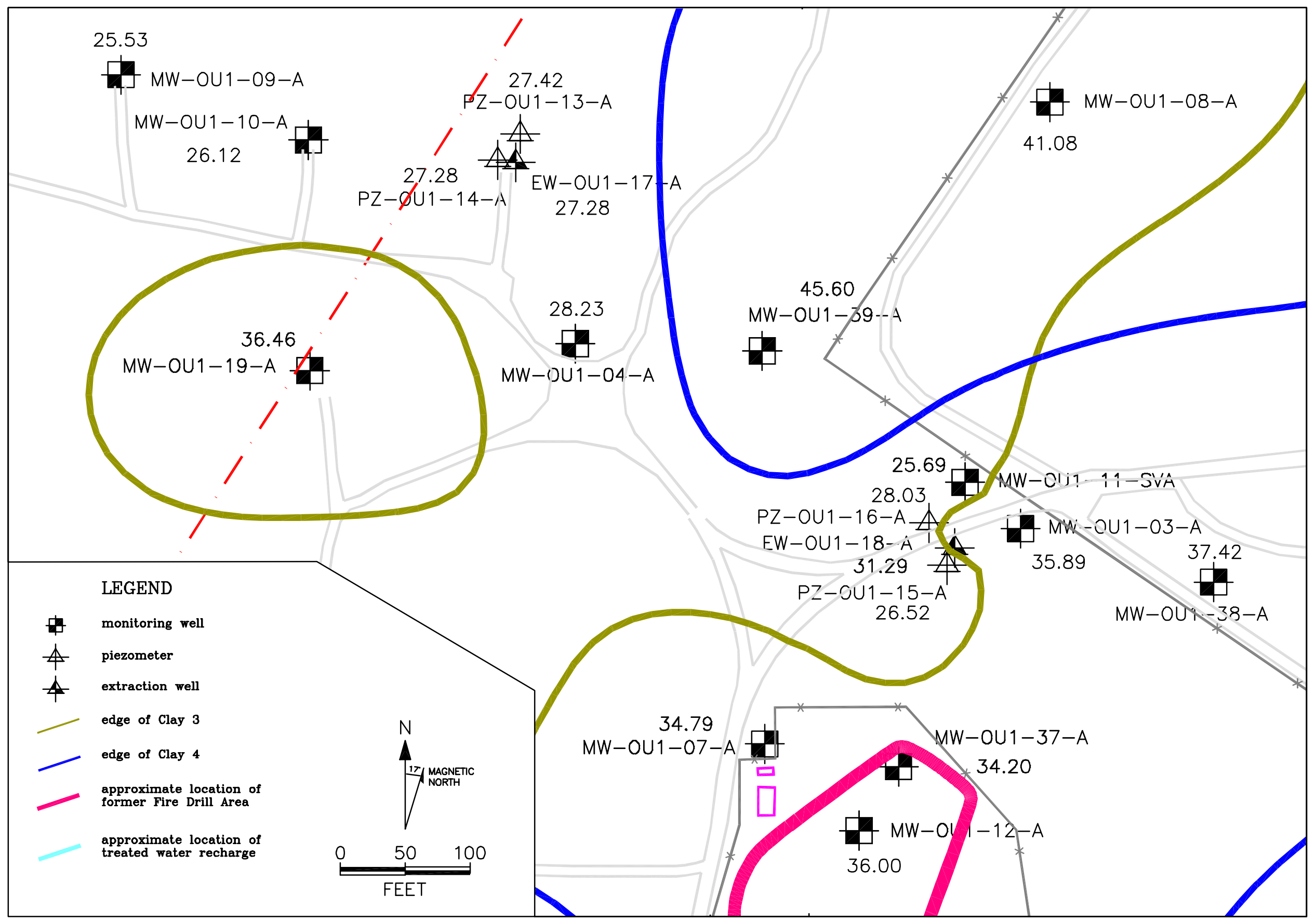

Figure 10.5-3. Elevation of the top of the FO-SVA (in feet) in the vicinity of EW-OU1-17-A and EW-OU1-17-18-A. 


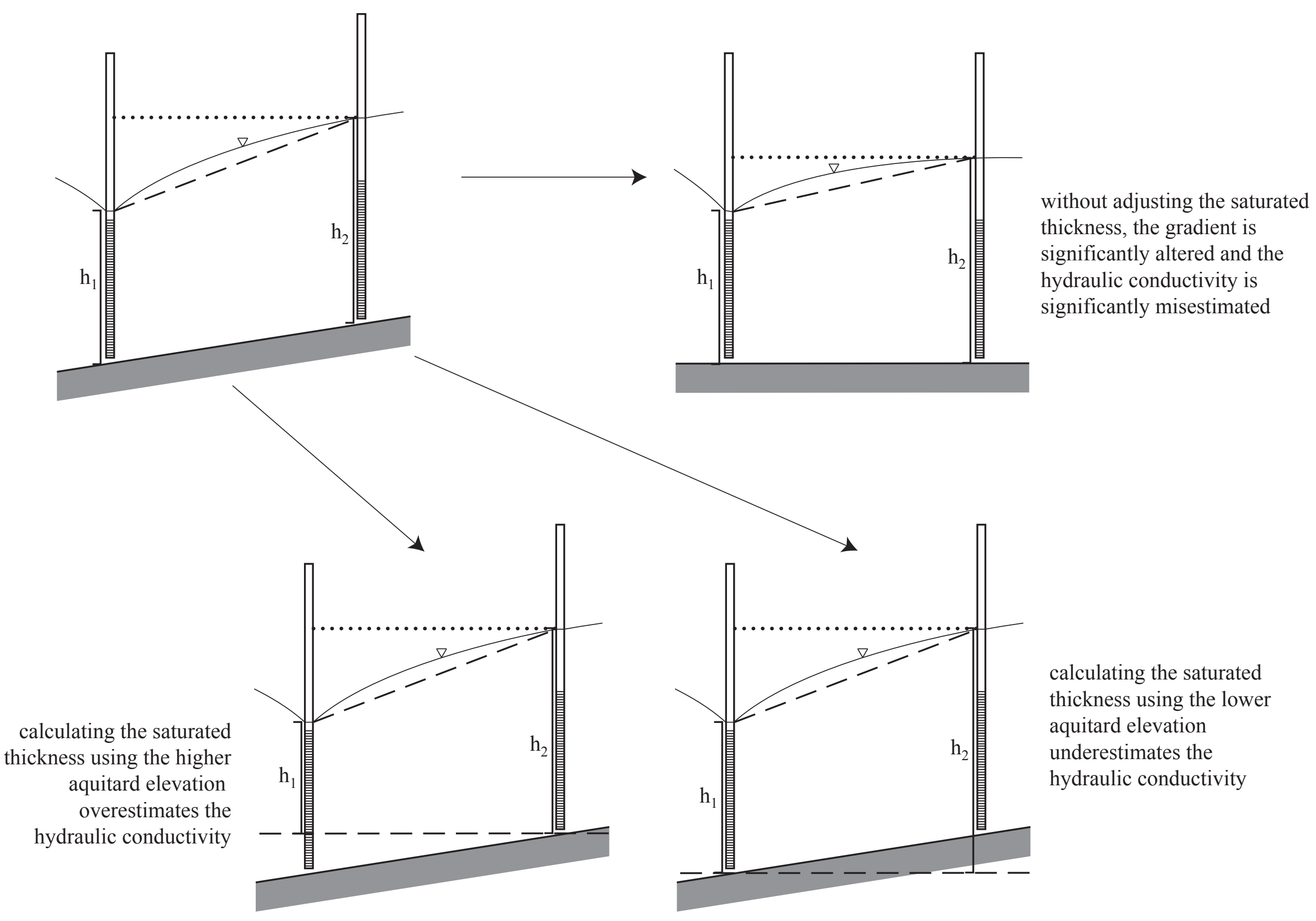

Figure 10.5-4. Consequences of variation in the elevation of the aquitard. 


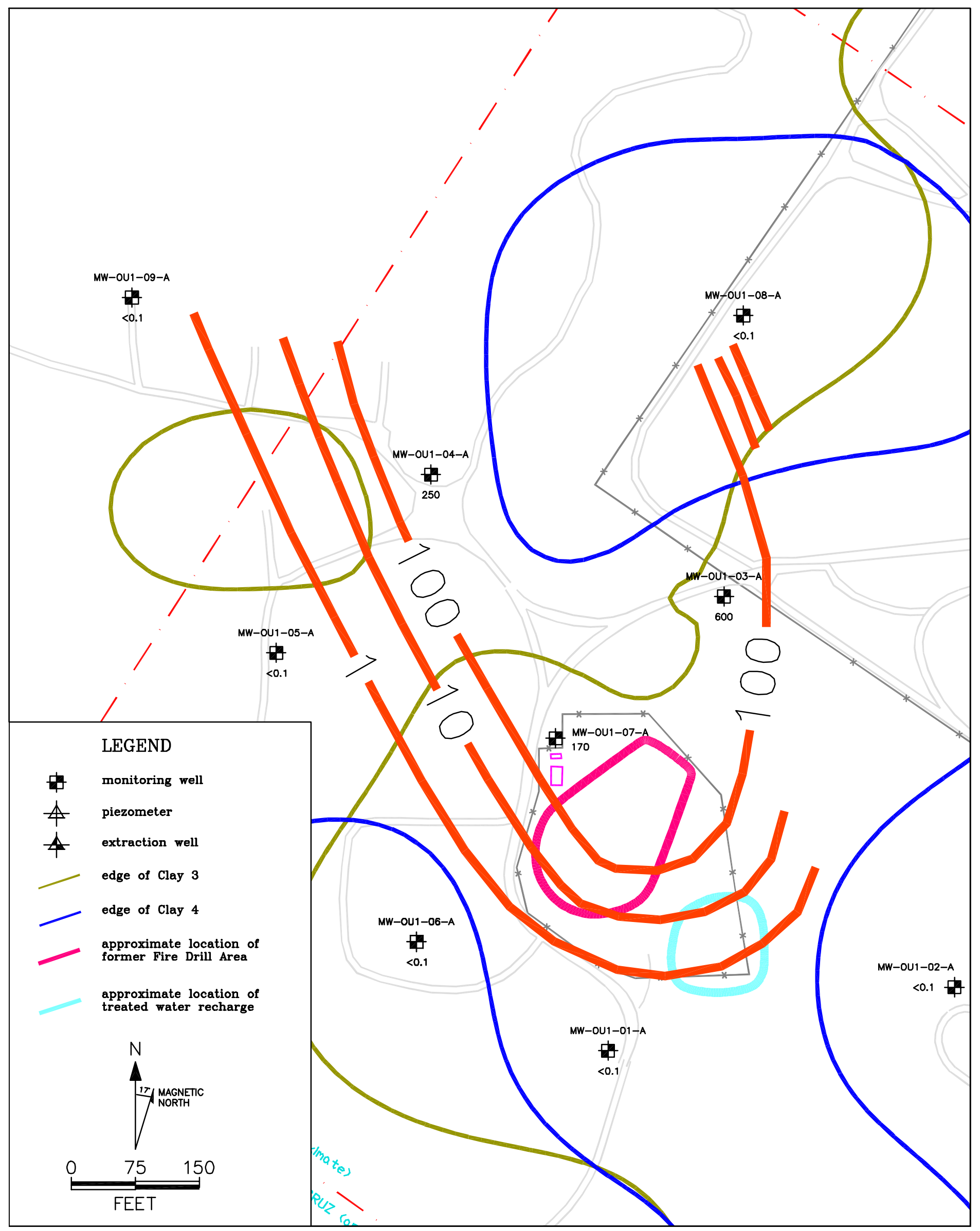

Figure 11.1-1. Isoconcentrations of TCE (in ug/L) in late 1986. 


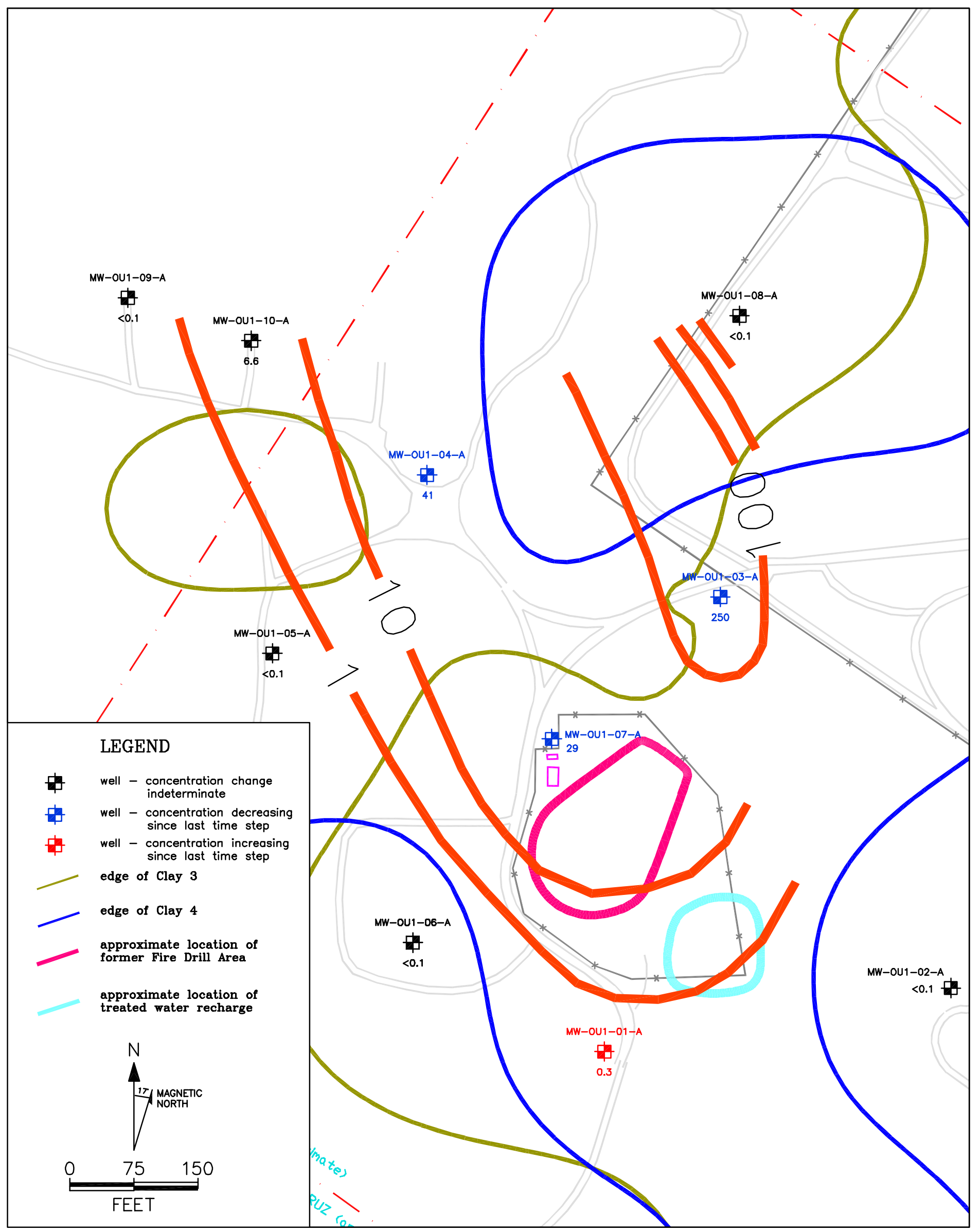

Figure 11.3-1. Isoconcentrations of TCE (in ug/L) in late 1987. 


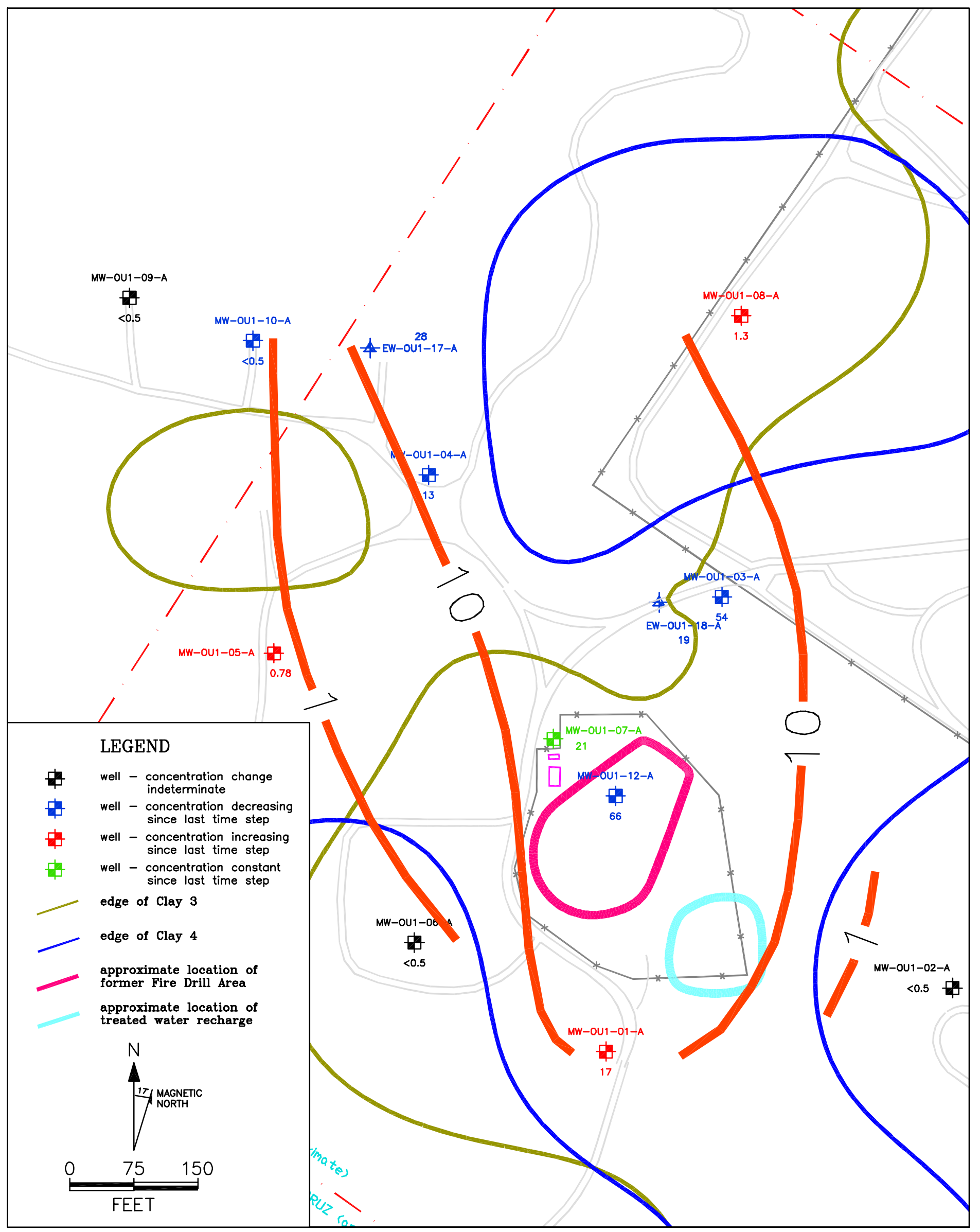

Figure 11.4-1. Isoconcentrations of TCE (in ug/L) in late 1990. 


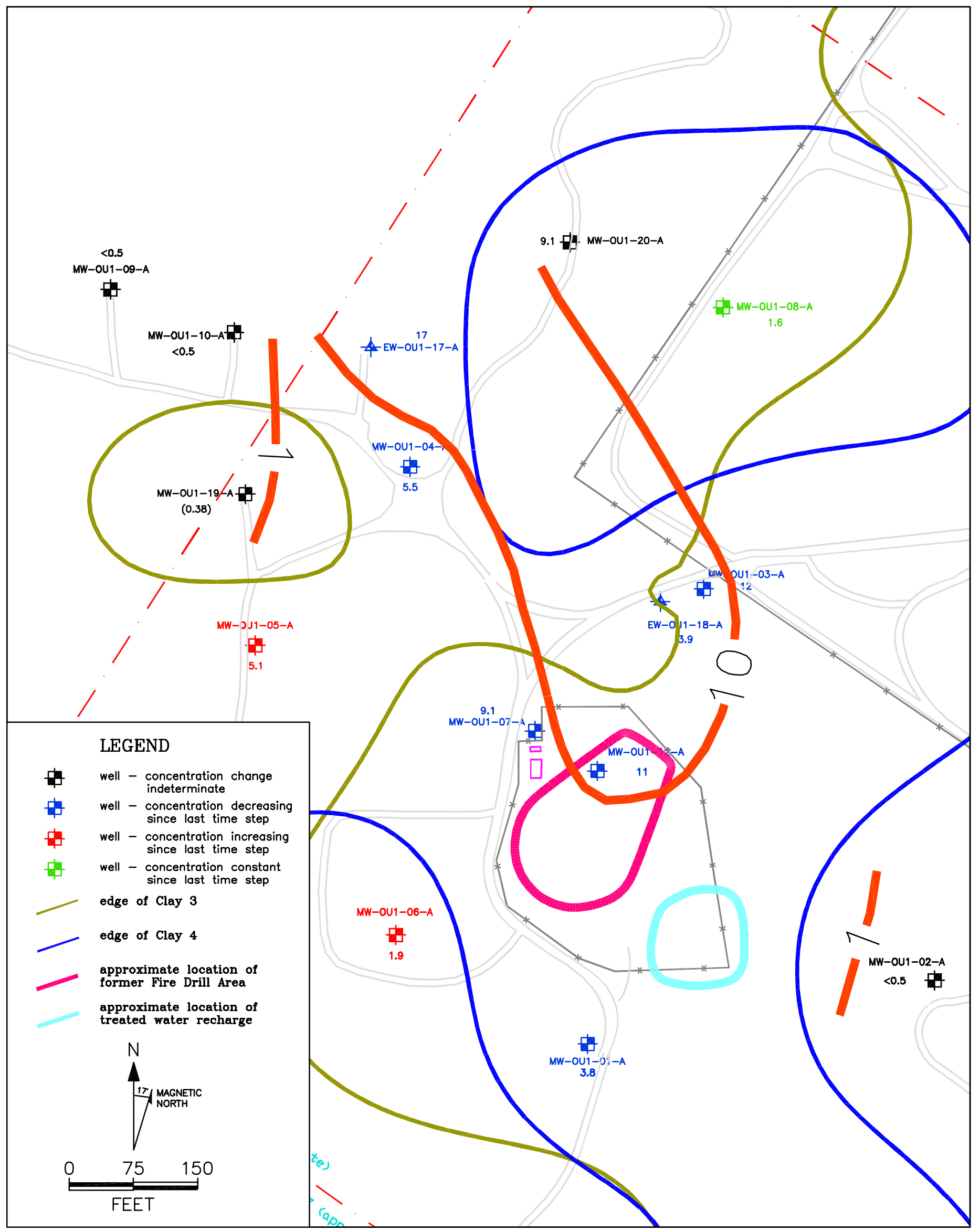

Figure 11.5-1. Isoconcentrations of $\mathrm{TCE}$ (in ug/L) in early 1994 (modified from Oldenburg et al. (2002)). 


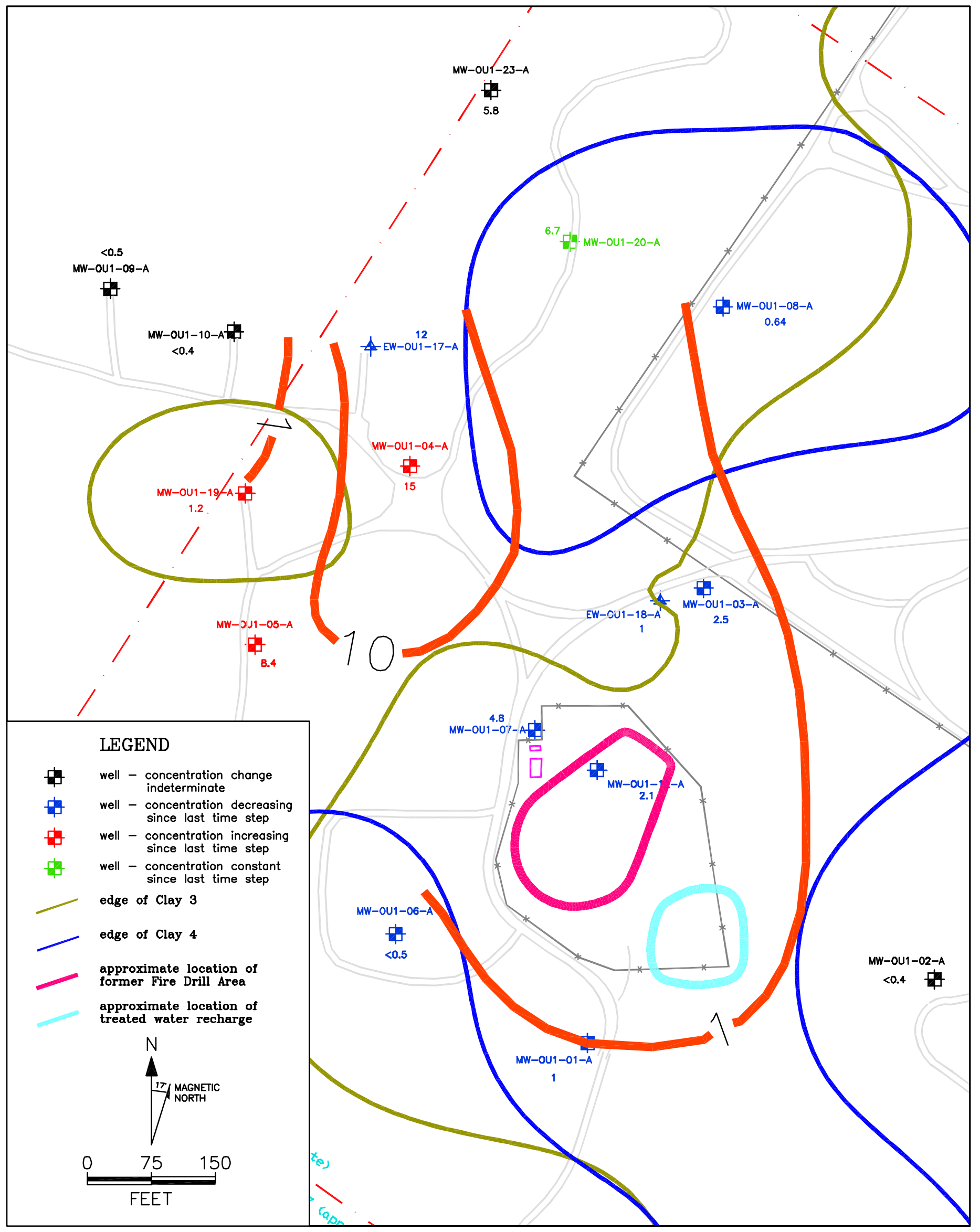

Figure 11.6-1. Isoconcentrations of TCE (in ug/L) in late 1997 (modified from Oldenburg et al. (2002)). 


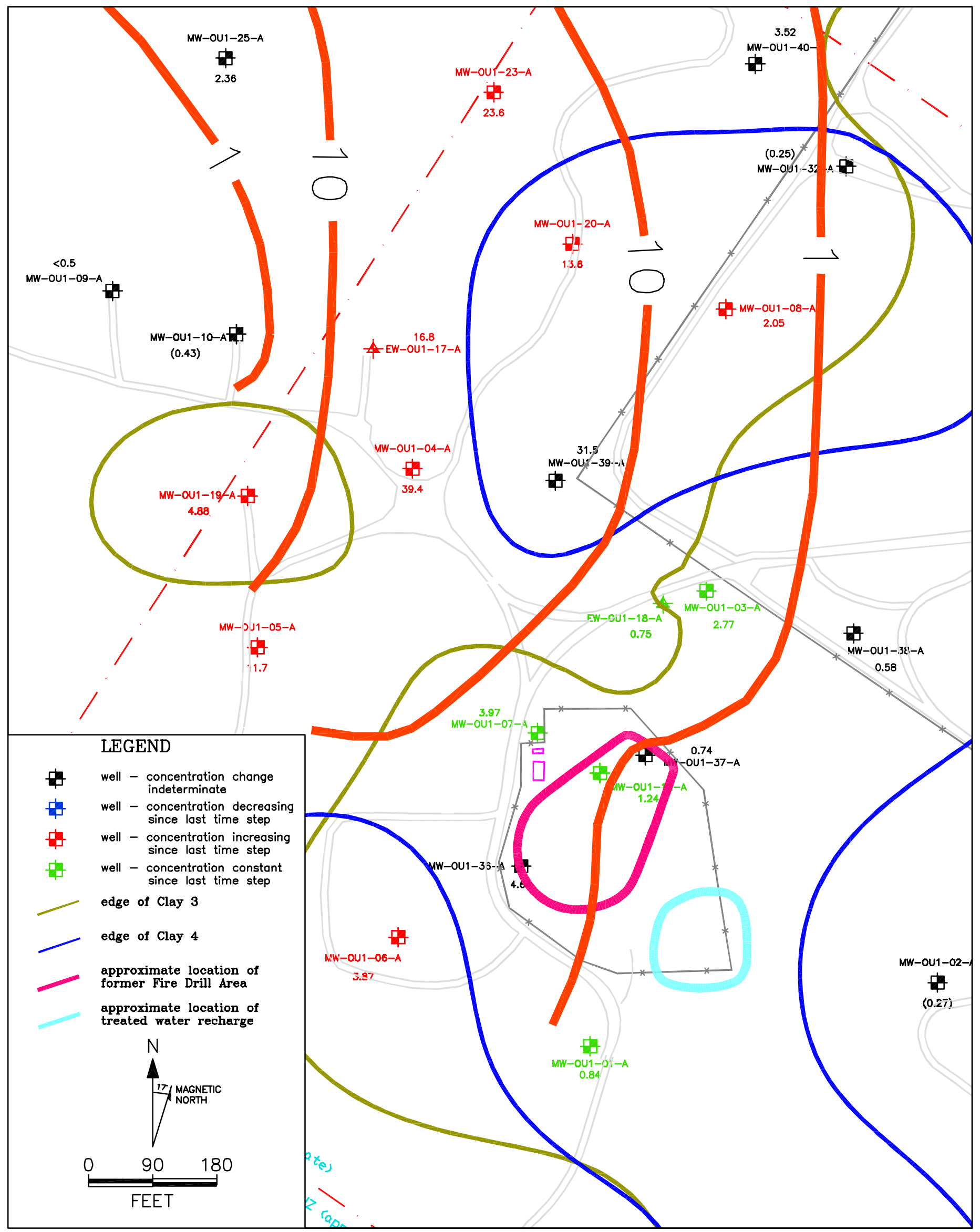

Figure 11.7-1. Isoconcentrations of TCE (in $\mathrm{ug} / \mathrm{L}$ ) in the vicinity of the FDA in late 1999 (modified from Oldenburg et al. (2002)). 


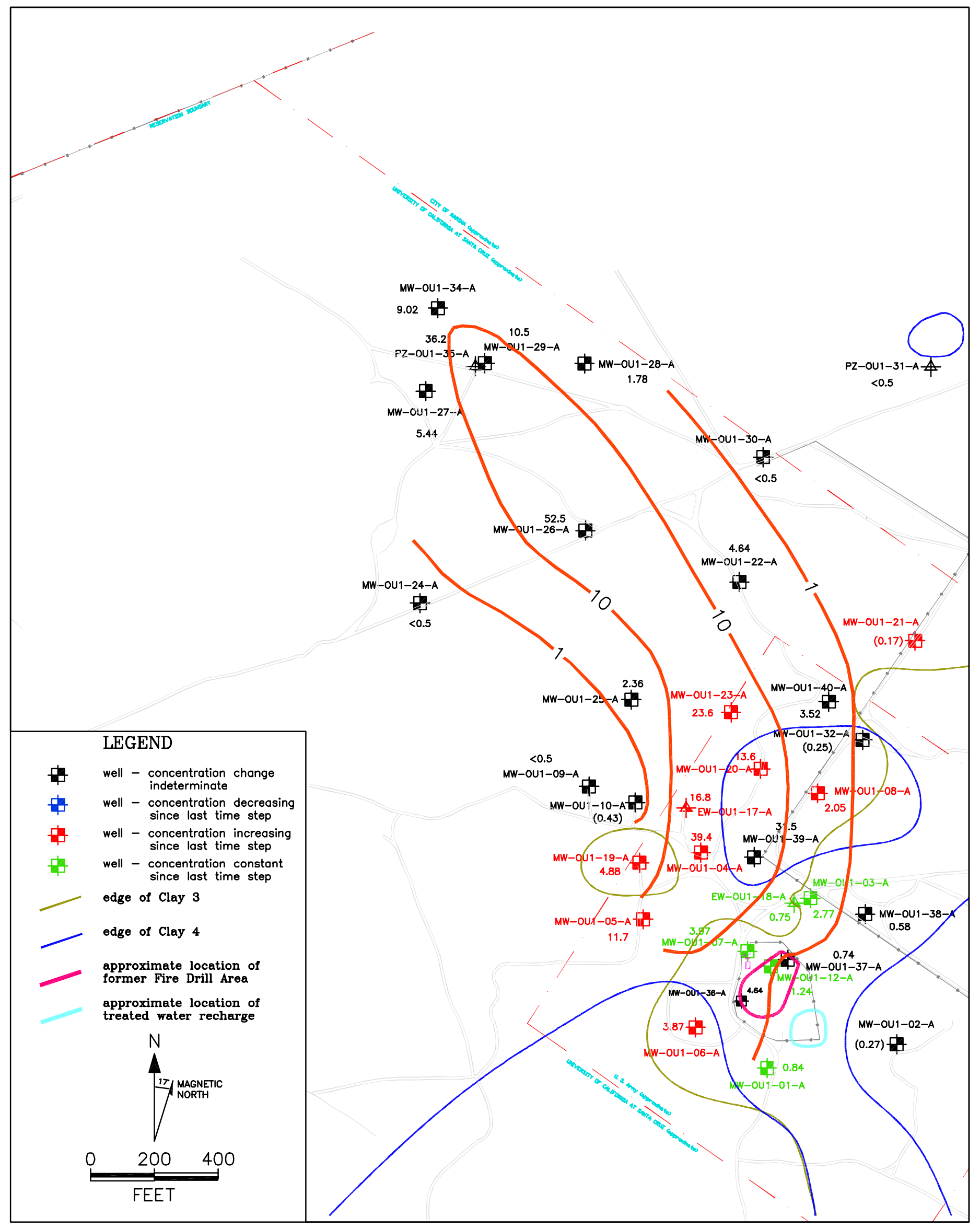

Figure 11.7-2. Isoconcentrations of TCE (in ug/L) in late 1999 (modified from Oldenburg et al. (2002)). 


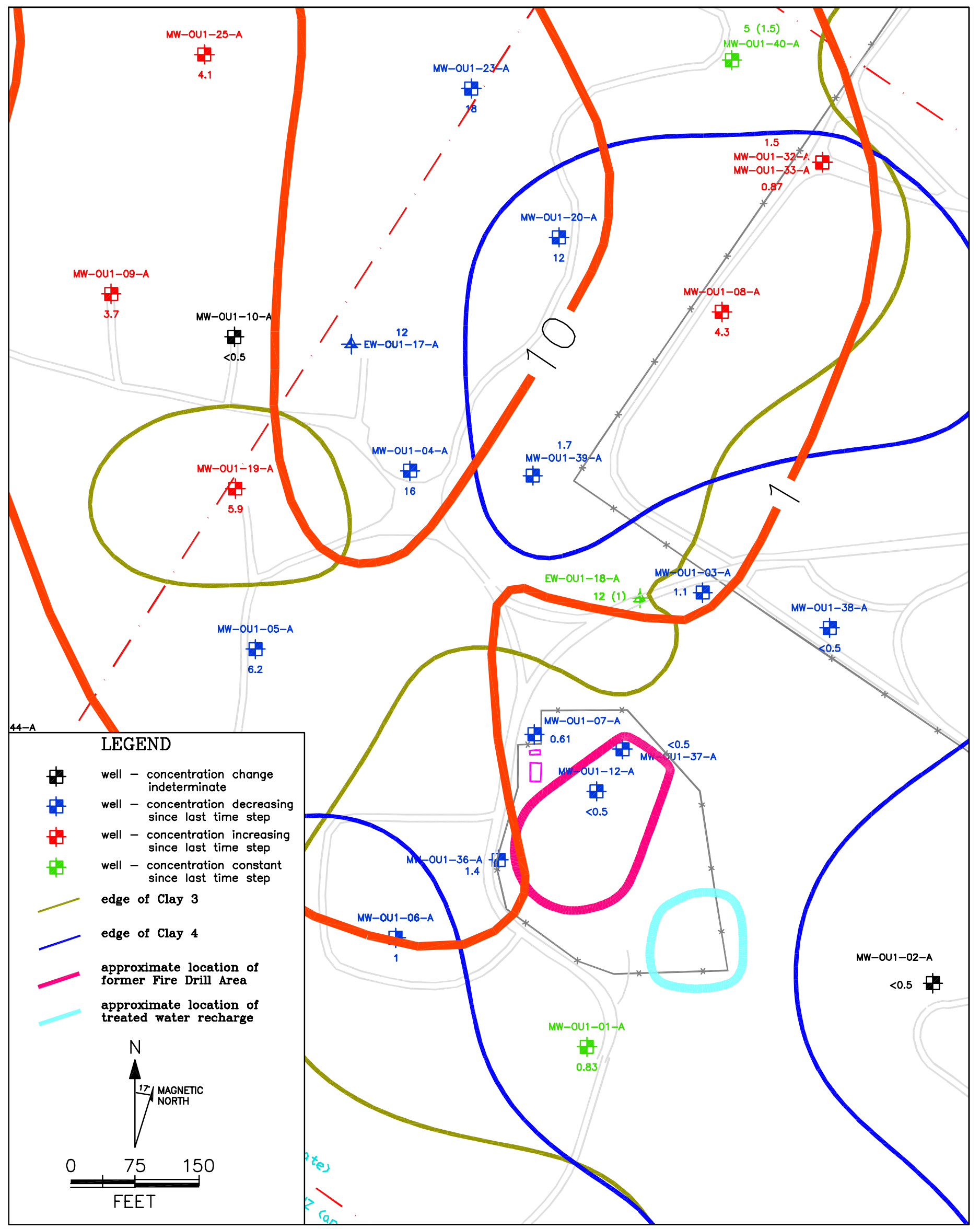

Figure 11.8-1. Isoconcentrations of $\mathrm{TCE}$ (in $\mathrm{ug} / \mathrm{L}$ ) in the vicinity of the FDA in early 2003. 


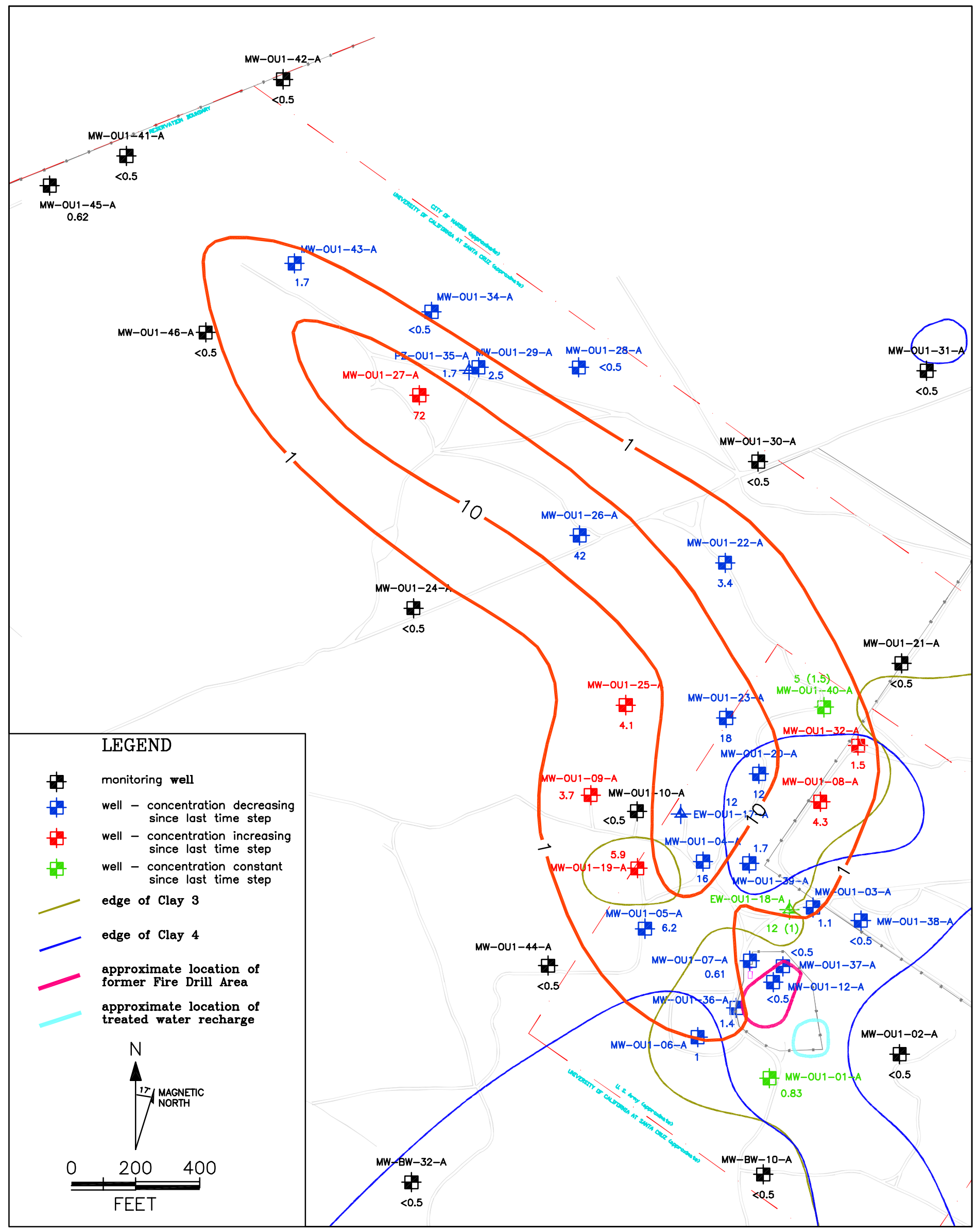

Figure 11.8-2. Isoconcentrations of TCE (in ug/L) in early 2003. 